\title{
Acquisition and Reduction of Data Obtained from Tank 101-SY In-Situ Ball Rheometer
}
C. L. Shepard
J. Abbott
M. A. Chieda
C. Unal
L. J. Kirihara
K. O. Pasamehmetoglu
J. R. Phillips
A. Graham
A. Shekarriz
T. I. Stokes
G. Terrones

February 1995

Prepared for the U.S. Department of Energy under Contract DE-AC06-76RLO 1830

Pacific Northwest Laboratory

Operated for the U.S. Department of Energy

by Battelle Memorial Institute 


\begin{abstract}
DISCLAIMER
This report was prepared as an account of work sponsored by an agency of the United States Government. Neither the United States Government nor any agency thereof, nor Battelle Memorial Institute, nor any of their employees, makes any warranty, expressed or implied, or assumes any legal liability or responsibility for the accuracy, completeness, or usefulness of any information, apparatus, product, or process disclosed, or represents that its use would not infringe privately owned rights. Reference herein to any specific commercial product, process, or service by trade name, trademark, manufacturer, or otherwise does not necessarily constitute or imply its endorsement, recommendation, or favoring by the United States Government or any agency thereof, or Battelle Memorial Institute. The views and opinions of authors expressed herein do not necessarily state or reflect those of the United States Government or any agency thereof.
\end{abstract}

\author{
PACIFIC NORTHWEST LABORATORY \\ operated by \\ BATTELLE MEMORIAL INSTITUTE \\ for the \\ UNITED STATES DEPARTMENT OF ENERGY \\ under Contract DE-AC06-76RLO 1830
}

Printed in the United States of America

Available to DOE and DOE contractors from the

Office of Scientific and Technical Information, P.O. Box 62, Oak Ridge, TN 37831; prices available from (615) 576-8401. FTS 626-8401.

Available to the public from the National Technical Information Service, U.S. Department of Commerce, 5285 Port Royal Rd., Springfield, VA 22161. 


\section{DISCLAIMER}

Portions of this document may be illegible in electronic image products. Images are produced from the best available original document. 
PNL-10170

UC-

$-2030$

Reissue

\title{
Acquisition and Reduction of Data Obtained from Tank 101-SY In-Situ Ball Rheometer
}

\author{
C. L. Shepard \\ M. A. Chieda \\ L. J. Kirihara \\ J. R. Phillips \\ A. Shekarriz \\ G. Terrones \\ J. Abbott ${ }^{1}$ \\ C. Unal ${ }^{1}$ \\ K. O. Pasamehmetoglu ${ }^{1}$ \\ A. Graham ${ }^{1}$ \\ T. I. Stokes ${ }^{2}$
}

February 1995

Prepared for

the U.S. Department of Energy

under Contract DE-AC06-76RLO 1830

Pacific Northwest Laboratory

Richland, Washington 99352

${ }^{1}$ Los Alamos National Laboratory

Los Alamos, New Mexico 87545

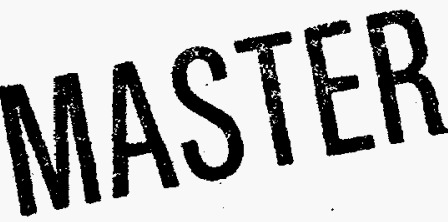

${ }^{2}$ Westinghouse Hanford Company

Richland, Washington 99352 


\section{Summary}

Development of the ball rheometer to measure rheological properties and density of the waste in Hanford Tank 241-SY-101 will be completed around September 1994. This instrument is expected to provide the first-of-its-kind in-situ measurements of the fluid properties, such as viscosity, of the waste contained within this tank that have been desired for years. Since the ball rheometer project began, a mixer pump has been installed in this tank, and by all accounts this pump has been very successful at mitigating the flammable gas problem associated with Tank 101-SY. Present plans now call for the use of mixer pumps in several other tanks.

The ball rheometer will serve as a diagnostic tool for judging the effectiveness of mixing in Tank 101-SY and others and will be one of few in-situ probes available for diagnostic measurements. The data requirements and basis of choice for the ball rheometer and the theory of the operation of the ball rheometer have been covered in previous reports (Pasamehmetoglu et al. 1993, Shepard 1994, Shepard et al. 1994). The in-situ data collection strategy and the methods of data analysis and reduction are presented in this final report concerning this instrument. Based on experiments performed at Los Alamos National Laboratory and Pacific Northwest Laboratory, it is believed that a generalized Bingham fluid model (Herschel-Bulkley fluid model) may be useful for describing at least some of the waste contained in Tank 101-SY, and data obtained in the tank will initially be reduced using this fluid model. The single largest uncertainty in the determination of the drag force on the ball is the drag force which will be experienced by the cable attached to the ball. This drag can be a substantial fraction of the total drag when the ball is deep within the tank. Careful accounting of the cable drag will be important in the reduction of the data.

It is expected that the fluid properties may be history dependent, thus rheological properties of the undisturbed fluid may be different from the same properties after the fluid has been disturbed by passage of the ball. The data collection strategy allows the determination of the waste fluid rheology both in the undisturbed state and after it has been disturbed by the ball. Fluid density will be measured at regular intervals. Unlike the rheological parameters, measurement of density requires no model for its interpretation; however, the effects of yield stress may need to be accounted for. This measurement can be made with fairly good accuracy and may provide the most useful data in determination of mixer pump effectiveness. 



\section{Contents}

Summary $\ldots \ldots \ldots \ldots \ldots \ldots \ldots \ldots \ldots \ldots \ldots \ldots \ldots \ldots \ldots \ldots \ldots \ldots$

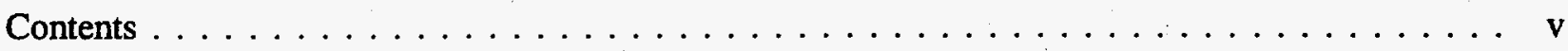

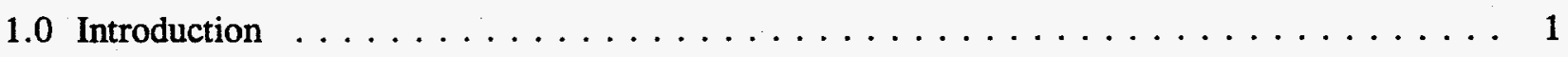

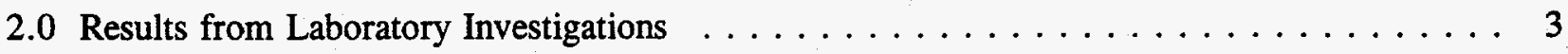

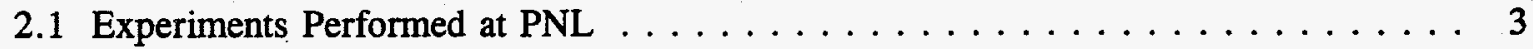

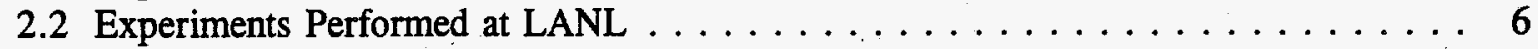

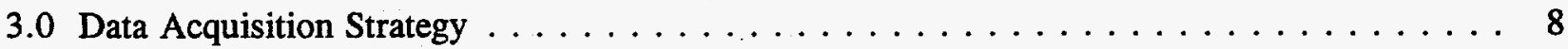

3.1 Measurements in the Riser Pipe and Dome Space $\ldots \ldots \ldots \ldots \ldots \ldots$

3.2 Measurements in the Waste ...................... 9

4.0 Reduction of Data $\ldots \ldots \ldots \ldots \ldots \ldots \ldots \ldots \ldots \ldots$

5.0 Expected Accuracies $\ldots \ldots \ldots \ldots \ldots \ldots \ldots \ldots \ldots \ldots \ldots$

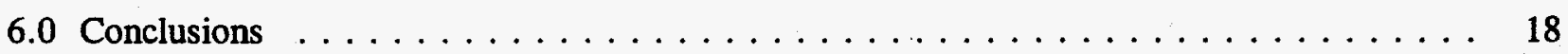

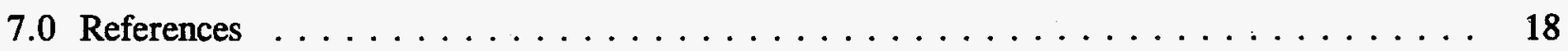

Appendix A: Experiments Performed at Pacific Northwest Laboratory $\ldots \ldots \ldots$. . . . . . A.1

Appendix B: Experiments Performed at Los Alamos National Laboratory . . . . . . . . . B.1 


\subsection{Introduction}

Since mid-1993 a team made up of staff from Westinghouse Hanford Company (WHC), Pacific Northwest Laboratory (PNL), and Los Alamos National Laboratory (LANL) has been developing a measurement instrument for determination of some of the fluid properties of the wastes contained in Tank 241-101-SY (hereafter abbreviated as 101-SY) on the Hanford Reservation. The ball rheometer was chosen for its simplicity, its ease of deployment, and its capabilities for providing data from which fluid density, yield stress, and apparent viscosity can be determined. The basis for its choice and the identified data requirements are outlined in an earlier report (Shepard 1994), while the underlying theory and practical application of the ball rheometer are given in other reports (Shepard et al. 1994; Pasamehmetoglu et al. 1993). The ball rheometer consists of a ball attached to a cable which is wound onto a spool. The system will be installed on a riser pipe through which entry into Tank 101-SY is obtained. The ball can be lowered into the waste or retrieved from the waste by rotation of the spool, which is mechanically connected to electric drive motors. The present ball is comprised of a tungsten alloy and is $9.1 \mathrm{~cm}$ in diameter and weighs about $16 \mathrm{lb}(7.3 \mathrm{~kg})$. It is likely that other balls of similar size but lower density, such as a steel ball, will also be employed. The cable is stranded stainless steel of diameter $0.32 \mathrm{~cm}(0.125$ inches $)$ and has a polyethylene coating. A diagram of the ball rheometer is shown in the following figure. The ball is deployed into the waste and retrieved by rotation of the take up spool. Typically the ball will be deployed at a constant velocity, which is adjustable over the velocity range from $0.1 \mathrm{~cm} / \mathrm{s}$ to $100 \mathrm{~cm} / \mathrm{s}$. The cable passes over a pulley to which a load cell is attached. The tension in the cable, or actually twice the tension in the cable is measured by this load cell. We will measure the tension in the cable as the ball is being moved through the waste at different velocities. From these measurements, the drag on the ball due to movement through the waste can be determined. The amount of drag depends on the rheology (roughly the yield stress and the viscosity) of the waste fluid, and we are interested in determining the rheology of the fluid. Static force measurements obtained while the ball is at rest in the fluid will allow a determination of the fluid density. We intend to characterize the fluid at all depths within the tank.

This report is largely concerned with the testing strategy when the ball rheometer is installed on Tank 101-SY. The strategy is based partially on the results of laboratory investigations conducted at LANL and PNL. The methods to be used for reduction of the data to obtain fluid properties is also a topic of interest here. Finally, some estimates of the accuracy we can expect in the derived fluid properties will be given.

In Section 2.0 of this report, we review the results obtained from laboratory investigations using chemical simulants of the waste. Experiments were performed at both LANL (primarily falling ball experiments) and PNL (primarily drag force measurements). These results are important for forming the tank testing strategy, which are presented in Section 3.0. The methods for reduction of the data to obtain fluid rheological parameters and fluid density are discussed in Section 4.0. Reduction of the data presently requires a fluid model, and we will initially assume that the fluid behaves as a generalized Bingham (Herschel-Bulkley) fluid and reduce the data to obtain parameters for the model. It should be noted that a time independent generalized Bingham fluid model may not adequately describe all or parts of the real waste. We can fully address the problem of data reduction only after we have acquired actual in-situ data. The actual tank waste may behave differently from the simulant tested in the laboratory. In Section 5.0 we present an estimate of the accuracies for the derived fluid 


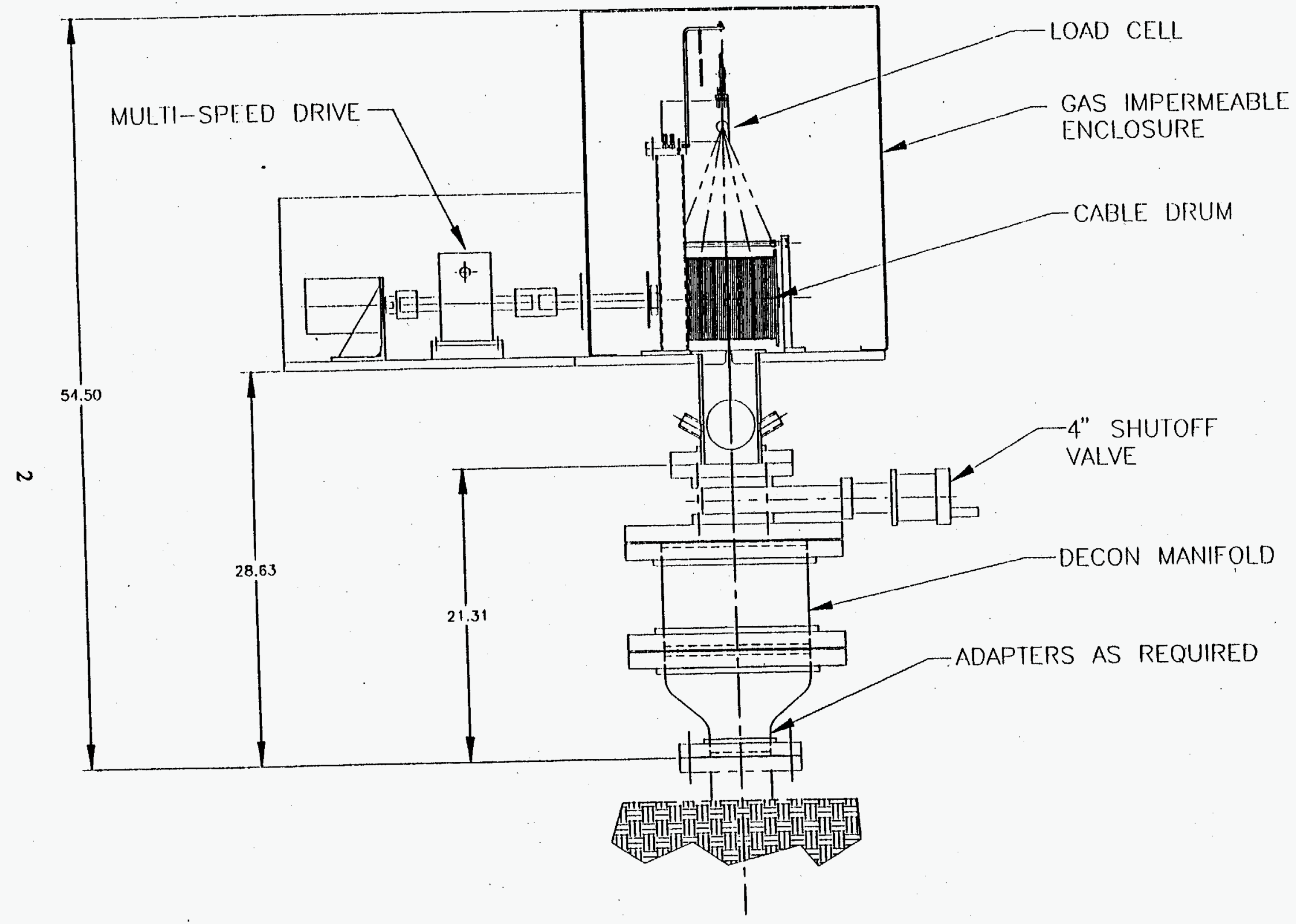

Diagram of the Ball Rheometer System Showing the Ball, Cable, Take-up Spool, Pulley, and Load Cell. The instrument fastens to a riser pipe through which entry into the waste tank is obtained. 
rheological parameters and the fluid density. Conclusions and a summary are given in Section 6.0. Appendix A contains detailed information about the experiments performed at both PNL and Appendix B contains detailed information about the experiments performed at LANL, as opposed to the cursory review presented in the main body of this report.

\subsection{Results from Laboratory Investigations}

Experiments were performed at both PNL and LANL in support of the ball rheometer project. Experiments at PNL used an experimental setup which closely resembles the actual hardware being constructed by WHC. The primary purpose of these tests was to examine unresolved issues concerning the expected performance of the in-tank ball rheometer. Experiments at LANL were concerned with determination of the fluid properties of a chemical simulant of the 101-SY waste which is expected to behave similarly to the actual waste fluid. These experiments were aimed at determining the applicability of fluid models to describe the behavior of the simulant and at examining the fluid behavior of the simulant. The experiments will be described separately below.

\subsection{Experiments Performed at PNL}

The force measured by the load cell will not simply be the drag force on the ball. Other forces also contribute to the measurement. In the reduction of the force data to obtain the rheology of the fluid, the drag force on the ball is of primary importance. In the measurement of density, the buoyancy force on the ball must be determined. It is necessary to determine all of the forces at work in these measurements and then determine which part of the total force is due to drag on the ball. As a result, the actual measured force will have to be corrected to account for quantities such as the weight of the ball, the weight of the deployed cable, the weight of the pulley, the friction in the pulley, and the buoyancy forces on both the cable and ball. Finally, the drag force on the cable has to be determined. Some of these forces can be obtained by laboratory measurements prior to deployment of the ball. For instance, the weights of all components and pulley friction should be well known ahead of time. Buoyancy can be reliably calculated from static measurements made in the tank. It turns out that only one force, the drag force on the cable, will present difficulties for measurement or calculation. This conclusion was reached independently at both laboratories.

A theoretical analysis was performed to identify the various forces measured with the load cell. Then, experiments were performed with simulants to estimate the contribution to the total force due to buoyancy and drag on the cable. In addition, constant velocity drag force experiments were performed using several ball sizes and simulants to determine how the drag forces on the ball varied with ball size and velocity for these fluids. These experiments simulate the manner in which data will be collected in actual work with the in-tank ball rheometer. Finally, we investigated the effects due to fluid boundaries (such as the air-fluid interface) and also transients that arise when motion of the ball is started and stopped. Experiments were performed with three different fluids: a chemical simulant of the waste, carbopol (a semi-clear polymer fluid containing no particles), and Bentonite clay (a mixture of clay and water having a high yield stress and viscosity) in order to span a reasonable range of Reynolds and Bingham numbers. We have attempted to parameterize the expected transient responses in terms of the fluid properties. Samples of the fluids were also 
with the sample contained in the gap between the cylinders. The results obtained with this instrument were then compared with results obtained by reducing the drag force data using theoretical relationships.

The equations giving the drag force on the ball in the case of a falling and rising ball are given respectively by (see Appendix),

$$
D_{b}=B_{b}-C\left(z-z_{0}\right)-\int_{z_{b}}^{z}\left[A\left(z^{\prime}\right)-B\left(z^{\prime}\right)\right] d z^{\prime}-\frac{\eta-\Delta R_{f}}{2} \text { falling ball }
$$

and,

$$
D_{b}=-B_{b}+C\left(z-z_{o}\right)-\int_{z_{0}}^{z}\left[A\left(z^{\prime}\right)+B(z)\right] d z^{\prime}-\frac{\eta+\Delta R_{r}}{2} \text { rising ball }
$$

where

$$
\begin{aligned}
D_{b} & =\text { drag force on ball } \\
B_{b} & =\text { buoyancy force on ball } \\
z_{0} & =\text { reference position of ball } \\
z & =\text { ball position } \\
A & =\text { drag coefficient for cable } \\
B & =\text { cable buoyancy coefficient } \\
C & =\text { weight per unit length of cable } \\
\eta & =\text { pulley friction coefficient } \\
\Delta R & =R(z)-R_{0} \\
R_{0} & =\text { load cell reading at reference location } z_{\mathbf{o}} .
\end{aligned}
$$

The above equations assume a reference measurement $\left(R_{0}\right)$ of the cable tension. This measurement should be made just above the surface of the waste (at $z_{0}$ ) and includes the weight of the ball, pulley, and the deployed cable. In the experiments, $\Delta \mathrm{R}$ will be a measured quantity. Some of the other quantities given in Eq. 1 and 2 will be well known but will not be directly measurable during experiments. The weight of the cable per unit length can be determined with prior measurements. Pulley friction as a function of load and speed can also be measured beforehand. Both the buoyancy on the cable and the drag on the cable may not be linear functions of the deployed cable length, since they depend on the fluid properties. If the density is known as a function of depth, then the cable buoyancy can be calculated as an integral over the cable length. For density measurements the drag forces and the pulley friction become zero and the density is calculated from

$$
B_{b}=-\int_{z_{0}}^{z} B(z) d z^{\prime}+C\left(z-z_{0}\right)-\frac{\Delta R}{2}
$$


and the relation

$$
\frac{\pi d^{3}}{6} \cdot \rho \cdot g=B_{b}
$$

where $\rho$ is the fluid density, $d$ is the ball diameter, and $g$ is gravitational acceleration. If the fluid density is measured at regularly spaced intervals, then the integral over the depth can be performed to obtain the total buoyancy of the cable. Thus, static measurements allow a direct determination of the buoyancy forces and therefore the fluid density. Errors in the estimation of fluid density may result if the fluid has a significant yield stress and the ball is partially supported by this force, which is unaccounted for in Eq. 3. Laboratory experiments with a well mixed simulant have shown that the effect is negligible. The same may not necessarily be true in the actual tank waste, and this subject will be revisited when actual data are obtained. In examining Eq. 1 and 2 and in consideration of the above comments, it is seen that all terms in these equations can be accounted for except the cable drag coefficient (A).

The drag on the cable depends on the rheological properties of the fluid, which may be a function of depth within the fluid. This drag will also depend upon the length of cable immersed in the fluid. If the ball is deep enough into the waste, the drag on the cable may be a substantial fraction of the drag on the ball. At immersion depths greater than about 3 meters, the surface area of the cable in contact with the waste exceeds the surface area of the ball. We need to know the drag on the ball alone in order to determine the fluid rheology. This means that we need to correct measurements for the drag on the cable, but we can make this correction only if we know the fluid rheology. We presently have no theory with which to calculate the cable drag even if we can estimate the fluid rheology. Laboratory investigations are continuing in order to obtain some knowledge of how to account for cable drag. In the general case it does not appear possible to experimentally determine both drag forces independently in in-situ tests. However, this possibility will be explored. An iterative approach may provide a possible solution of this problem. Knowledge of the cable drag force as a function of position in the waste will allow the calculation of the integral for the total cable drag at any depth into the waste. We will discuss this problem in more detail in the Section 4.0, which deals with data reduction.

Experiments were performed to verify that the buoyancy of the ball is given by Archimedes Principle even when the ball is in motion through non-Newtonian fluids. These experiments verified that Archimedes Principle is applicable for these fluids and the measurement of fluid density will be possible in experiments conducted in the tank. Again however, if the fluid has a significant yield stress the accuracy of density determinations may suffer.

Experiments were conducted where only the drag forces acting on cables were measured. As with all of our experiments, the range of Reynolds number and Bingham number was limited. For experiments involving just the cables, the Reynolds number was always less than 0.1 while the Bingham numbers ranged from about 1 to 10 . The results indicate that while the drag force per unit length of cable is small, the total force acting over a long cable may in some cases be comparable to the drag force on the ball. The drag force is dependent on the types of fluids tested, but appears weakly dependent on cable velocity. This result suggests that the drag is dominated by forces needed to yield the fluid, rather than by viscous drag. However, no clear trends are apparent from the data. The drag force does not seem to correlate with the fluid yield stress, Bingham number, or Reynolds 
number. These experiments will be repeated in further attempts to understand the correlation between cable drag and fluid rheology.

There was concern that, for rising ball tests, the passage of cable through a region of fluid prior to the passage of the ball through the same fluid may affect the drag force on the ball due to the prior disturbance of the fluid. Experiments with the chemical simulant (well mixed), the bentonite clay, and the carbopol have shown that the effect is negligibly small. These experiments were mostly performed at Reynolds numbers less than 1.0.

In any experiment there will be a transition region where the ball accelerates to a constant velocity and steady state fluid flow is established about the ball. Available theory with which we will reduce the drag force data is based on steady state fluid flow. Experiments were conducted to examine the pull distance required before steady state drag is observed. The distance depends somewhat on the fluid rheology, but is typically of the order of one ball diameter, at least in our tests where the Reynolds number typically less than unity. The range of Reynolds numbers expected in actual testing in the tank may be substantially higher than 1 , perhaps as high as $\operatorname{Re}=50$. In use of the ball rheometer in the waste tank, a pull distance of greater than one ball diameter will probably be required, and we plan initially to use at least three diameters. The required pull distance can be determined in actual in-situ testing, and adjustments will be made as necessary.

The effects of interfaces were also investigated in our experiments. For the fluids tested, a boundary (such as the fluid-air interface) begins to affect the measured drag forces when the ball approaches to within about one ball diameter of the interface. For experiments within the tank then, experiments should begin well away from known boundaries, such as the surface and the tank bottom. Interfaces within the fluid where the character of the fluid changes dramatically will be observed over a distance of several ball diameters over which it will be difficult to obtain reliable steady state data.

\subsection{Experiments Performed at LANL}

Primarily free-falling ball experiments were conducted in these tests. In addition, a significant effort was put forth to produce a large quantity of a chemical simulant. The primary focus of the experiments was to determine the applicability of continuum fluid mechanics in the analysis and reduction of ball rheometer data and to determine an appropriate fluid model with which to describe the fluid. Data were obtained with two simulants; an "aged" simulant which has been resident at LANL for years and a new simulant just recently prepared and chemically very similar to the older simulant. Tests show that the two simulants are not the same, but do not differ greatly. A generalized Bingham fluid model appears to be applicable for both of these fluids. The effect of cable drag was also investigated analytically. Calculations based on the assumption of a Newtonian fluid indicate that cable drag can be a substantial fraction of the drag on the ball, in agreement with the experimental findings at PNL. Both laboratories have independently identified cable drag as a major factor in the reduction of the actual in-situ data. In addition, experiments were conducted with a settled simulant in order to observe how the particulates in the fluid settle and how the fluid rheology changes as a result of the settling. Results from this testing have contributed to the testing strategy which will be discussed below. For instance, based on these laboratory tests we will conduct experiments to probe the dependence of fluid properties on the shearing history of the fluid. It was observed in these experiments that the behavior of the fluid depends on this past history. Also, these tests showed that 
the undisturbed fluid can only be tested in falling-ball experiments, rather than with retrieving-ball experiments. Details of the laboratory investigations performed at LANL are given in the Appendix.

Experimental work at LANL required a considerable amount of simulant. Some existing waste simulant was available, but not nearly enough. Thirty gallons of new simulant was prepared following a procedure developed at LANL. The chemical composition of the new simulant is similar to other formulations used at PNL and is based on the chemical composition of the real waste as determined from sampling. Of course, radioactive components are omitted. While chemically very similar to existing PNL and LANL waste simulants, there was no assurance that all simulants would have exactly similar rheological properties. In order to assure that results obtained at PNL can be compared to those obtained at LANL, about 10 gallons of the new simulant was shipped to PNL for laboratory experiments. Future testing at PNL will be performed with this simulant.

Testing with the simulants was performed using free-falling ball rheometry. In addition, a Couette viscometer was used for an independent characterization of the simulant. Couette viscometry is based upon dissapative resistance in a fluid between two concentric cylinders with at least one of them rotating. Falling-ball tests utilized a variety of balls of different sizes and densities. The balls fell through a $5-\mathrm{cm}$ diameter and $50-\mathrm{cm}$ length column of waste simulant and the flight path of the balls through the column was recorded using $x$-ray radiography and a video recording system. The ball velocities were determined from the video images. Experiments were performed with well-mixed and settled simulants.

Experiments with a well-mixed homogeneous simulant showed very good reproducibility in the terminal velocities of similar balls dropped through the simulant in repeated tests. The conclusion drawn from these experiments was that the well-mixed fluid behaved as a continuum and was therefore amenable to theoretical treatment as a single phase fluid. In addition, the rheology for the well mixed simulants could be determined from these data. Both simulants ("old" and "new") appeared to behave as generalized Bingham fluids. However the new simulant had a much higher yield stress.

Results from Couette viscometer tests with the same well-mixed simulants showed qualitatively similar results, but the viscosities were consistently lower by about a factor of two than viscosities determined by the falling-ball method. In addition, there were differences in the power law indices, with the indices being less. using the Couette viscometer. The most likely cause for the discrepancy is that the simulant is not exactly described with the simple power law model. Small samples taken from a large volume of simulant were used for these tests, and non uniform sampling may also be a cause for the discrepancies.

Data obtained from falling-ball tests with a settled simulant suggest that the simulant is a history dependent non Newtonian fluid. The fluid apparently thins after being subjected to shear. In repeated falling ball tests through a simulant in which particles had been allowed to settle under gravity, the first ball through a region always dropped slower than subsequent balls dropped through the same region. A fluid model could not be determined for the settled simulant due to the variability of ball velocities in repeat tests. The experiments show that steps should be taken in actual experiments with the tank to determine the history dependence of the fluid rheological properties. As described below, these measurements will be obtained. 
The additional complication introduced by the presence of a cable attached to the ball was addressed analytically. Both theoretical calculations and numerical calculations which include appropriate end effects indicate that drag on the cable when the ball as near the tank bottom may be a substantial fraction of the total measured drag. The calculations were based on a Newtonian model for the fluid, and improvements could be made by using non-Newtonian fluid models. However, these studies along with the experimental measurements obtained at PNL establish that cable drag will have to be accurately accounted for in the reduction of the actual in-tank data.

\subsection{Data Acquisition Strategy}

We desire to obtain a complete profile of the fluid properties from the top of the waste to the bottom. Measurements will be taken proceeding downwards, primarily with a falling ball operated at constant velocity. Once a complete test has been performed, we may desire to perform measurements from bottom to top in order to obtain repeat supplemental data. It should be noted that initially we will have incomplete knowledge the actual waste rheological character and the manner in which the rheology changes as a function of depth in the waste. The goal of the testing is to obtain this information and to establish as completely as possible the nature of the waste held within the tank, at least along one vertical dimension. Our testing strategy will reflect this goal. We begin this testing description by assuming that the ball rheometer system is in place on the selected tank riser and ready for deployment.

\subsection{Measurements in the Riser Pipe and Dome Space}

With the ball fully retracted in the "home position," the ball position should be verified to be at distance zero, our reference position. After opening the gate valve which seals the instrument from the tank riser pipe, lower the ball at $1 \mathrm{~cm} / \mathrm{s}$ for $1 \mathrm{~cm}$ and obtain a force measurement after the ball is stopped. The static density mode should be used for this measurement. This measurement determines the weight of the ball and the reading can be checked with the expected result. A reading which deviates from the expected value indicates that either an incorrect load cell has been installed (if there is a gross difference between measured value and expected value) or perhaps the calibration has shifted. The measurement is obtained near the home position so that immediate changes can be made if the measurement indicates a problem. It is fully expected that the measurement will be within tolerances, and the primary purpose of this measurement will be to detect long-term drifts in the apparent weight of the ball which could be due to instrument drift or waste buildup on the ball. Laboratory tests with a chemical simulant performed at PNL have shown that buildup of crystals and other material on the ball and cable occurs very slowly, and for durations of less than about a month buildup should not be a problem. However, our data analysis procedures will identify and quantify these effects.

The ball should then be lowered very slowly through the riser pipe $(1 \mathrm{~cm} / \mathrm{s})$ while the load cell is monitored to observe reductions in the apparent weight of the ball. Such an observation would be an indicator that the ball is being impeded by the riser pipe or material within the riser pipe. No data are collected in this procedure. However, if the ball becomes stuck or begins to show signs that it is becoming stuck, the ball should be stopped and steps taken to understand the difficulty. Visual 
verification that the ball has passed through the riser pipe and into the dome space should be obtained utilizing the DACS camera. By the same means, it should also be verified that the cable is not in contact with the riser pipe after the ball has passed through the pipe.

After the ball has passed through the riser, it should be lowered by another $50 \mathrm{~cm}$ and brought to rest. A static measurement should then be obtained. Then four constant velocity measurements should be obtained: (1) lower the ball at $1 \mathrm{~cm} / \mathrm{s}$ for $100 \mathrm{~cm}$, (2) raise the ball at $1 \mathrm{~cm} / \mathrm{s}$ for $100 \mathrm{~cm}$, (3) lower the ball at $10 \mathrm{~cm} / \mathrm{s}$ for $100 \mathrm{~cm}$, (4) raise the ball at $10 \mathrm{~cm} / \mathrm{s}$ for $100 \mathrm{~cm}$. These tests are designed to check for pulley friction and the results should be compared to expected results based on previous laboratory testing. Long-term deviations may indicate a changing pulley friction. A static measurement should follow the final test.

The ball should then be lowered at $1 \mathrm{~cm} / \mathrm{s}$ to very near the surface of the waste and another static measurement should be obtained. No data need be collected or recorded while the ball is falling. Approach to the surface can be verified by the DACS camera or by prior knowledge of the location of the surface and consideration of the amount of cable which has been released from the cable spool, and the measurement should be performed within several inches of the actual fluid surface. Exact position is not critical, but the ball should not be in contact with the waste. This measurement forms the reference measurement against which all other measurements will be compared. In Eqs. (1) and (2), this measurement provides $R_{0}$. At this point we are ready for measurements in the waste fluid.

\subsection{Measurements in the Waste}

The first task is to remove a large enough volume of crust from the area immediately beneath the ball so that we can perform tests in the waste. There are several alternative methods for removing the crust. The first attempt will be to see if the ball itself can either push through or past the crust. If this fails, then water lancing will probably be the next option. In any event, the crust must be removed so that it does not interfere with the measurements.

Lower the ball at constant velocity $(1 \mathrm{~cm} / \mathrm{s})$ for $20 \mathrm{~cm}$ while recording data. We should observe that the apparent weight of the ball changes by about $12 \mathrm{~N}$ as the ball travels from the dome space completely into the fluid. The spatial midpoint of this gradual change in cable tension marks the level of the fluid, and that level should be recorded on a data sheet. If the change is much larger than 12 $\mathrm{N}$, then possibly the ball is either partially or totally supported by a crust layer. The DACS camera should be used to verify the condition. Steps should be taken to position the ball past the crust layer. Possible tactics include repeated high velocity $(1 \mathrm{~m} / \mathrm{s})$ impacts of the ball with the crust or perhaps water lancing of the crust. It is essential that the ball travel into the liquid region beyond the crust. Lower the ball at $1 \mathrm{~cm} / \mathrm{s}$ until the ball is $30 \mathrm{~cm}$ below the bottom of the crust layer. As the ball is falling, observe and record the drag force data. If there is a substantial drag, it may be due to friction between the cable and a portion of the crust. As much as possible utilize the DACS camera to help in making a determination. If the crust is impeding the cable, take steps to eliminate the problem. There is little point in continuing unless the cable is free from any influence due to the crust.

Perform a static density measurement. Now a series of repeated measurements will be obtained from this location throughout the entire depth of the tank. We will perform measurements at four 
velocities: $0.1,1.0,3.0$, and $10.0 \mathrm{~cm} / \mathrm{s}$. These velocities are chosen to span as wide a velocity range as is reasonable practical, thereby providing data over a similarly broad range of strain rate. A minimum of three velocities are required in order to reduce the data in terms of a three-parameter model. A complete set of experiments will require $120 \mathrm{~cm}$ of distance in the fluid $(30 \mathrm{~cm}$ for each velocity). An implicit assumption in the reduction of the data will be that the fluid can be characterized by the same model parameters over the entire $120-\mathrm{cm}$ distance spanned by a set of measurements. This assumption may not necessarily hold true for the entire depth of the waste. One means of observing changes which occur over a smaller distance scale is to group contiguous sets of data obtained at four (or three) velocities and perform essentially a running average over $120 \mathrm{~cm}$ (or 90 $\mathrm{cm}$ ) every $30 \mathrm{~cm}$.

Starting with the ball at about $30 \mathrm{~cm}$ beneath the bottom of the crust, lower the ball at $0.1 \mathrm{~cm} / \mathrm{s}$ for 1 $\mathrm{cm}$ and at the highest data rate (100 samples/s). This step is taken to obtain the initial transient force spike which occurs during the initiation of ball movement and provides an independent estimate of the fluid yield stress. This step will be repeated at the beginning of each drop into undisturbed fluid. Now lower the ball at $0.1 \mathrm{~cm} / \mathrm{s}$ for $30 \mathrm{~cm}$ and at standard data collection rates $(15 \mathrm{samples} / \mathrm{s})$. Retrieve the ball at the same speed. Repeat these measurements. From the graphic display, determine if there is any measurable change in the drag force between the two experiments. If a change is observed, repeat the experiment a third time and a fourth time if necessary. When these measurements are done, the ball should be back at its original location, about $30 \mathrm{~cm}$ beneath the crust surface. Increase the velocity to $1.0 \mathrm{~cm} / \mathrm{s}$ and repeat the experiment twice. Repeat the procedure (i.e., two complete runs) at 3.0 and $10.0 \mathrm{~cm} / \mathrm{s}$ velocities. The point of these measurements is to observe if the fluid changes character as a result of the shearing caused by the ball. Changes can be attributed possibly to mixing or to history dependent behavior (such as thixotropy). Also, by obtaining data at four velocities, some average character for the fluid in the $30-\mathrm{cm}$ section should be obtainable. Lower at $1 \mathrm{~cm} / \mathrm{s}$ for $30 \mathrm{~cm}$ and obtain a static density measurement. We are now at the lower point of the first set of experiments (the fluid immediately beneath the ball has yet to be probed) and are ready to repeat measurements with a different initial velocity. We first perform the drop test at $0.1 \mathrm{~cm} / \mathrm{s}$ for $1 \mathrm{~cm}$. We then repeat all measurements but start at $1 \mathrm{~cm} / \mathrm{s}$ velocity (we perform up to four experiments at this velocity) and then proceed to $5.0,10.0$, and $0.1 \mathrm{~cm} / \mathrm{s}$. We then lower the ball $30 \mathrm{~cm}$ and perform another static density measurement. We are now ready to perform experiments at the third velocity, $3.0 \mathrm{~cm} / \mathrm{s}$. After the initial drop test at $0.1 \mathrm{~cm} / \mathrm{s}$ for $1 \mathrm{~cm}$, the exact same procedure is followed, with an initial velocity of $3.0 \mathrm{~cm} / \mathrm{s}$ followed by $10.0-, 0.1-$, and $1.0-\mathrm{cm} / \mathrm{s}$ velocity experiments. After lowering the ball and obtaining another static density measurement, the same procedure is followed with the velocity sequence of $10.0,0.1,1.0$, and 3.0 $\mathrm{cm} / \mathrm{s}$. We then lower the ball $30 \mathrm{~cm}$ and obtain another density measurement. At this point a complete sequence has been obtained and we are ready to repeat the entire process again for the next $120 \mathrm{~cm}$ of waste. In such a fashion we should work our way downward through the entire tank.

It may happen that the drag force on the ball will increase as we proceed deeper into the waste such that it is no longer possible to obtain high velocities such as $10 \mathrm{~cm} / \mathrm{s}$ with only gravity acting in the downward direction on the ball. If this event occurs, it becomes necessary to reduce our velocity range. From the data we should be able to determine a reasonable estimate of the free-fall terminal velocity and then set a new upper limit which is somewhat less than this velocity. In such a case, the similarity between the upwards travelling experiments and the downwards travelling experiments will be broken. Only the velocities of the falling experiments need be adjusted and we will maintain the same velocity range for the retrieval measurements. If the free-fall terminal velocity falls below 1 $\mathrm{cm} / \mathrm{s}$, then it will be difficult to obtain sufficient data over a wide enough range of strain rate to 
adequately produce a rheological curve for the fluid, at least for the falling ball case. When this condition is reached, it is probably best to terminate the falling-ball experiments as described above. Choosing the constant force mode of operation and setting the force as low as possible, we will simply record the free-fall velocity for the falling ball case. Retrieval experiments will be conducted as before, however, so we will still be able to obtain a rheological curve from these data. Density measurements will be obtained at $30 \mathrm{~cm}$ intervals just as above.

It is planned that all experiments will be conducted over the same distances, namely $30 \mathrm{~cm}$, and an implicit assumption is that this distance will be sufficient for obtaining a steady state condition. Laboratory experiments suggest that this distance will be sufficient, but these tests were not complete and the tank waste may not behave like the chemical simulants used in laboratory testing. For instance, no tests were performed at a ball velocity of $10 \mathrm{~cm} / \mathrm{s}$, nor were any balls greater than $5 \mathrm{~cm}$ in diameter used. If in the field we observe in any test that $30 \mathrm{~cm}$ is not a sufficient pull distance to achieve steady state then we will increase the distance to perhaps $60-$ or $90-\mathrm{cm}$. It may be that conditions are such that we never achieve steady state, in which case we will have to deal with reducing transient data, which will probably be a formidable task.

If the condition occurs where the ball simply will no longer fall through the waste at any velocity, then we will terminate the downwards travelling phase of the experiments and proceed with the retrieval phase of the measurements. Upon completion of the retrieval experiments, a decision will be made as to the viability of water lancing in order to obtain data from deeper in the tank.

A complete set of data obtained over $120 \mathrm{~cm}$ will require from about 30 minutes to 60 minutes to obtain, depending on the exact velocity sequence which is followed. If we assume an average time of 45 minutes per set, it will require about 6 hours to perform a complete profile of the tank from top to bottom. Retrieval experiments will require about the same time. For planning purposes, 16 hours of operation time should be allowed for a complete set of experiments and personnel should be so advised.

From the experiments above, we should have a very good notion of the ball weight which the fluid will support. If the apparent weight of the tungsten alloy ball never falls below about $80 \mathrm{~N}$ (measured), then a steel ball of the same diameter will also fall through the waste. Subsequent experiments conducted at later dates should then be performed using a steel ball rather than the tungsten alloy ball. Use of the steel ball allows for use of a more sensitive load cell, such as the 15- or 25-lb full-scale load cell. The advantage gained from this configuration will be most evident in the determination of the fluid density, which can then be reliably determined to within $1 \%$. Determination of model parameters may or may not be improved, but measurement capabilities towards lower viscosities and yield stresses should result. If the steel ball will sink under gravity though most of the tank, we can conclude that the fluid viscosity and yield stress are lower than the upper limits determined to date. An experimental procedure similar to the one described above should be followed.

The above experiments are conducted with the ball generally progressing in the downwards direction, although experiments with the ball in retrieval are performed along with the falling ball tests. A similar set of experiments will be performed with the ball generally heading in the upwards direction. These experiments can commence at any time after the falling-ball experiments are concluded. Experiments with the ball in retrieval will provide essentially the same information as the falling-ball experiments. The time-dependent behavior of the fluid can be probed by a comparison of results 
obtained for both sets of experiments. For example, if the fluid recovers its original characteristics within several hours after the initial passage of the ball through the waste, we should be able to observe this behavior in the retrieval experiments. In addition, a comparison of results may allow some insight into determination of cable drag in the waste. In retrieval the cable leads the ball and is pulled through relatively undisturbed fluid; while in the falling-ball experiments, the cable is always travelling in fluid which has been sheared by the ball. Except for this difference, the experiments will provide basically the same information and, at a minimum, provide a repeat of the falling ball experiments.

The experiments begin by first retrieving the ball $30 \mathrm{~cm}$ from its original position, which will be either at the tank bottom or the position of deepest travel in the falling ball runs. Obtain density information using the dynamic density mode. Raise the ball at $0.1 \mathrm{~cm} / \mathrm{s}$ for $30 \mathrm{~cm}$. Lower the ball at the same speed. Repeat these measurements. From the graphic display determine if there is any measurable change in the drag force between the two experiments. If a change is observed, repeat the experiment a third time and a fourth time if necessary. When these measurements are done, the ball should be back at its original location, about $30 \mathrm{~cm}$ above its deepest position. Increase the velocity to $1.0 \mathrm{~cm} / \mathrm{s}$ and repeat the experiment twice. Repeat the procedure (i.e., two complete runs) at 3.0 and $10.0 \mathrm{~cm} / \mathrm{s}$ velocities. The point of these measurements is to observe if the fluid changes character as a result of the shearing caused by the ball. Changes can be attributed possibly to mixing or to shear-dependent behavior (such as thixotropy). Also, by obtaining data at four velocities, some average character for the fluid in the $30-\mathrm{cm}$ section should be obtainable. Raise the ball at $1 \mathrm{~cm} / \mathrm{s}$ for $30 \mathrm{~cm}$ and obtain a density measurement. We are now at the upper point of the first set of experiments (the fluid immediately above the ball has yet to be probed) and are ready to repeat measurements with a different initial velocity. We repeat all measurements but start at $1 \mathrm{~cm} / \mathrm{s}$ velocity (we perform up to four experiments at this velocity) and then proceed to $5.0,10.0$, and $0.1 \mathrm{~cm} / \mathrm{s}$. We then raise the ball $30 \mathrm{~cm}$ at $1 \mathrm{~cm} / \mathrm{s}$ and perform another density measurement. We are now ready to perform experiments at the third velocity, $3.0 \mathrm{~cm} / \mathrm{s}$. The exact same procedure is followed, with an initial velocity of $3.0 \mathrm{~cm} / \mathrm{s}$ followed by $10.0-, 0.1-$, and $1.0-\mathrm{cm} / \mathrm{s}$ velocity experiments. After raising the ball and obtaining another density measurement, the same procedure is followed with the velocity sequence of $10.0,0.1,1.0$, and $3.0 \mathrm{~cm} / \mathrm{s}$. We then raise the ball $30 \mathrm{~cm}$ at $1 \mathrm{~cm} / \mathrm{s}$ and obtain another density measurement. At this point a complete sequence has been obtained and we are ready to repeat the entire process again for the next $120 \mathrm{~cm}$ of waste. In such a fashion we should work our way upwards through the entire tank.

After completion of the retrieval experiments another short set of experiments should be performed. These experiments are done in order to obtain some information about cable drag. Starting at $1 \mathrm{~cm} / \mathrm{s}$ velocity, lower and raise the ball through the entire depth of the tank four separate times. Repeat the procedure at $3-$ and $10-\mathrm{cm} / \mathrm{s}$ ball velocities. If there are regions over which the drag force varies linearly with pull or fall distance we can perhaps obtain an estimate of the contribution due to drag on the cable.

It should be clear that the rising ball experiments are exactly the same as the falling-ball experiments, except performed in the opposite direction. The same contingencies will apply in case the ball will not drop at the desired speeds. Experiments will terminate when we have reached a position within $30 \mathrm{~cm}$ of the bottom of the crust. The time required to perform a complete set of experiments will be very similar to the time taken to perform the falling-ball tests, estimated to be about 6 hours. If experiments are concluded and there is no desire to obtain more data, the ball should be retrieved back into the ball rheometer container. In retrieval through the dome space, the position of the fluid 
surface should be determined and the apparent weight of the ball should be measured at the reference position just above the fluid surface. If differences are noted these may indicate material buildup on the ball or cable or instrumental drift. In addition to rechecking these values, pulley friction should again be measured. The procedures for accomplishing these measurements are identical to those described earlier except that the waste surface location is determined with the ball going from fluid into the dome space. There is no need to repeat the initial measurement of the ball weight with the cable almost fully retracted. Rather, the ball should simply be returned to the home position. Extreme care should be taken as the ball approaches the riser pipe from below and full use of the DACS camera should be taken.

In the event that more data are desired later on, the ball should be stored in the rheometer enclosure unless retrieval data are needed, in which case the ball should be left as near to the bottom of the tank as possible.

\subsection{Reduction of Data}

Experimental work with chemical simulants along with rheological data obtained previously with core samples from tank 101-SY have allowed the conclusion that the waste fluid can be modeled approximately as a history dependent generalized Bingham plastic fluid. In reality, many fluids are very complex in their fluid properties and cannot be exactly described by any of the standard fluid models. Fluid models have as their primary advantage a mathematical simplicity and, by virtue of parameters contained within these models, allow a description of the fluid in terms of these parameters. For instance, in the generalized Bingham fluid model, the parameters are termed the consistency index, the power law index, and the yield stress. These parameters only have meaning within the context of the model, and their relationship to fundamental physical parameters is not well established. It is not particularly important for the fluid model to describe the fluid except in a general sense. In our reduction of the data obtained with the ball rheometer, we will initially attempt to describe the fluid in terms of a generalized Bingham fluid, at least for regions where some mixing of the waste has occurred. Such a choice allows the great convenience of a fluid description with a very small number of parameters (three), and a more general reduction is probably not possible or advisable. A model which included all of the correct physics would better characterize the waste but inclusion of this type of model into other codes would be very difficult. For very general fluids, notions such as viscosity and yield stress begin to lose their meaning, and we then have to invent other terms with which to describe the fluid. A clearer picture of the fluid behavior would not likely result from such an endeavor, and informing data users (who want to hear terms such as viscosity) of the fluid properties could become quite confusing. However, it should be remembered that our description of the fluid will always be somewhat approximate.

The data reduction strategy outlined here represents our best present ideas of how to go about analysis of the drag force data. In fact the methods and models used to reduce the actual data may not be completely determined until these data are collected. Perhaps a generalized Bingham model will simply not be appropriate to adequately describe all of the waste. We are presently unsure of the best manner in which to account for drag on the cable, and laboratory investigations are continuing on this problem. Methods for reducing the data will evolve once data are collected in the field. 
For a generalized Bingham fluid, the shear stress $(\tau)$ is related to the shear rate $(\gamma)$ by the following equation (Chhabra 1993):

$$
\begin{aligned}
& \tau=\tau_{0}+m \gamma^{n} \text { for } \tau>\tau_{0} \\
& \gamma=0 \text { for } \tau \leq \tau_{0}
\end{aligned}
$$

Thus, there are three parameters in the model: the yield stress $\left(\tau_{0}\right)$, the consistency index $(\mathrm{m})$, and the power law index (n). If $n=1$ then $\mathrm{m}$ is the viscosity and the fluid is a Bingham fluid. If $\tau_{0}=0$ and $n=1$, then the fluid is Newtonian; while if $\tau_{0}=0$ and $n<1$, the fluid is a power law fluid. It is seen that the generalized Bingham fluid model contains as subsets three other fluid models. The relationship between the drag coefficient $\left(C_{d}\right)$ and the drag force experienced by a ball of diameter (d) traversing the fluid at velocity $(\mathrm{V})$ is given by, in the case of Newtonian fluids,

$$
F_{d}=\frac{1}{2} \rho C_{d} V^{2}\left(\frac{\pi}{4} d^{2}\right)
$$

where, in the limit of small Reynolds number, the drag coefficient is given by

$$
C_{d}=\frac{24}{R e}
$$

For non-Newtonian fluids, the typical approach has been to utilize Eq. 6 using a modified drag coefficient which depends on dimensionless model parameters such as the Reynolds number or the Bingham number. We will adopt the results of Attapattu (Chhabra 1993), who gives the Reynolds number as

$$
\operatorname{Re}=\frac{\rho V^{2-n} d^{n}}{m}
$$

and the Bingham number as

$$
B i=\frac{\tau_{0}}{m\left(\frac{V}{d}\right)^{n}}
$$

Attapattu relates the drag coefficient to a dynamic parameter by

$$
C=\frac{24}{Q}
$$

where 


$$
Q=\frac{R e}{1+K B i}
$$

Attapattu states that the correlation is valid over 8 orders of magnitude in the dynamic parameter. The parameter $\mathrm{K}$ is chosen so that, for any particular set of measurements, Eq. 10 is valid (i.e., the coefficient remains 24). This parameter probably depends on fluid rheology and is not a constant; however, Attaputtu gives a value of very nearly one. If we assume that the power law coefficient is very nearly unity and further assume that the lowest viscosity of interest will be about 10 poise and that the lowest yield stress will be about 100 dynes $/ \mathrm{cm} 2$, we can estimate the range of the Reynolds number and the dynamic parameter for our in-tank experiments. Reynolds numbers range from about 0.1 (lowest velocity) to 10 (highest velocity) while the dynamic parameter ranges from 0.004 to about 2 , if we estimate that $K=1$ in Eq. 11. The dynamic parameter is within the applicable correlation range given by Attapattu. Substituting for all quantities, we find that the drag force on the ball is given by

$$
F_{d}=3 \pi m d^{2-n} V^{n}\left(1+K \frac{\tau_{0} d^{n}}{m V^{n}}\right)
$$

There are three unknowns in Eq. 12; thus, if we obtain drag force data at three or more different velocities, we can solve for all three parameters. Eq. 12 will be the basic theoretical equation by which we relate measured drag force on the ball to the fluid properties. For $\mathbf{n}=1$ and $\mathrm{Bi}=0$ (i.e., $\tau_{0}=0$ ), the above expression reduces to the well-known result for Newtonian fluids in the limit of small Reynolds numbers.

Eq. 12 can be rewritten as

$$
F_{d}=3 \pi d^{2}\left(m\left(\frac{V}{d}\right)^{n}+K \tau_{0}\right)
$$

or

$$
F_{d}=M\left(\frac{V}{D}\right)^{n}+B
$$

where $M$ is a constant and $B$ is nearly constant if $K$ does not vary significantly over the range of shear rates spanned by the data. One method for determining the parameters $\mathbf{M}$ and $\mathbf{B}$ is to plot the drag force data against $(\mathrm{V} / \mathrm{d})^{\mathrm{n}}$ and then perform a least squares best fit of the drag force to a straight line where $n$ is varied. The best fit gives $n$, and the resulting slope and intercept give $M$ and $B$, from which $\mathrm{m}$ and $\tau_{\mathrm{o}}$ are determined.

Note that the method outlined for data acquisition allows some choices for the reduction of the data. We are obtaining data at four velocities rather than three; so if data from all four velocities are considered in the determination of the three model parameters, we will have four equations with three unknowns and the parameters are then overdetermined. A statistical analysis can then be performed 
to determine the parameter values which best fit each set of data obtained at four velocities. Alternatively, we can take any set of three measurements and determine the model parameters. It may make sense to fit the data to the model for the lowest three velocities $(0.1,1.0$, and $3.0 \mathrm{~cm} / \mathrm{s})$ and then the highest three velocities $(1.0,3.0$, and $10.0 \mathrm{~cm} / \mathrm{s})$ and compare results for the parameters. There should be reasonable agreement if the model is fairly representative of the fluid. The best average representation should be obtained by full consideration of all four data sets, however.

We can obtain a characterization of the fluid for each $30-\mathrm{cm}$ increment, since multiple measurements at different velocities will be obtained for each increment. These characterizations will describe the fluid after it has been well sheared by the ball. Only the data obtained as the ball first traverses any $30-\mathrm{cm}$ increment is representative of the undisturbed fluid. Clearly, we will have data at only one velocity for this case.

For the undisturbed fluid, drag force data obtained at four velocities over a distance of $120 \mathrm{~cm}$ will be reduced to obtain the average fluid properties over that distance. Since the ball velocities will be chosen sequentiaily, we can reduce any contiguous set of four separate measurements (or, for that matter, any set of three measurements). Thus, while the results represent data obtained over $120 \mathrm{~cm}$, we can update the results every $30 \mathrm{~cm}$.

There appears to be no satisfactory method to determine drag force on the cable other than by calculation. Given that the fluid properties are known, the drag on the cable can be calculated. For each $30 \mathrm{~cm}$ distance in the fluid, the drag on the cable will always be much smaller than the drag on the ball. One means of calculating the cable drag is to first reduce the data, assuming there is no drag, and arrive at the fluid description. Then we correct the apparent drag on the ball to account for the drag on the cable and recalculate the fluid properties (actually, the model parameters). In order to use this method we need to understand the relationship between fluid rheology and the drag on the cable. We do not presently have this knowledge, but laboratory studies are continuing towards a solution to this problem. Assuming that we can account for cable drag, continued iteration will produce a consistent set of model parameters; and since the contribution of cable drag is incrementally small, convergence should occur very quickly. When the ball is subsequently lowered, we need to include the integrated cable drag calculated in all previous steps as a part of the correction. In this manner we can determine the cable drag just as we determine the model parameters, $30 \mathrm{~cm}$ at a time. We cannot, for each $30-\mathrm{cm}$ increment, determine the cumulative drag on the cable from the single measurement. This method will only work if the data are reduced in a particular order, from the top of the fluid to the bottom.

Reduction of static measurement data to obtain fluid density is straightforward. Again, however, the data must be reduced in order, from the top of the fluid to the bottom, in order to perform the integral for the contribution to the buoyancy force due to the cable. The contribution due to the cable will be a small correction. Density measurements in regions of the fluid with a high-yield stress may be difficult, owing to residual stresses in the fluid which will contribute to the apparent weight of the ball. For this reason we will obtain density measurements in regions of the fluid which have already been well sheared by the ball. 


\subsection{Expected Accuracies}

The accuracies we can expect to obtain in the determination of model parameters has been discussed in a previous report (Shepard et al. 1994), where it was assumed that a Bingham model for the fluid would be appropriate. The only difference between the model used in that report and the one used here is the addition of a power law index. This extra degree of freedom and the expected error in measuring the drag force on the ball will allow substantial errors in the calculated quantities, possibly making it difficult to differentiate the power law index from one. Experiments with well-mixed simulants have shown that the power law index is fairly close to 1.0 , which is the Bingham fluid value. Given the restricted range of strain rates which will be experimentally available, it will be difficult to determine a power law index different from 1 unless it is much different from 1 . Precise determination of this index is made especially difficult due to the expected large uncertainty in the effective viscosity. Therefore the analysis presented in the earlier report gives a realistic picture of the accuracies we can expect if we adopt a generalized Bingham fluid model. The drag on the ball is expected to be due primarily to yielding of the fluid with a small contribution due to viscous drag. As a result, it is expected that the fluid yield stress will be determined to good precision but there will be considerable uncertainty in the viscosity (perhaps as much as 50 to $100 \%$ ).

The effect of cable drag as a source of uncertainty was not discussed in detail in the earlier report. It has since been recognized that this factor represents the most important and least accessible correction to the drag force data. The current plan is to attempt to calculate the correction. We will also perform in-situ experiments aimed at estimating cable drag. While the error in our calculation or measurement of cable drag may be incrementally small, the cumulative errors may be substantial, especially if we consistently overestimate or underestimate the cable drag contribution. For low Reynolds numbers (less than about 1) the total error in the cable drag force will affect the determination of the yield stress, but will introduce no significant error into the viscosity. It will appear as a systematic velocity-independent error in the reduction of any group of four data sets. Since the determination of viscosity relies on the velocity dependent part of the drag force, it will not be affected by the constant offset due to miscalculation of the cable drag. The yield stress is determined from the velocity independent part of the drag force and, therefore, the yield stress will reflect the error in the cable drag term. The error is estimated to be less than about $25 \%$, based on the total expected cable drag as compared to drag on the ball. For higher Reynolds numbers the picture becomes more complicated because the drag on the ball due to yield stress may not be constant. We can probably expect Reynolds numbers of around 10 in actual experiments. In this case increased uncertainty in the calculated viscosities will probably result.

Errors in the determination of the density will depend primarily on the load cell used for the measurements. The load cells have a nominal rated accuracy of $0.1 \%$ of full-scale reading. If we use a $100 \mathrm{lb}(450 \mathrm{~N})$ range load cell, then the resolution is about $0.45 \mathrm{~N}$. The fluid density is expected to range between about 1.4 and $1.6 \mathrm{~g} / \mathrm{cm}^{3}$ (a rather limited dynamic range), so that the expected buoyancy force will be around $5.9 \mathrm{~N}$. The pulley arrangement results in a doubling of this force, so we expect that we can measure density to within about $4 \%$ of true value with this load cell. As can be seen above, the expected total change in density will be about $13 \%$ of the mean value, and so resolution of $4 \%$ will produce relatively course results. Resolution on the order of $1 \%$ would be highly desirable, especially in view of the fact that the density data may provide the most reliable and interpretable information concerning the action of the mixer pump. It would be advantageous to use a 
more sensitive load cell (15- or 25-lb full-scale) which would allow for the desired accuracy. If the initial experiments demonstrate that drag forces are sufficiently small to allow use of more sensitive load cells, measurements will be repeated using such load cells and perhaps a lower density (steel) ball.

\subsection{Conclusions}

We have presented a plan for the collection of in-situ data with the ball rheometer and the subsequent reduction of these data. This plan is fairly detailed and, if followed, should allow the extraction of meaningful information about the waste fluid contained in Tank 101-SY. The plan implicitly assumes that we simply wish to determine fluid rheology and density from the top of the waste to the bottom, and is presented to accomplish this goal. Contingencies have been described to account for as many possibilities as could be imagined. It should be remembered that this plan is by no means complete or all inclusive. Only time and careful planning will determine the breadth of measurements we wish to make with this instrument. It is expected that it will be called upon to provide extended service as a diagnostic tool, since the availability of in-situ measurement instruments for the tanks is quite limited. It should be remembered that the ball rheometer can only directly measure fluid rheology and density, nothing more. The interpretation of what these quantities suggest, especially in judgment of mixer pump performance, will depend on other factors involving the use of the mixer pump.

We will reduce the drag force data to obtain fluid rheological parameters by assuming that the fluid can be adequately described with the generalized Bingham fluid model. It is expected that this model should be applicable, based on experimental results with chemical simulants of the waste. If actual data obtained from the tank indicates that this model is quite inappropriate, then the fluid model question will be revisited. Data will be obtained at four ball velocities so that determination of the three model parameters can be performed. Both the undisturbed fluid and the "well-mixed" or . "highly sheared" fluid will be characterized.

We do not expect to obtain highly accurate rheological values, with expected errors of perhaps $50 \%$ for the viscosity and $25 \%$ for the yield stress. Viscosities below about 10 to 100 poise will be difficult to measure, as discussed in previous reports. Data users have consistently reported that such accuracies are sufficient. Unless residual stresses due to the yield stress of the fluid present difficulties, we expect to be able to make fairly accurate measurements of density, within $1 \%$ error if a low-range load cell can be used.

\subsection{References}

Chhabra, R. P. 1993. Bubbles, Drops, and Particles in Non-Newtonian Fluids, (CRC Press, Boca Raton, FL).

Pasamehmetoglu, K. O., C. Unal, and J. Edwards. December 1993. The Evaluation of Methods for Rheology Measurements of the Waste Contained in Hanford Tank 241-SY-101. Los Alamos National Laboratory Report LA-UR-93-4300. 
Shepard, C. L. 1994. Report on Data Requirements and Hardware Selection for In-Situ Ball Rheometer, PNL-10171. Pacific Northwest Laboratory, Richland, Washington.

Shepard, C. L., J. B. Colson, K. O. Pasamehmetoglu, C. Unal, J. H. Edwards, and J. Abbott. 1994. Theory of Operation for The Ball Rheometer, PNL-10240. Pacific Northwest Laboratory, Richland, Washington. 


\section{Appendix A}

\section{Experiments Performed at Pacific Northwest Laboratory}





\section{Figures}

A.1. Diagram of the Ball Rheometer System Showing the Ball, Cable, Take-up Spool, Pulley, and Load Cell . . . . . . . . . . . . . . . . . . A.2

A.2. Forces Acting on a Ball in Motion in a Fluid $\ldots \ldots \ldots \ldots \ldots \ldots \ldots$

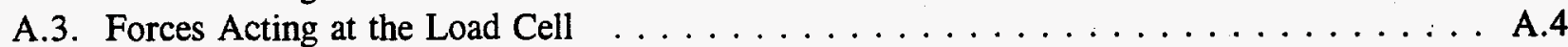

A.4. Plot of ball drag force measured with chemical simulant with the 1 inch ball first falling

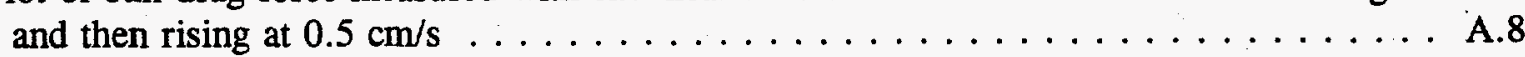

A.5. Plot of ball drag force measured with chemical simulant with the 2 inch ball first falling and then rising at $0.5 \mathrm{~cm} / \mathrm{s} \ldots \ldots \ldots \ldots \ldots \ldots \ldots \ldots \ldots$

A.6. Plot of ball drag force measured with carbopol with the 0.5 inch ball first falling and

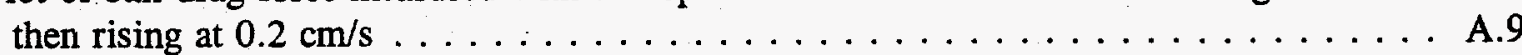

A.7. Plot of the ball drag force measured with carbopol with the 1 inch ball first falling and then rising at $0.2 \mathrm{~cm} / \mathrm{s} \ldots \ldots \ldots \ldots \ldots \ldots \ldots \ldots \ldots \ldots \ldots$

A.8. Plot of the ball drag force measured with carbopol with the 2 inch ball first falling and then rising at $0.2 \mathrm{~cm} / \mathrm{s} \ldots \ldots \ldots \ldots \ldots \ldots \ldots \ldots \ldots$

A.9. Plot of the ball drag force measured with bentonite clay with the 2 inch tungsten ball falling at $0.2 \mathrm{~cm} / \mathrm{s}$

A.10. Plot of the ball drag force measured with bentonite clay with the 2 inch tungsten ball

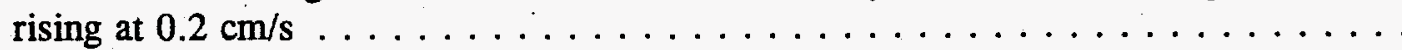

A.11. Plot of the drag force on a 0.125 inch diameter cable being withdrawn from the

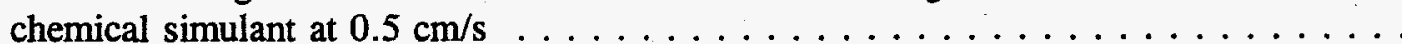

A.12. Plot of the drag force on a 0.125 inch diameter cable being withdrawn from the

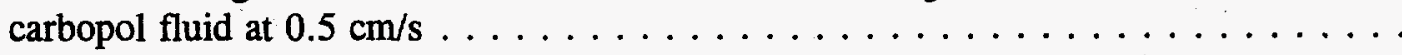

A.13. Plot of the drag force on a 0.125 inch diameter cable being withdrawn from the bentonite clay at $0.5 \mathrm{~cm} / \mathrm{s}$.

A.14. Plot of the ball drag force measured with the chemical simulant with the 1 inch ball being withdrawn completely from the fluid at $0.5 \mathrm{~cm} / \mathrm{s}$

A.15. Plot of the ball drag force measured with carbopol with the 1 inch ball being withdrawn completely from the fluid at $0.5 \mathrm{~cm} / \mathrm{s}$

A.16. Plot of the ball drag force measured with bentonite clay with the 1 inch ball being withdrawn completely from the fluid at $0.5 \mathrm{~cm} / \mathrm{s}$

A.17. Plot of the combined drag force due to 0.125 inch diameter cable and 1 inch ball being pulled through the chemical simulant at $0.5 \mathrm{~cm} / \mathrm{s} \ldots \ldots \ldots \ldots \ldots \ldots$

A.18. Plot of the combined drag force due to 0.125 inch diameter cable and 1 inch ball being pulled through carbopol at $0.5 \mathrm{~cm} / \mathrm{s}$

A.19. Plot of the combined drag force due to 0.125 inch diameter cable and 1 inch ball being pulled through bentonite clay at $0.5 \mathrm{~cm} / \mathrm{s}$

A.20. Rheogram for carbopol as measured with the Bohlin rheometer . . . . . . . . . . . A.23

A.21. Rheogram for bentonite clay as measured with the Bohlin rheometer . . . . . . . A.23

A.22. Rheogram for chemical simulant as measured with the Bohlin rheometer . . . . . . . . A.24 


\section{Tables}

A.1. Drag Force per Unit Length on Cable $\ldots \ldots \ldots \ldots \ldots \ldots \ldots \ldots \ldots$

A.2. Drag Forces on Ball $\ldots \ldots \ldots \ldots \ldots \ldots \ldots \ldots \ldots \ldots \ldots \ldots \ldots \ldots$

A.3. Drag Force on Ball with Different Cables $\ldots \ldots \ldots \ldots \ldots \ldots \ldots \ldots \ldots \ldots$

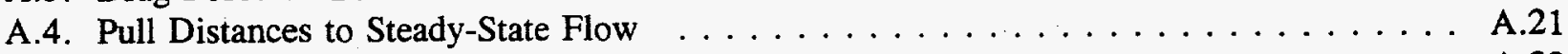

A.5. Interface-Effects Distance . . . . . . . . . . . . . . . . . . A.22

A.6. Comparison of Experimental Results Obtained with Ball Rheometer and Laboratory

Rheometer for Three Simulants . . . . . . . . . . . . . . . A.25 


\title{
Results of Laboratory Experiments in Support of the Ball Rheometer Project
}

\author{
Chester L. Shepard, Leslie J. Kirihara, M. Andrew Chieda, \\ Alireza Shekarriz, Guillermo Terrones, Jon Phillips \\ Pacific Northwest Laboratory
}

\section{A1.0 Introduction}

The ball rheometer is being developed in order to perform in-situ measurements of tank waste rheological properties, initially in Tank 101-SY. Previous reports have described the need for these data (Shepard 1994), rheological measurements of tank wastes (Pasamehmetoglu et al. 1993), and the theory of operation of the ball rheometer (Shepard et al. 1994). In this report we will concentrate on the reduction of the expected load cell data to obtain drag force on the ball and the methods we will employ to determine the waste's rheological properties from the drag force data. The ball rheometer consists of a ball attached to a cable which is wound onto a spool. The system will be installed on a riser pipe through which entry into Tank 101-SY is obtained. The ball can be lowered into the waste or retrieved from the waste by rotation of the spool, which is mechanically connected to electric drive motors. The present ball is comprised of a tungsten alloy and is $9.1 \mathrm{~cm}$ in diameter and weighs about $16 \mathrm{lb}(7.3 \mathrm{~kg})$. It is likely that other balls of similar size but lower density, such as a steel ball, will also be employed. The cable is stranded stainless steel of diameter $0.32 \mathrm{~cm}(0.125$ inches $)$ and has a polyethylene coating. A diagram of the ball rheometer is shown in Figure A.1. The ball is deployed into the waste and retrieved by rotation of the take up spool. Typically the ball will be deployed at a constant velocity, which is adjustable over the velocity range from $0.1 \mathrm{~cm} / \mathrm{s}$ to $100 \mathrm{~cm} / \mathrm{s}$. The cable passes over a pulley to which a load cell is attached. The tension in the cable, or actually twice the tension in the cable is measured by this load cell. We will measure the tension in the cable as the ball is being moved through the waste at different velocities. From these measurements, the drag on the ball due to movement through the waste can be determined. The amount of drag depends on the rheology (roughly the yield stress and the viscosity) of the waste fluid, and we are interested in determining the rheology of the fluid. Static force measurements obtained while the ball is at rest in the fluid will allow a determination of the fluid density. We intend to characterize the fluid at all depths within the tank.

The report is organized as follows. In Section 2 we examine the forces involved in measurements with the load cells. The goal is to identify the drag force contribution to the total force measured with the load cell. Not all of these forces will be measurable in the tank, and accurate estimates from laboratory measurements will have to suffice. We will present the results of laboratory tests to determine some of the forces involved in Section 3. 


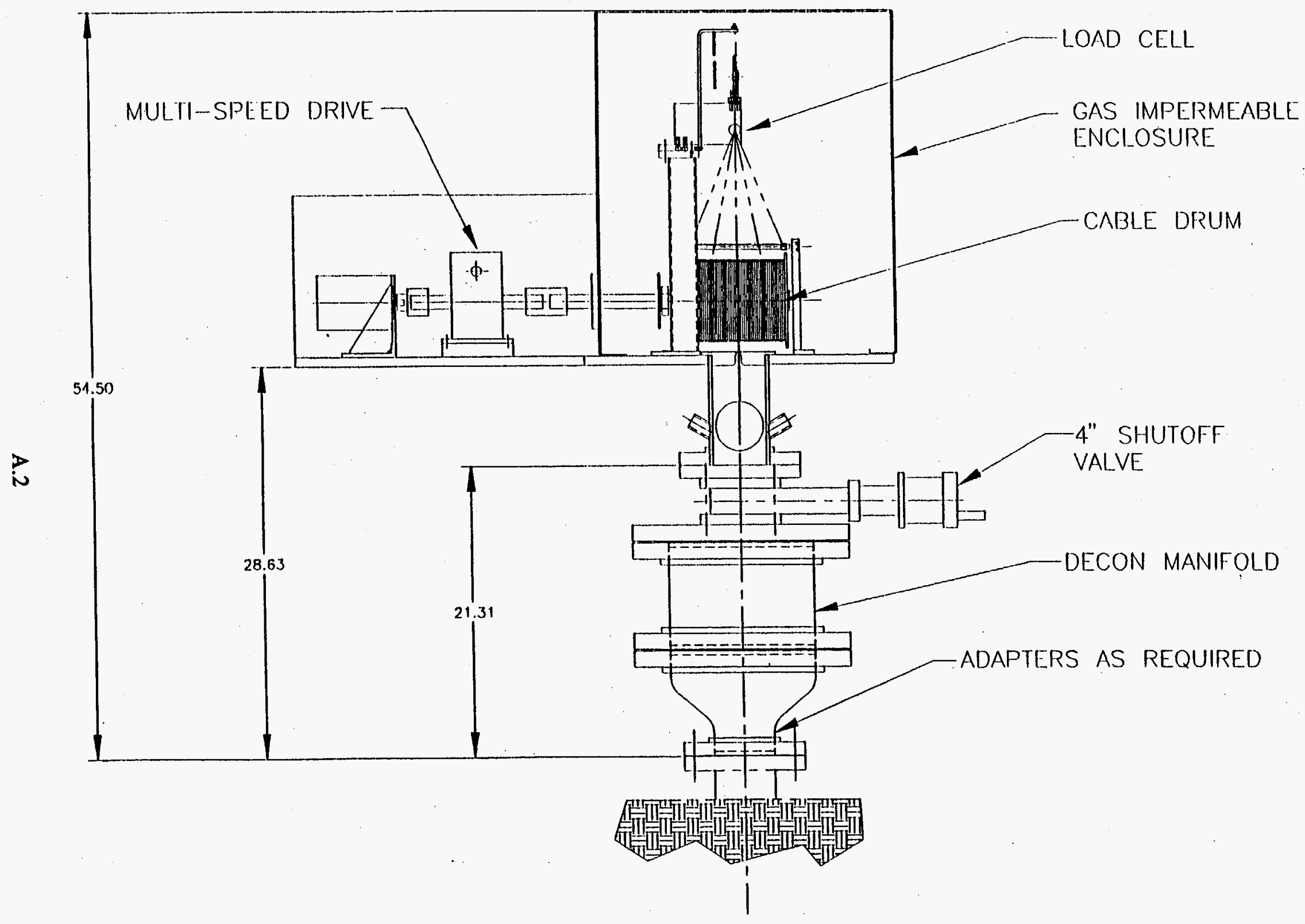

Figure A.1. Diagram of the Ball Rheometer System Showing the Ball, Cable, Take-up Spool, Pulley, and Load Cell 


\section{A2.0 Determination of Drag Forces on the Ball}

The load cell measures the total tension in the cable to which the ball is tethered plus frictional forces in the pulley plus the weight of the pulley assembly. Only part of the total force is due to viscous drag on the ball. It is imperative that we be able to account for all of the forces involved and separate out the drag force contribution, since this force can be related to the rheological properties of the fluid. We will begin with a theoretical description of the ball rheometer system.

\section{A2.1 Theory}

We desire to understand and identify the forces which play a part in the Ball Rheometer. First consider the forces acting on the ball in the fluid and let upward forces be positive while downward acting forces are negative. Assume that the ball is falling at some constant velocity. The forces are shown in Figure A.2.

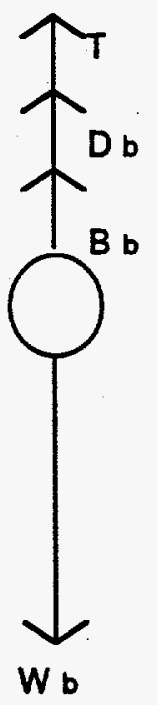

Figure A.2. Forces Acting on a Ball in Motion in a Fluid

where

$$
\begin{aligned}
T & =\text { tension in the cable at the ball } \\
D_{b} & =\text { drag force on the ball due to the liquid } \\
B_{b} & =\text { buoyancy force on the ball due to the liquid } \\
W_{b} & =\text { weight of the ball in air }
\end{aligned}
$$

The equilibrium condition is 


$$
T+D_{b}+B_{b}-W_{b}=0
$$

Now consider the forces acting at the load cell, as shown in Figure A.3.

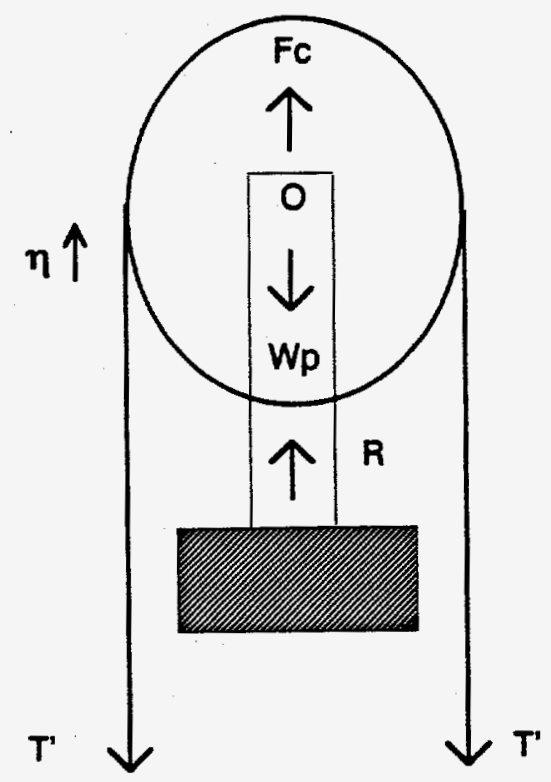

Figure A.3. Forces Acting at the Load Cell

where

$$
\begin{aligned}
\mathrm{T}^{\prime} & =\text { tension in cable at pulley } \\
\eta & =\text { friction in pulley } \\
\mathrm{W}_{\mathrm{p}} & =\text { weight of pulley and other components } \\
\mathrm{F}_{\mathrm{c}} & =\text { counterbalance force } \\
\mathrm{R} & =\text { force with which the load cell pushes back. This is the load cell reading. }
\end{aligned}
$$

The equilibrium condition is

$$
R+F_{c}=2 T^{\prime}-\eta+W_{p}
$$

In general the tension at the pulley does not equal the tension at the ball.

$$
T^{\prime}=T+W_{c}-D_{c}-B_{c}
$$

where

$W_{c}=$ weight of deployed cable
$D_{c}=$ total drag force on cable 
$B_{c}=$ buoyancy force on cable

Using Eq. (A.3) and substituting for $\mathrm{T}^{\prime}$ in Eq. (A.2) gives

$$
R+F_{c}=2\left[T+W_{c}-D_{c}-B_{c}\right]-\eta+W_{p}
$$

Using Eq. (A.1) and substituting for T in Eq. (A.4) gives

$$
R+F_{c}=2\left[W_{b}-D_{b}-B_{b}-D_{c}-B_{c}+W_{c}\right]-\eta+W_{p}
$$

or, upon rearrangement

$$
R=2\left[\left(W_{b}-\frac{F_{c}}{2}\right)-\left(D_{b}+B_{b}\right)-\left(D_{c}+B_{c}-W_{c}\right)\right]-\eta+W_{p}
$$

Eq. (A.6) shows that the counterbalance force can be viewed as equivalent to using a lighter ball of weight $\left(W_{b}-F_{c} / 2\right)$. The cable-related force terms, $D_{c}, B_{c}$, and $W_{c}$, are not constant but will depend linearly on the amount of cable deployed in the waste.

Let $\mathrm{z}_{\mathrm{o}}$ be the distance at which the ball is just above the surface of the waste. At this location,

$$
R_{o}=2\left[\left(W_{b}-\frac{F_{c}}{2}\right)+W_{d}\left(z_{o}\right)\right]+W_{p}
$$

At some distance $z>z_{0}$, we have

$$
R=R_{o}-2\left[\left(D_{b}+B_{b}\right)+\left(D_{c}+B_{c}-W_{c}(z)\right)\right]-\eta
$$

If we assume

$$
\begin{aligned}
& D_{c}=\int_{z_{0}}^{z} A\left(z^{\prime}\right) d z^{\prime} \\
& B_{c}=\int_{z_{o}}^{z} B\left(z^{\prime}\right) d z^{\prime} \\
& W_{c}=C\left(z-z_{o}\right)
\end{aligned}
$$

where $C$ is a constant and $A$ and $B$ depend on position in the waste, then we can write 


$$
\Delta R_{f}=R-R_{o}=-2\left[\left(D_{b}+B_{b}\right)+\int_{z_{o}}^{z}\left(A\left(z^{\prime}\right)+B\left(z^{\prime}\right)\right) d z^{\prime}-C\left(z-z_{o}\right)\right]-\eta
$$

If we obtain the load cell measurement at $\mathrm{z}_{\mathrm{o}}$ and concern ourselves with load cell measurement differences $\left(R-R_{o}\right)$, then the situation is simplified somewhat. Solving Eq. (A.7) for $D_{b}$ gives

$$
D_{b}=-\left[B_{b}+\int_{z_{o}}^{z}\left(A\left(z^{\prime}\right)+B\left(z^{\prime}\right)\right) d z^{\prime}-C\left(z-z_{o}\right)+\frac{\eta+\Delta R_{f}}{2}\right]
$$

Thus, in order to determine the actual drag force on the ball, several parameters must be determined independently. These include:

- the buoyancy of the ball, which may depend on waste type

- the buoyancy on the cable

- the drag on the cable

- the weight of the cable

- the friction in the pulley, which may depend on velocity and load.

Eqs. (A.7) and (A.8) hold for a falling ball. For a rising ball, the drag forces on the ball and cable as well as the pulley frictional force reverse in direction. Eq. (A.6) becomes

$$
R=2\left[\left(W_{b}-\frac{F_{c}}{2}\right)+\left(D_{b}-B_{b}\right)+\left(D_{c}-B_{c}+W_{c}\right)\right]+\eta-W_{p}
$$

Following the same procedure as before, Eqs. (A.7) and (A.8) become, for a rising ball, respectively,

$$
\begin{gathered}
\Delta R_{r}=R-R_{0}=2 D_{b}-2 B_{b}+2 \int_{z_{0}}^{z}\left(A\left(z^{\prime}\right)-B\left(z^{\prime}\right)\right) d z^{\prime}+2 C\left(z-z_{o}\right)+\eta \\
D_{b}=B_{b}+\frac{\Delta R_{r}-\eta}{2}-\int_{z_{o}}^{z}\left(A\left(z^{\prime}\right)-B\left(z^{\prime}\right)\right) d z^{\prime}-C\left(z-z_{o}\right)
\end{gathered}
$$

Equations (A.8) and (A.11) relate the drag force on the ball to other quantities. We will use Eqs. (A.7) and (A.10) in some of the analysis of data which follows. With the load cell we will measure 
$\Delta \mathrm{R}$. Pulley friction can be determined from laboratory measurements, as can the cable weight per unit length. Therefore only the buoyancy forces and the drag on the cable are not well known prior to deployment of the ball rheometer. Values for these forces may depend on the fluid properties and therefore cannot be determined ahead of time. We have performed laboratory experiments with several fluids in order to determine representative values for these forces, but their actual determination will have to be made in the tank if possible.

\section{A3.0 Results of Laboratory Investigations}

Experiments were performed with several fluids to determine the ranges of parameters which we might expect in tests which will be performed in the tanks. Quantities such as the buoyancy forces and drag forces were measured with simulants which included a chemical simulant, Bentonite clay, and carbopol. The experimental arrangement was our standard configuration. The fluids were held in a 5 gallon bucket so that total fluid depth was about $30 \mathrm{~cm}$ and the bucket diameter was also about $30 \mathrm{~cm}$. In most tests a steel ball was suspended over a pulley with a thin stainless steel braided cable normally used and marketed for fishing applications. The pulley and ball were supported by a load cell which measured total tension in the cable. These results are presented in this Section.

\section{A3.1 Buoyancy Force on the Ball}

For static measurements in a material with a yield stress the buoyancy force on the ball may not necessarily be given by the change in the apparent weight of the ball, since the ball can be partially supported by the yield stress. In dynamic measurements it is not clear if the buoyancy is simply the weight of the displaced fluid, although it appears difficult to describe it otherwise. Due to this uncertainty, we performed experiments to determine the dynamic buoyancy of the fluids. The buoyancy force on the ball is most easily determined from total force measurements obtained while the ball is rising and while the ball is falling. For these tests we used a very thin wire for a cable, so that the drag, weight, and buoyancy of the cable could be neglected. Adding Eqs. (A.7) and (A.10) with the cable related terms set to zero we obtain

$$
B_{b}=\frac{-\left(\Delta R_{f}+\Delta R_{r}\right)}{4}
$$

Some of the relevant data are shown in Figures A.4 through A.8 for 0.5-, 1.0-, and 2.0- inch balls and for the chemical simulant and carbopol. All of the data show buoyancies, from Eq. (A.12), which are consistent with results obtained using Archimedes Principle. The measured densities of the chemical simulant and carbopol are $1.55 \mathrm{~g} / \mathrm{cm}^{3}$ and $0.96 \mathrm{~g} / \mathrm{cm}^{3}$ respectively. From Archimedes Principle we therefore expect buoyancies of $13.3 \mathrm{~g}$ and $106 \mathrm{~g}$ for the 1- and 2-inch balls in the chemical simulant and buoyancies of $1.0 \mathrm{~g}, 8.2 \mathrm{~g}$, and $66.0 \mathrm{~g}$ for $0.5-, 1$ - and 2- inch balls submersed in carbopol. The data shown in these figures indicate buoyancies in close agreement. For the chemical simulant we determine buoyancies of $12.5 \mathrm{~g}$ and $103 \mathrm{~g}$ for the 1- and 2-inch balls while for the carbopol we determine buoyancies of $1.0 \mathrm{~g}, 8.5 \mathrm{~g}$, and $67.5 \mathrm{~g}$. We can conclude that the dynamic buoyancy force in these fluids is given by the weight of the displaced fluid. 


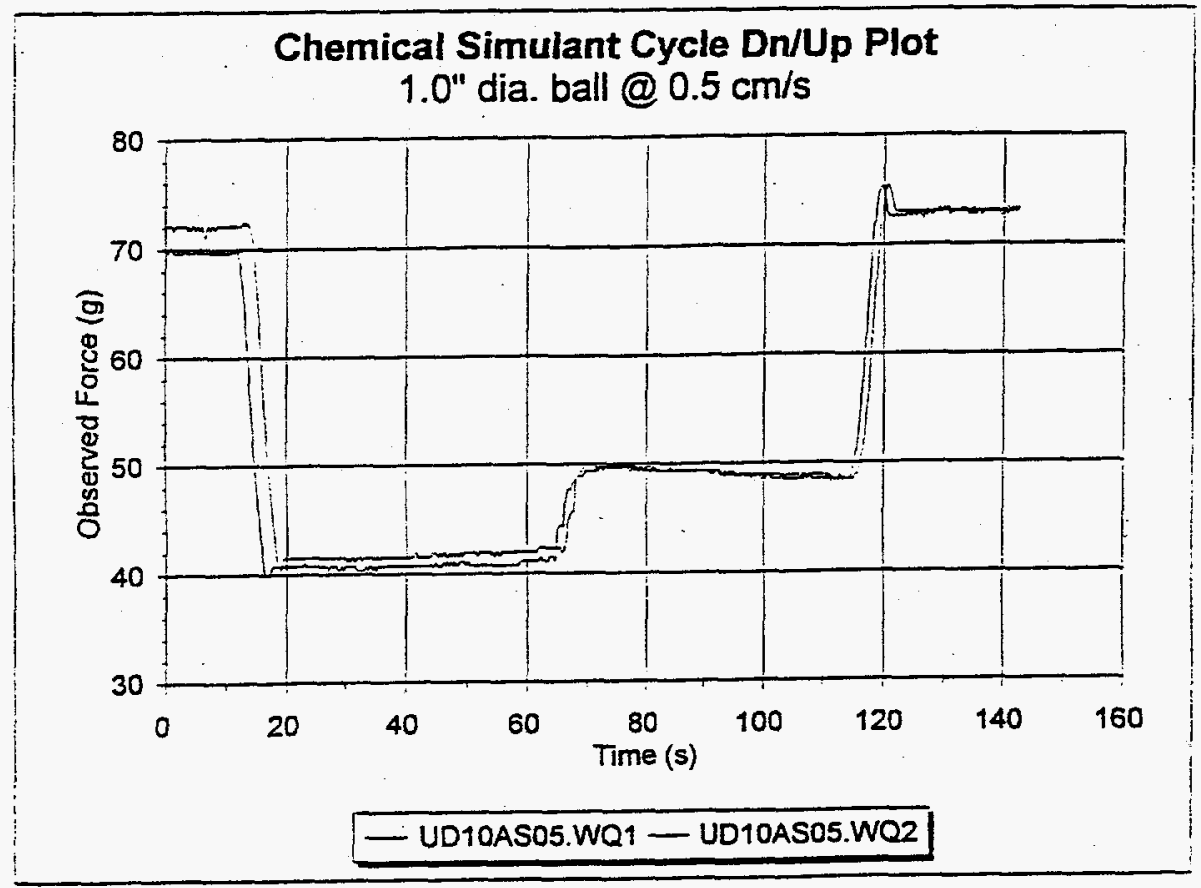

Figure A.4. Plot of ball drag force measured with chemical simulant with the 1 inch ball first falling and then rising at $0.5 \mathrm{~cm} / \mathrm{s}$

In the data presented in Figures A.4-A.8, the ball is initially in air and is then lowered into the fluid until the bottom of the container is approached. The ball is then retrieved at the same velocity. In order to apply Eq. (A.12) a reference value is needed $\left(R_{o}\right)$. This value is the apparent weight of the ball prior to entering the fluid. For example in Figure A.4, this value is $70 \mathrm{~g}$ in one case and $72 \mathrm{~g}$ in another.

Similar high quality data are not available for the Bentonite clay mixture because this fluid would not allow the free sinking of any of the test balls. This fluid had a very high yield stress, and its density was $1.05 \mathrm{~g} / \mathrm{cm}^{3}$. The data which are available, shown in Figures A.9 and A.10, are consistent with the notion that the buoyancy is given by Archimedes Principle. Some comment is necessary to describe how these data were collected. Since the ball, which was formed from tungsten powder and had a diameter of 1.925 inches, would not freely sink, weights were attached to it using a platform and a thin hollow rod. One end of the rod rested on the ball while the other end held the weights on a platform which was well above the surface of the clay mixture. The ball was then lowered into the waste at $0.2 \mathrm{~cm} / \mathrm{s}$. The reference weight shown in Figure A.9 was about $2200 \mathrm{~g}$. Before retrieving the ball, the platform, weights, and rod were removed. Then the clay was moved to fill in the hole left behind while the ball was falling. The thin rod has little effect on the total drag while the ball is falling because of the large hole which the ball leaves in its wake. Very little material comes in contact with the rod. Therefore, in Figure A.10, the weight of the platform and other weights (2044 g) should be added to the drag curve to compensate for their removal and to allow its use with Figure A.9. As the plots show there is a large uncertainty in the buoyancy obtained from these data, since stable drag forces were not obtained. Using reasonable values from the plots we obtain a buoyancy of $64 \mathrm{~g}$ for the ball, while the expected value is $66 \mathrm{~g}$. The uncertainty in the value obtained from the plots is about $15 \mathrm{~g}$. Based on the results of measurements with all three fluids and especially the chemical simulant and carbopol, which also have a yield stress, we conclude that the buoyancy is 


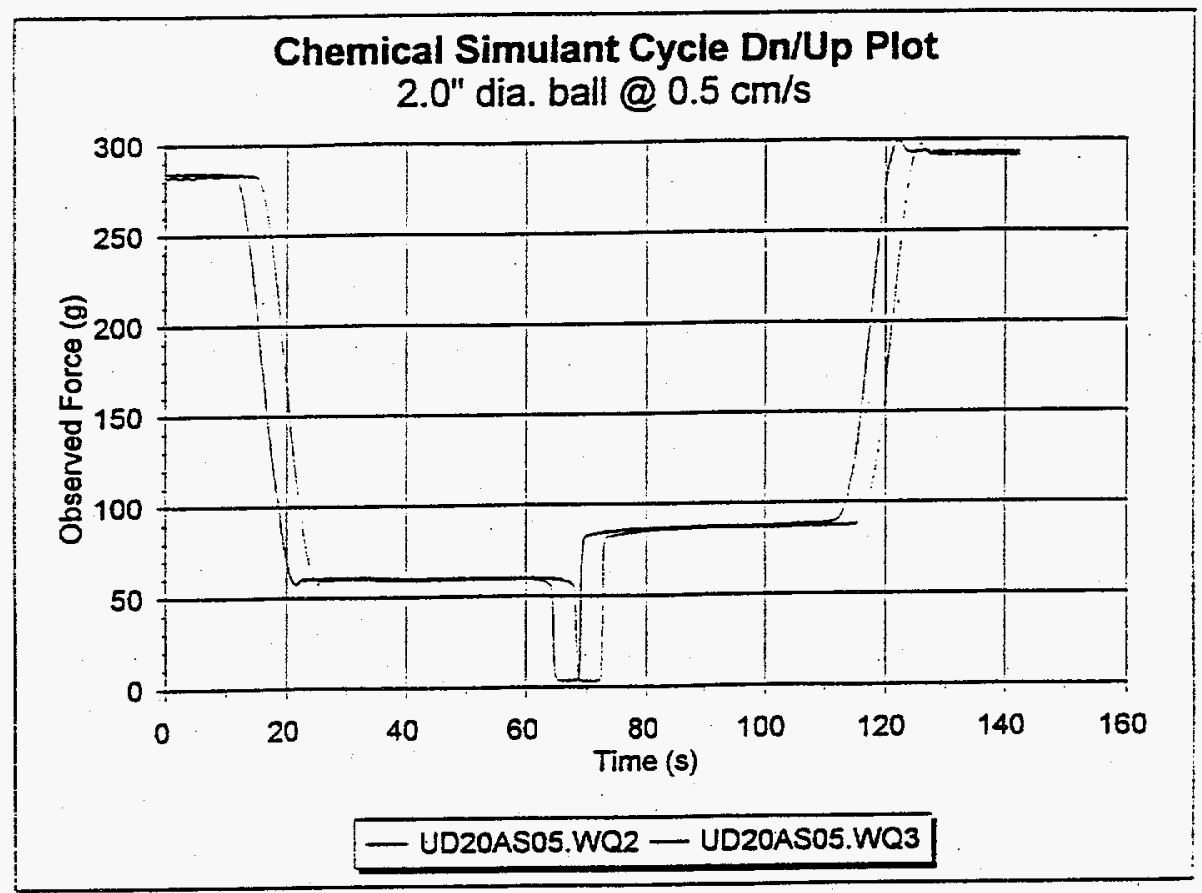

Figure A.5. Plot of ball drag force measured with chemical simulant with the 2 inch ball first falling and then rising at $0.5 \mathrm{~cm} / \mathrm{s}$

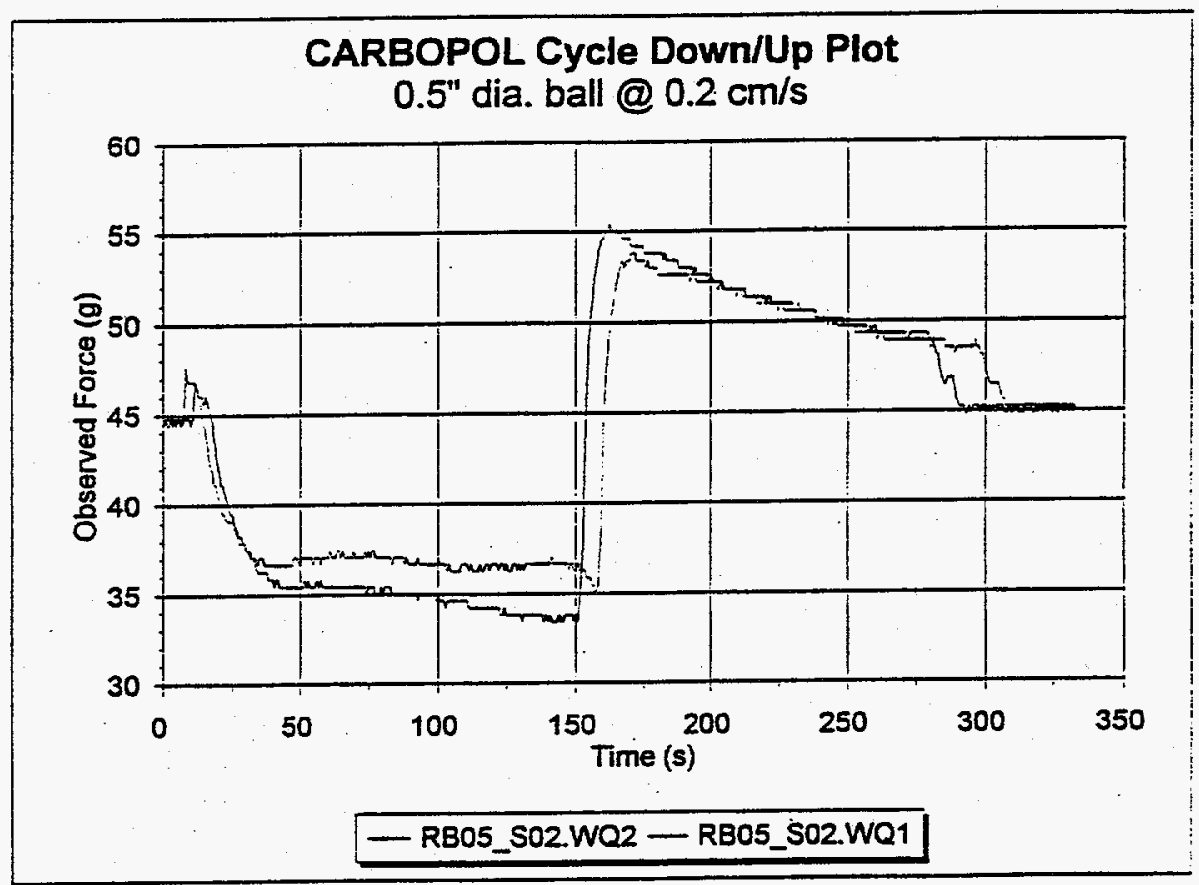

Figure A.6. Plot of ball drag force measured with carbopol with the 0.5 inch ball first falling and then rising at $0.2 \mathrm{~cm} / \mathrm{s}$ 


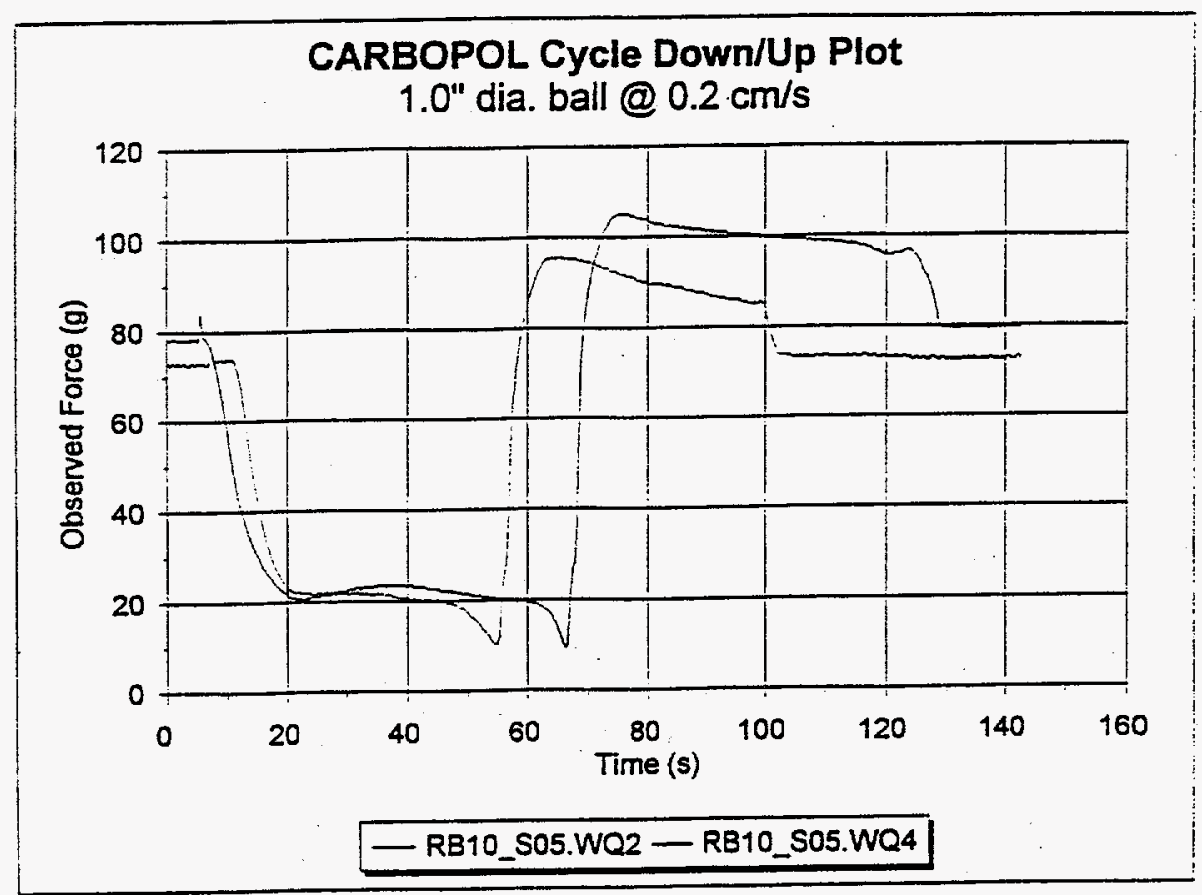

Figure A.7. Plot of the ball drag force measured with carbopol with the 1 inch ball first falling and then rising at $0.2 \mathrm{~cm} / \mathrm{s}$

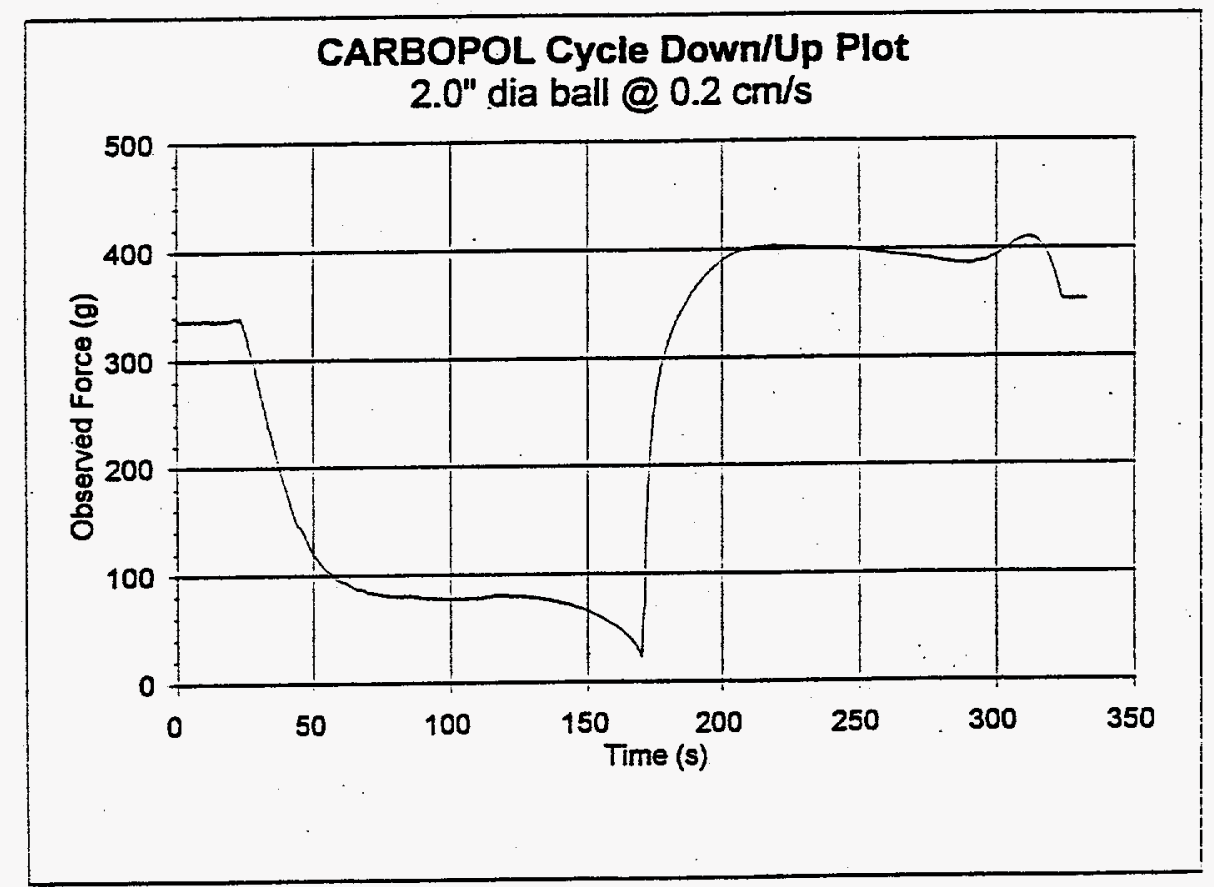

Figure A.8. Plot of the ball drag force measured with carbopol with the 2 inch ball first falling and then rising at $0.2 \mathrm{~cm} / \mathrm{s}$

\section{A.10}




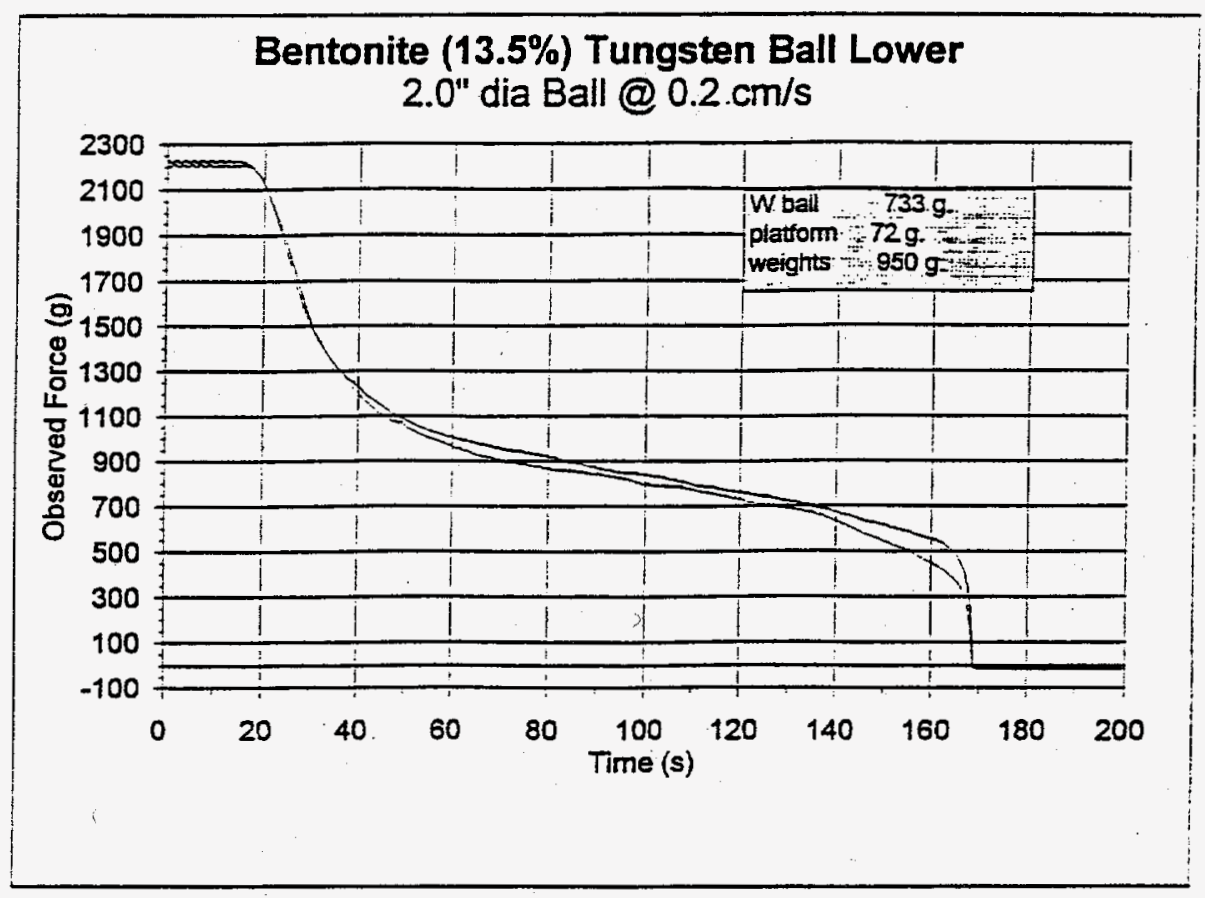

Figure A.9. Plot of the ball drag force measured with bentonite clay with the 2 inch tungsten ball falling at $0.2 \mathrm{~cm} / \mathrm{s}$

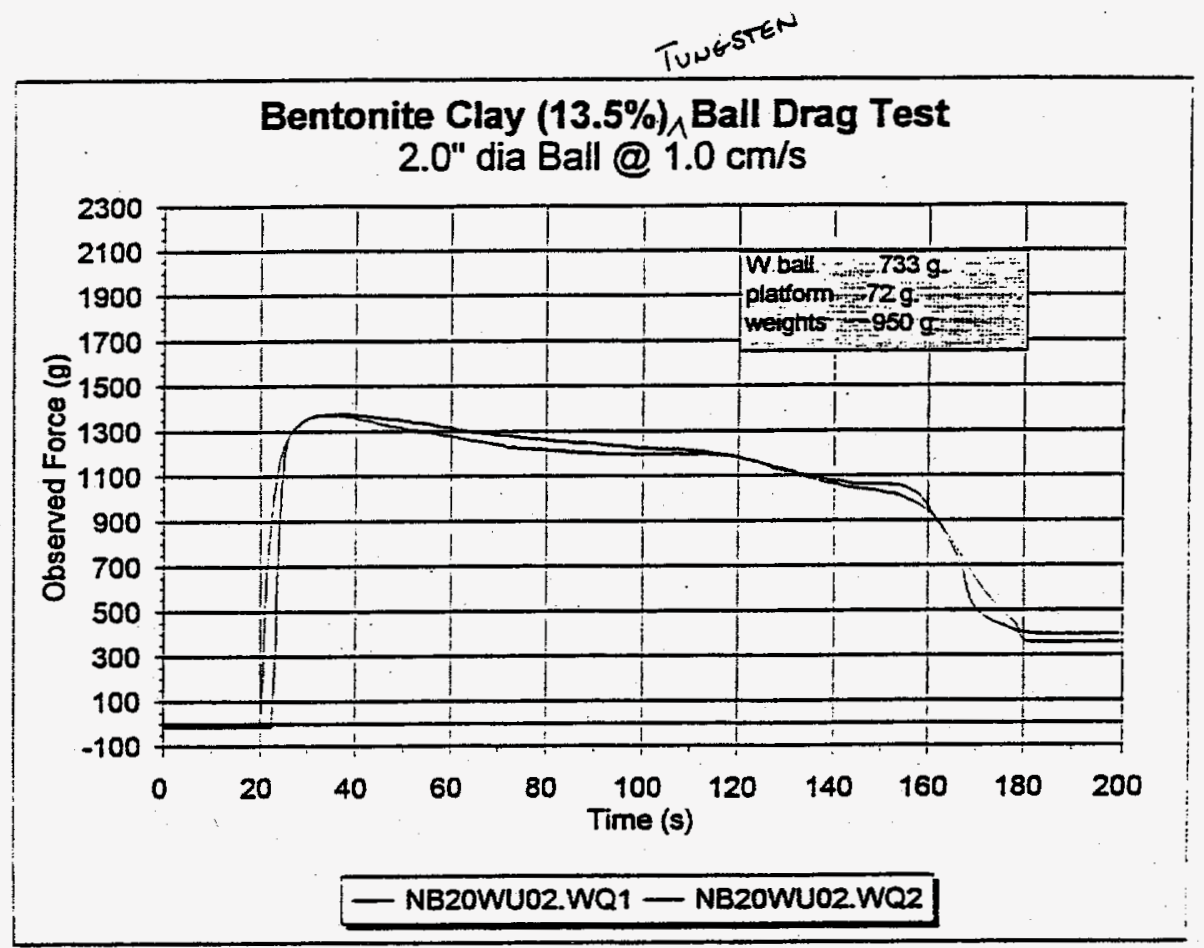

Figure A.10. Plot of the ball drag force measured with bentonite clay with the 2 inch tungsten ball rising at $0.2 \mathrm{~cm} / \mathrm{s}$

\section{A.11}


given by the weight of the displaced fluid.

The verification that the buoyancy force is given by the weight of the displaced fluid regardless of fluid type allows the calculation of both B and B( $\left.z^{\prime}\right)$ in Eqs. (A.8) and (A.11), since the fluid density will be measured as a function of ball position.

\section{A3.2 Drag Forces on the Cable}

Drag force on the cable was measured in a relatively simple manner. A length of cable was placed vertically in the fluid and extended downwards to the bottom of the container. Three cable diameters were used, 0.013-, 0.125-, and 0.250-inches. Weighted stainless steel tubing was used for the larger sizes while a stiff stainless steel wire cable was used for the small size. The cables were then withdrawn at constant velocity while the drag force was monitored. The slope of the drag force as a function of distance or time (divided by two to account for the experimental arrangement) could then be used to obtain the drag force per unit length of the cable. In the cases of the 0.125 - and 0.250 inch cables which have substantial weights, corrections were applied to the data to account for the increase in cable tension due to the withdrawal of the cable from the fluid and into the air, where there is no buoyancy. Representative data are shown in Figures A.11 through A.13, which show the drag on a 0.125 inch diameter cable at $0.5 \mathrm{~cm} / \mathrm{s}$ velocity for the three different fluids. The results obtained from all of the data are summarized in Table A.1.

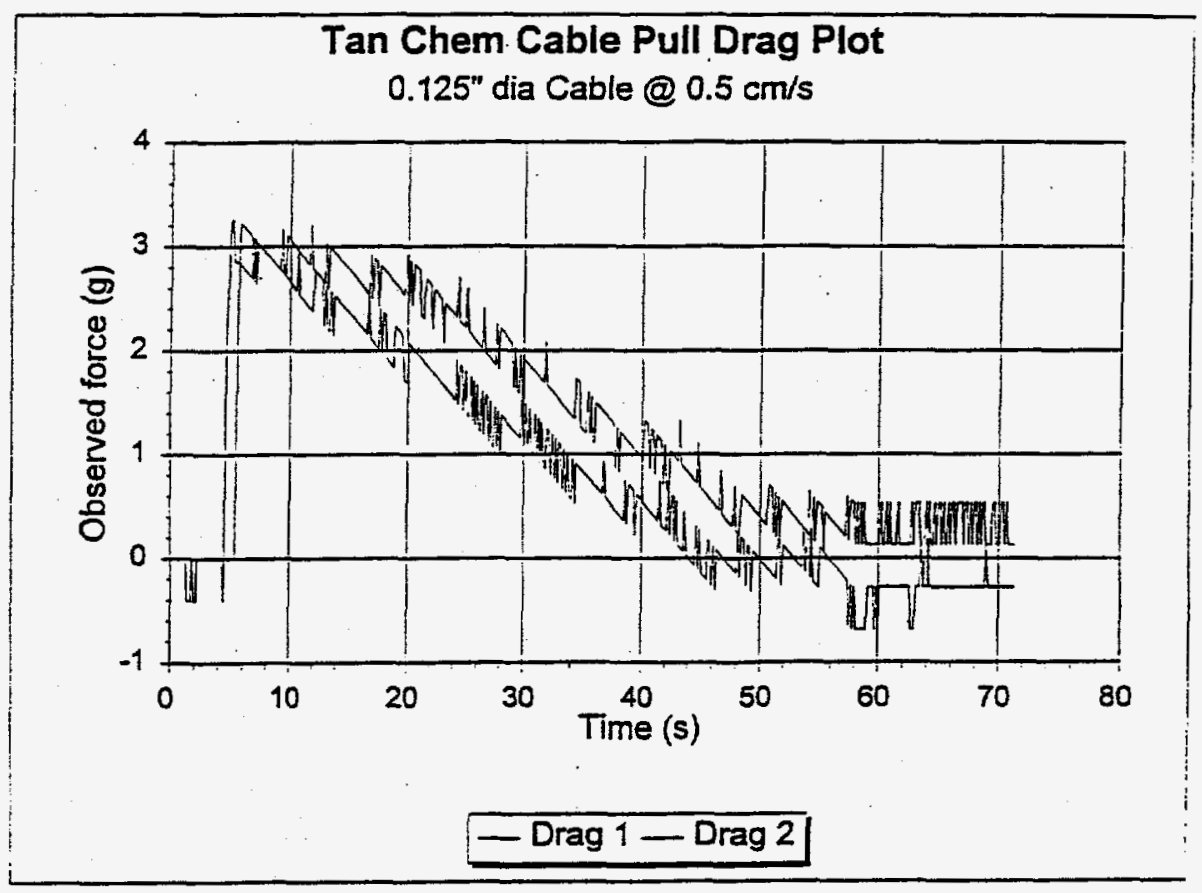

Figure A.11. Plot of the drag force on a 0.125 inch diameter cable being withdrawn from the chemical simulant at $0.5 \mathrm{~cm} / \mathrm{s}$ 


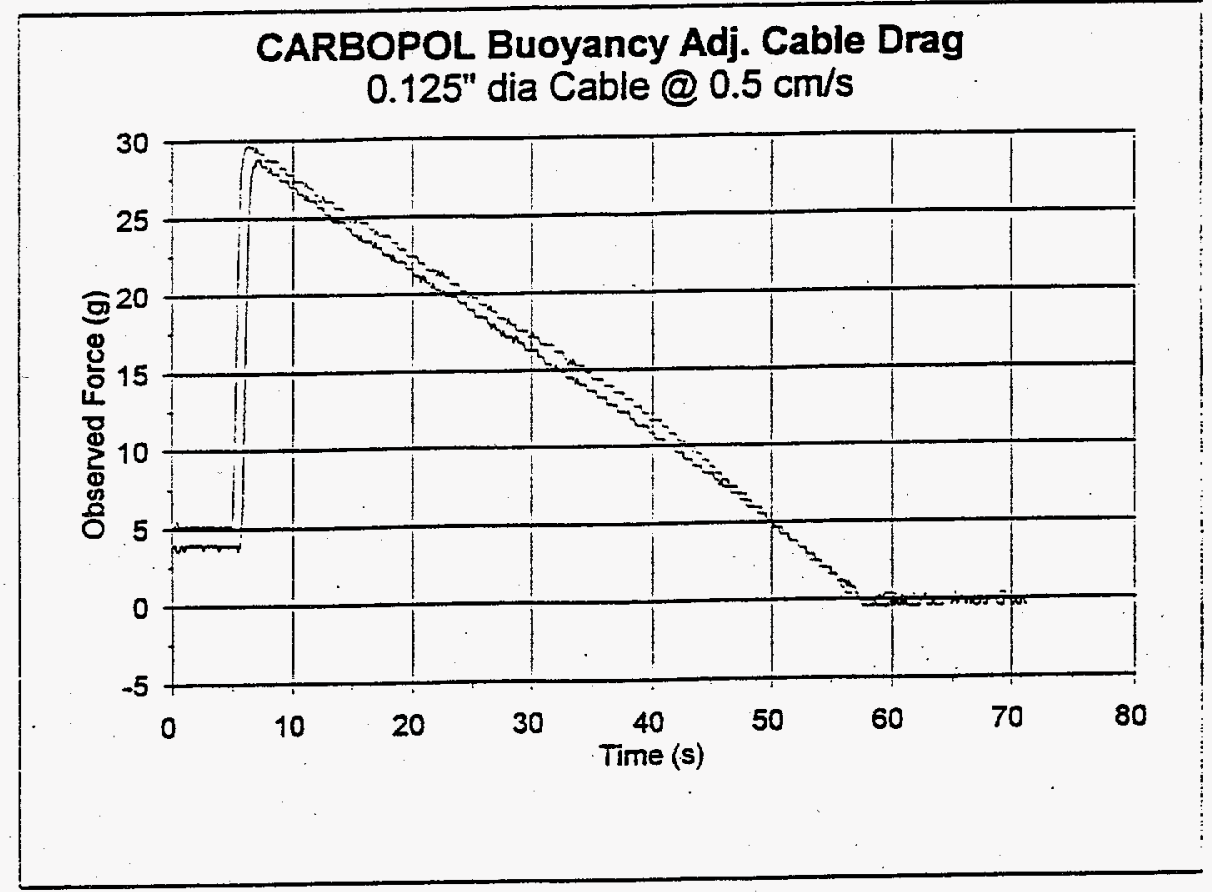

Figure A.12. Plot of the drag force on a 0.125 inch diameter cable being withdrawn from the carbopol fluid at $0.5 \mathrm{~cm} / \mathrm{s}$

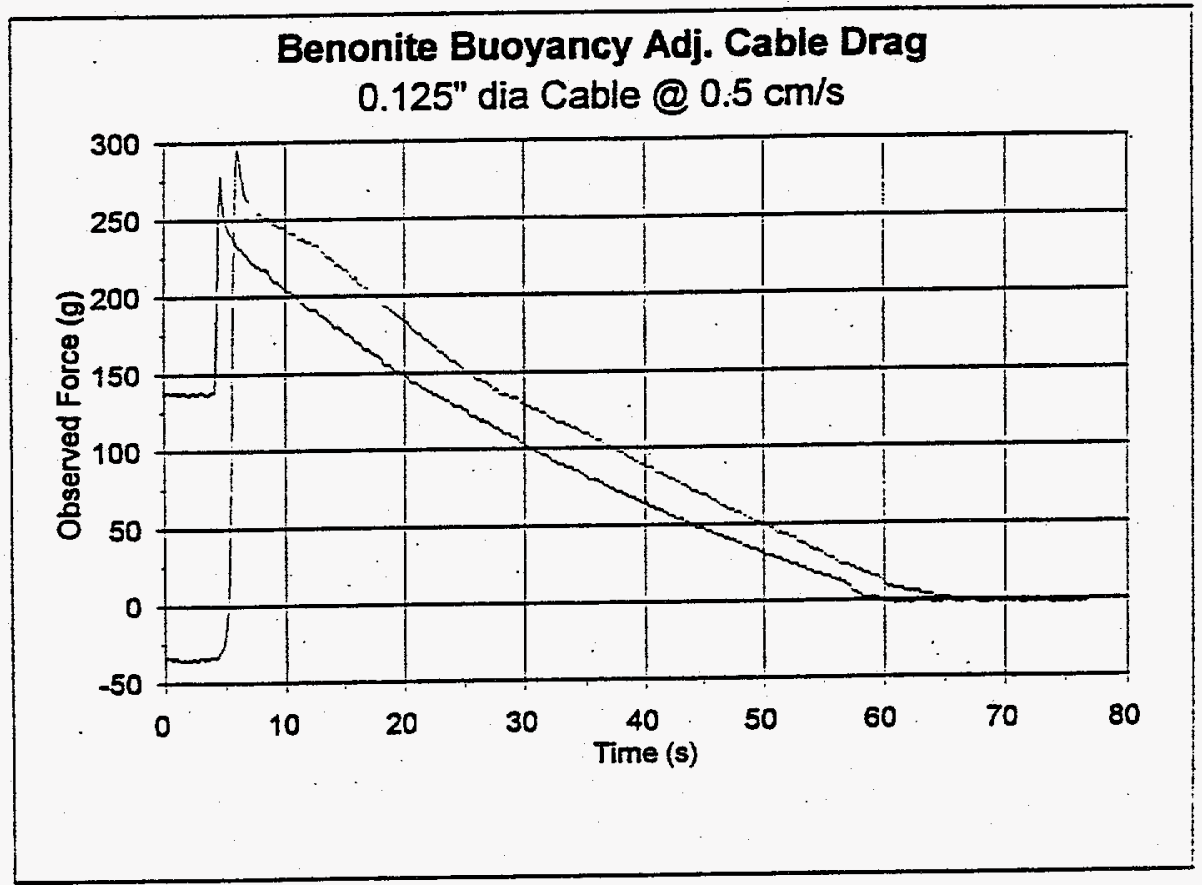

Figure A.13. Plot of the drag force on a 0.125 inch diameter cable being withdrawn from the bentonite clay at $0.5 \mathrm{~cm} / \mathrm{s}$

\section{A.13}


Table A.1. Drag Force per Unit Length on Cable

\begin{tabular}{|c|c|c|c|}
\hline \multirow[b]{2}{*}{$\begin{array}{c}\text { Cable Diameter, } \\
\text { (inches) }\end{array}$} & \multicolumn{3}{|c|}{ Cable Velocity $(\mathrm{cm} / \mathrm{sec})$} \\
\hline & 0.1 & 0.5 & 1.0 \\
\hline & \multicolumn{3}{|c|}{ Drag Force $(\mathrm{gm} / \mathrm{cm})$} \\
\hline & \multicolumn{3}{|c|}{ Chemical Simulant } \\
\hline 0.013 & 0.05 & 0.04 & 0.04 \\
\hline 0.125 & 0.09 & 0.09 & 0.10 \\
\hline 0.250 & 0.10 & 0.10 & 0.09 \\
\hline$\cdot$ & \multicolumn{3}{|c|}{ Carbopol } \\
\hline 0.013 & 0.10 & 0.11 & 0.12 \\
\hline 0.125 & 0.29 & 0.52 & 0.65 \\
\hline \multirow[t]{2}{*}{0.250} & 0.98 & 1.15 & 1.89 \\
\hline & \multicolumn{3}{|c|}{ Bentonite Clay } \\
\hline 0.013 & 0.52 & 0.52 & 0.53 \\
\hline 0.125 & 1.91 & 4.17 & 4.03 \\
\hline 0.250 & 3.27 & 5.71 & 6.18 \\
\hline
\end{tabular}

For the chemical simulant the drag force on the cable does not seem to depend on the cable diameter or the cable retrieval speed. For the carbopol and Bentonite clay, both diameter and speed are important, but there is no apparent simple correlation. A more thorough discussion of these results will be presented after we discuss results obtained for the fluid rheological parameters. In actual practice in the tank, it is important to establish the drag force on the cable from in-situ measurements.

\section{A3.3 Drag Force on Ball}

The drag force on balls of diameters $0.5-, 1.0-$, and 2.0 - inches at velocities of $0.1-, 0.5-$, and 1.0$\mathrm{cm} / \mathrm{s}$ were measured for all three fluids. Results for the 1 inch ball at $0.5 \mathrm{~cm} / \mathrm{s}$ velocity are shown in Figures A.14 through A.16. The results for all of the data are summarized in Table A.2. For all fluids the velocity dependence of the drag force is very weak. The dependence on ball size is strong, scaling roughly as the square of the diameter. Both of these factors suggest that the drag force is dominated by the yield stress of the material. It is from data such as these that the model describing 
Table A.2. Drag Forces on Ball

\begin{tabular}{|c|c|c|c|}
\hline & \multicolumn{3}{|c|}{ Ball Velocity $(\mathrm{cm} / \mathrm{sec})$} \\
\hline $\begin{array}{l}\text { Ball Diameter, } \\
\text { (inches) }\end{array}$ & 0.1 & 0.5 & 1.0 \\
\hline & \multicolumn{3}{|c|}{ Drag Force (grams) } \\
\hline & \multicolumn{3}{|c|}{ Chemical Simulant } \\
\hline 0.5 & - & - & - \\
\hline 1.0 & 1.7 & 1.8 & 2.2 \\
\hline \multirow[t]{2}{*}{2.0} & 6.4 & 6.8 & 7.6 \\
\hline & \multicolumn{3}{|c|}{ Carbopol } \\
\hline 0.5 & 4.5 & 6.0 & 6.0 \\
\hline 1.0 & 16 & 19 & 22 \\
\hline \multirow[t]{2}{*}{2.0} & 75 & 92 & 97 \\
\hline & \multicolumn{3}{|c|}{ Bentonite Clay } \\
\hline 0.5 & 44 & 48 & 50 \\
\hline 1.0 & 138 & 150 & 155 \\
\hline 2.0 & 562 & 600 & 655 \\
\hline
\end{tabular}

the behavior of the fluid must be obtained. The reduction of these data will be described below in the discussion of results obtained with the Bohlin rheometer.

\section{A3.4 Cable-Ball Interaction}

There has been some concern that operation of the ball in the retrieval mode may lead to measurement errors due to the disturbance of the waste by the cable prior to the passage of the ball through the same waste. Clearly as the cable diameter approaches the ball diameter the drag on the ball will be diminished since the fluid would no longer have significant contact with the ball. However, in the case where the cable diameter is small compared to the ball diameter, which should always be the case, the effect should be very small unless the cable somehow changes the character of the fluid through which the ball will pass. We tested this concern experimentally. If the cable causes very little change in the character of the waste in the retrieval mode, then we should observe that the drag force on the ball plus cable system should equal the drag force on the cable plus the drag force on the ball measured independently. The results for the drag force on the cable and drag force on the ball 


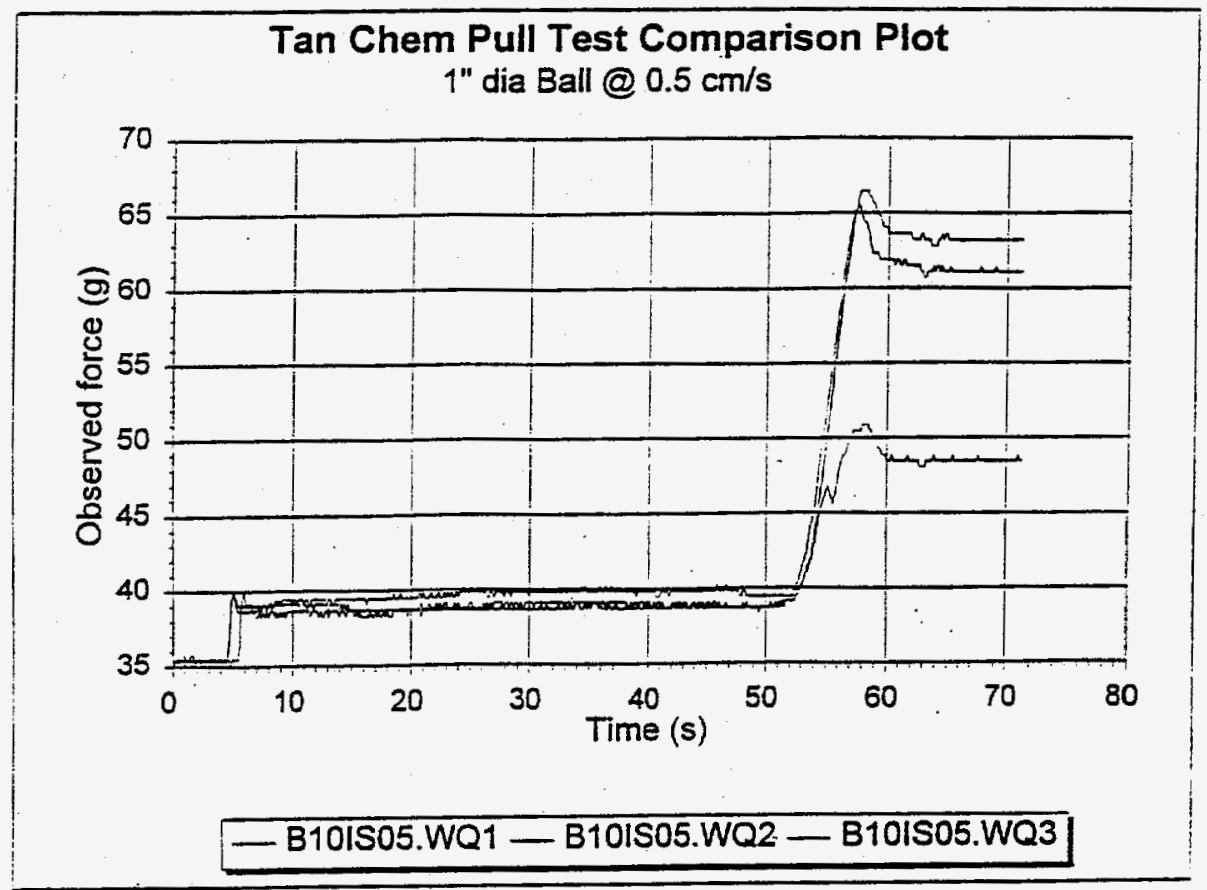

Figure A.14. Plot of the ball drag force measured with the chemical simulant with the 1 inch ball being withdrawn completely from the fluid at $0.5 \mathrm{~cm} / \mathrm{s}$

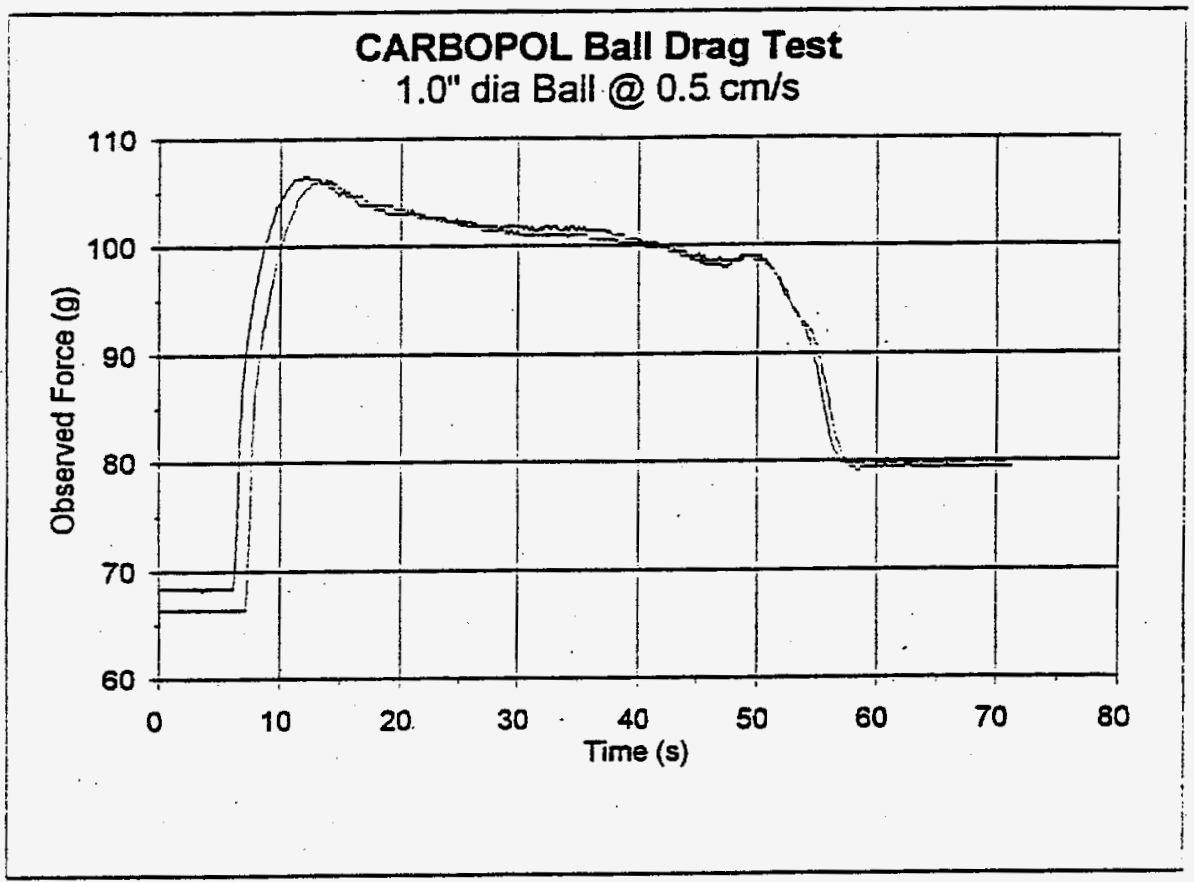

Figure A.15. Plot of the ball drag force measured with carbopol with the 1 inch ball being withdrawn completely from the fluid at $0.5 \mathrm{~cm} / \mathrm{s}$ 


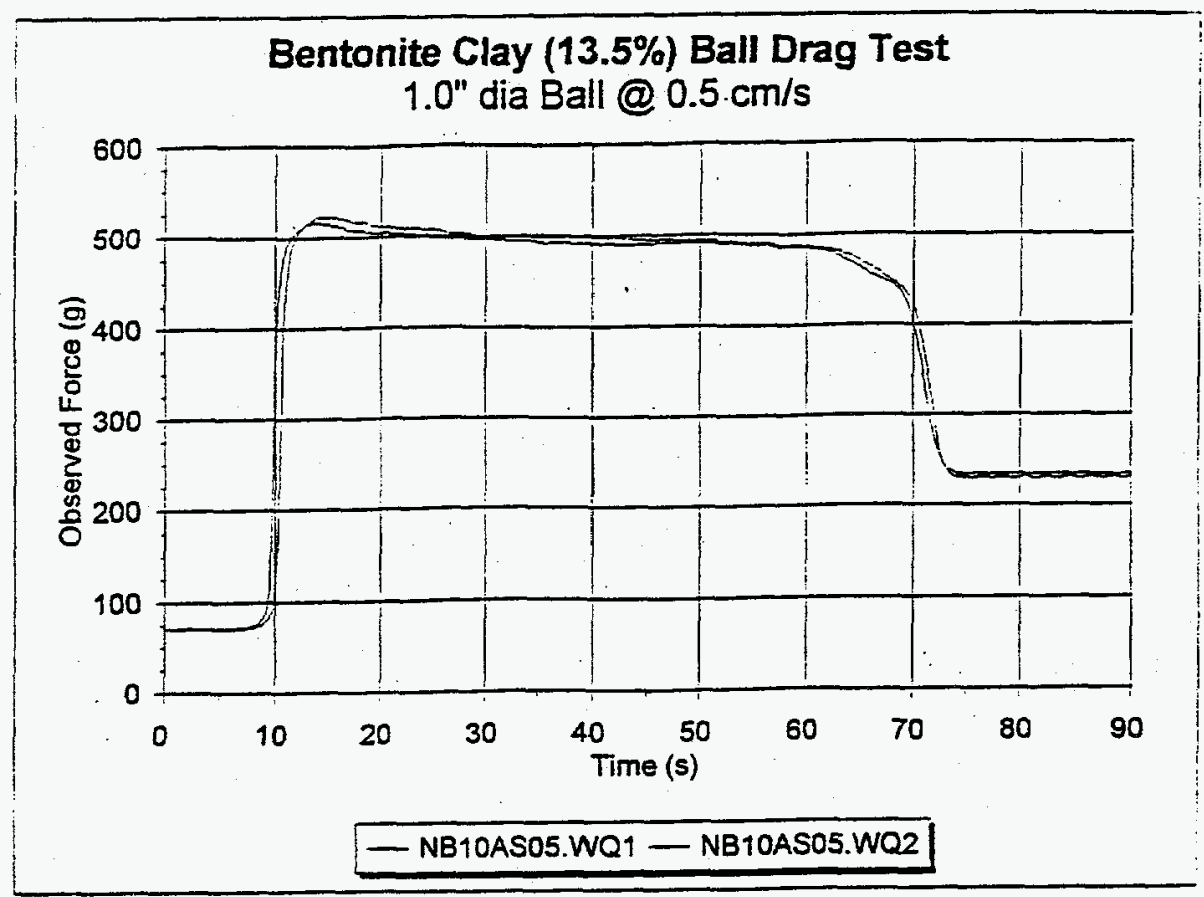

Figure A.16. Plot of the ball drag force measured with bentonite clay with the 1 inch ball being withdrawn completely from the fluid at $0.5 \mathrm{~cm} / \mathrm{s}$

have been presented above. In the measurements of the drag force on the ball, shown in Table A.2, a thin stainless steel cable was used. The drag on this wire is negligible compared to the drag on the ball and so the results shown for drag force on the ball can be taken as due to the ball only. We performed experiments where cables of diameter 0.125 and 0.250 inches were attached to 1.0 - and 2.0-inch-diameter balls, and drag force measurements were made as these systems were pulled through the fluids at constant velocities. After accounting for the drag force on the cable, the drag forces on the balls were compared to the same drag forces measured with the thin wire. Within experimental error there appears to be no differences. These results suggest that the interaction between cable and ball is negligible and can be neglected.

Results for the 1-inch ball with the 0.125-inch-diameter cable are shown in Figures A.17 through A.19 for all three fluids and a velocity of $0.5 \mathrm{~cm} / \mathrm{s}$. These plots have been corrected to account for the weight and buoyancy of the cable and the manner in which these change as the cable is being withdrawn from the fluid. The drag on the cable accounts for the apparent slope in the curves, and this drag decreases as the cable and ball are withdrawn from the fluid. The drag near the end of the pull where the cable is nearly completely withdrawn from the fluid represents the contribution of the ball to the total drag. It is this drag force which should be compared to the drag force measured when the ball was retrieved with the thin cable. The determination of drag forces from these plots is not simple, due to the fact that experimentally it is advantageous to allow for a flexible zero offset and this advantage was used to the fullest extent here. The results for all of the measurements are shown in Table A.3. In nearly all cases the drag forces listed in this table are in close agreement with the corresponding drag forces shown in Table A.2. There is no clear trend in the comparison of the data in these two tables. It is seen from Table A.3, however, that, on average, the drag force measured with the 0.250 inch cable attached to the ball is somewhat less than the corresponding drag 


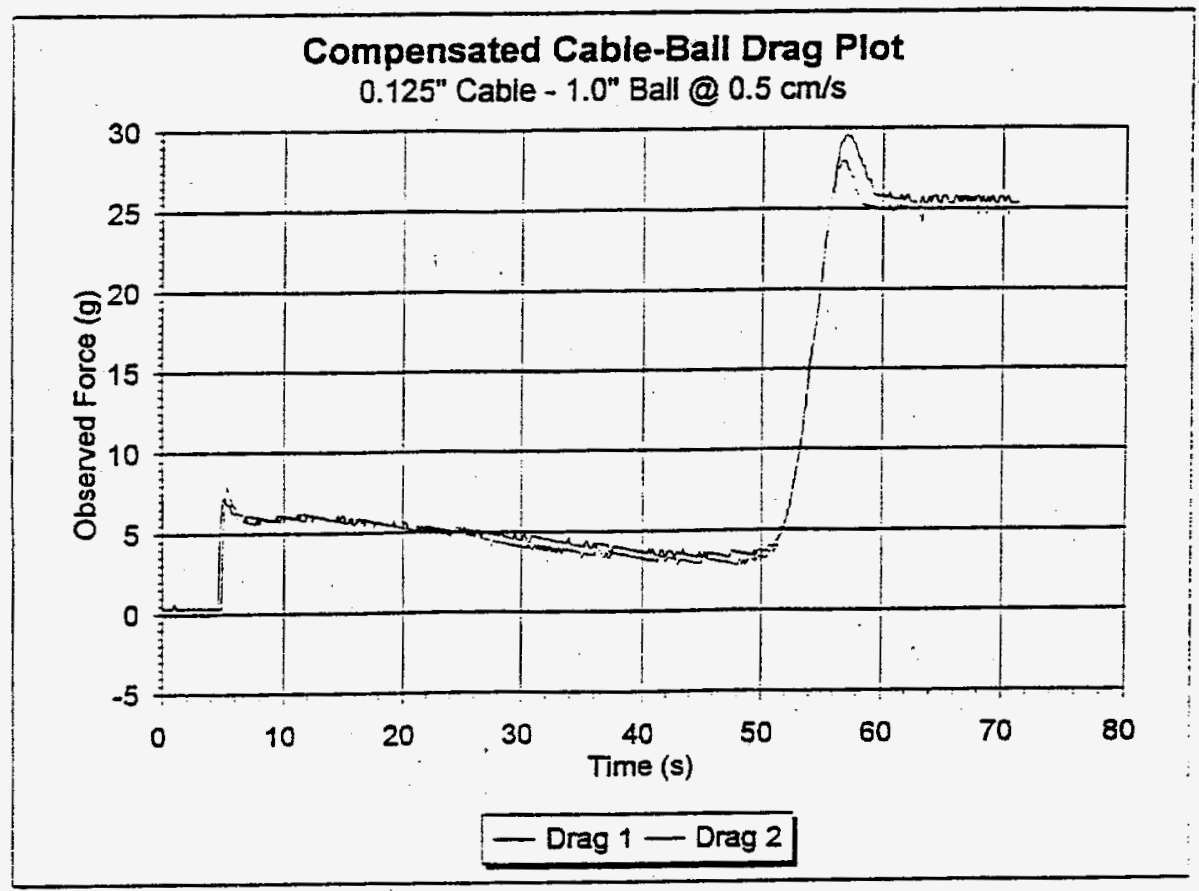

Figure A.17. Plot of the combined drag force due to 0.125 inch diameter cable and 1 inch ball being pulled through the chemical simulant at $0.5 \mathrm{~cm} / \mathrm{s}$

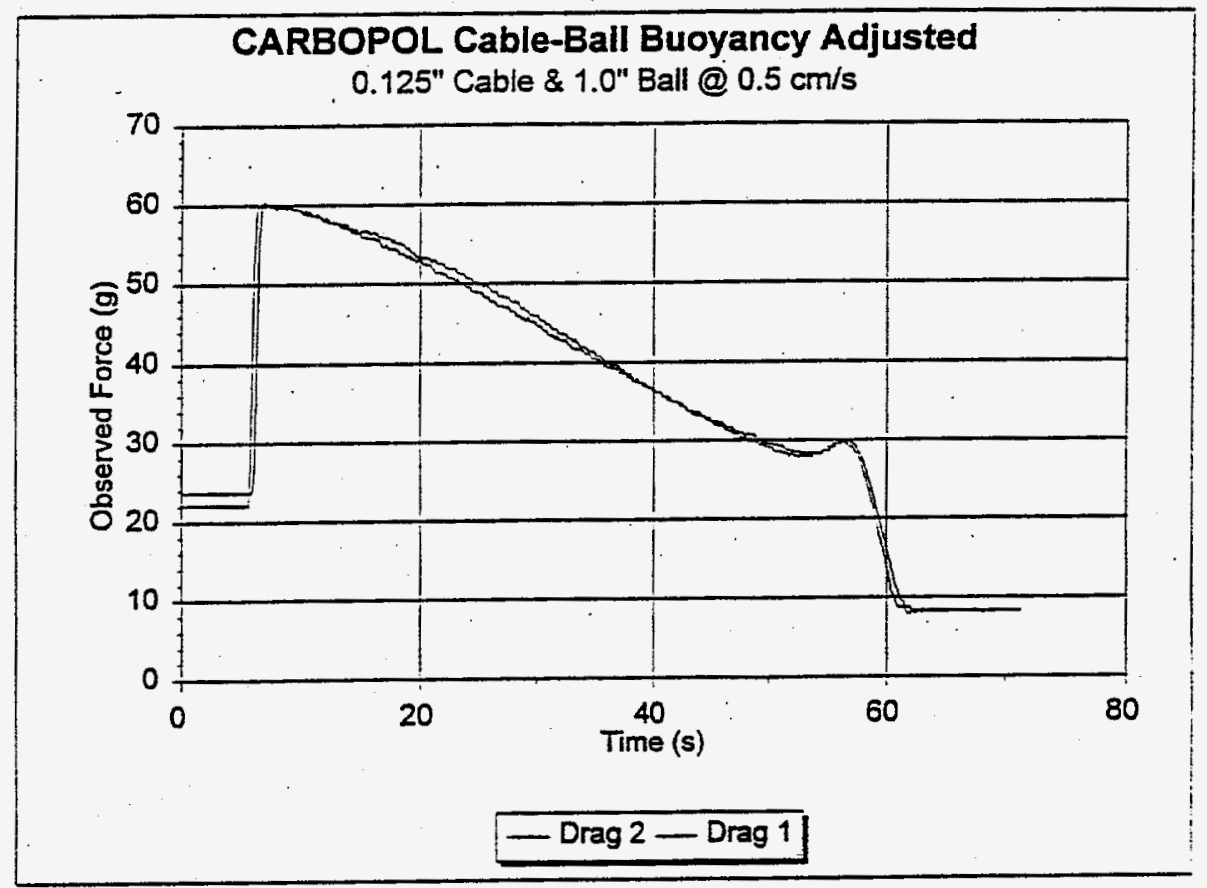

Figure A.18. Plot of the combined drag force due to 0.125 inch diameter cable and 1 inch ball being pulled through carbopol at $0.5 \mathrm{~cm} / \mathrm{s}$ 


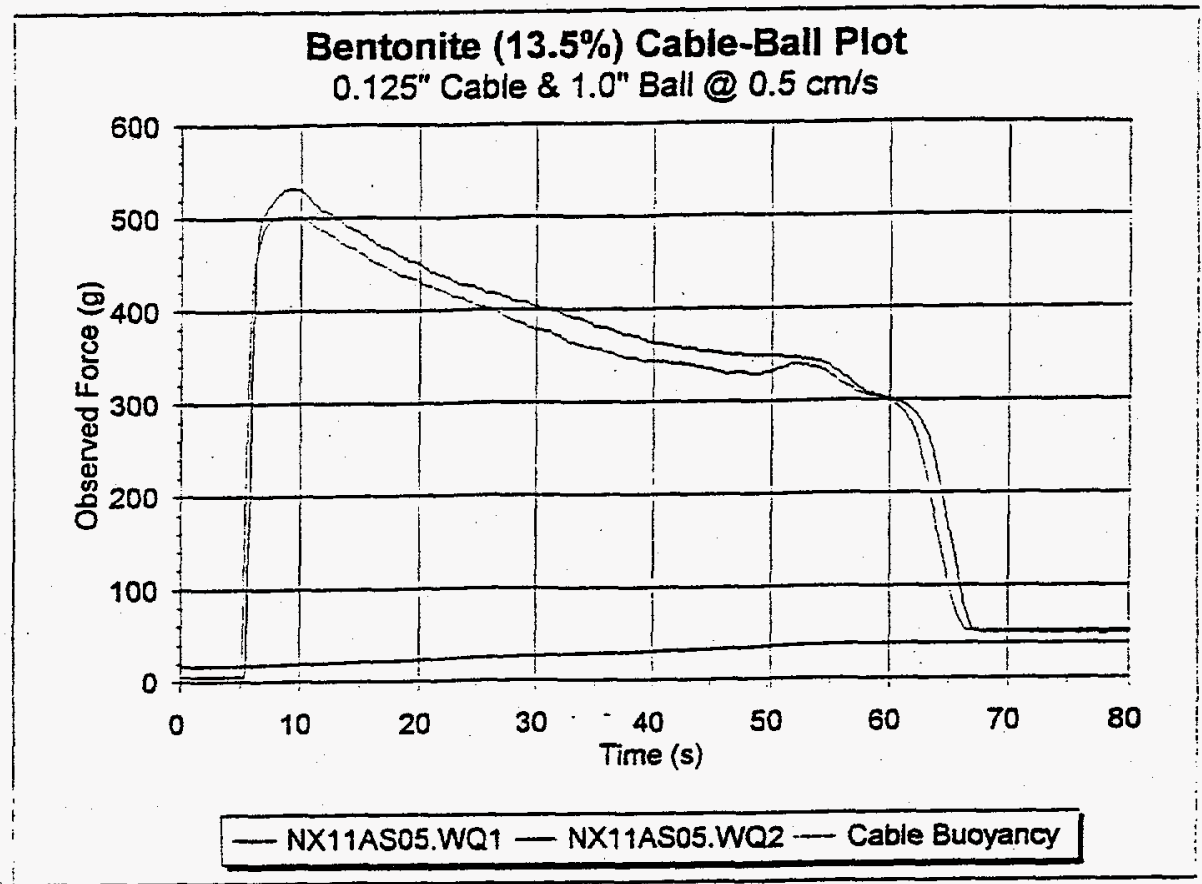

Figure A.19. Plot of the combined drag force due to 0.125 inch diameter cable and 1 inch ball being pulled through bentonite clay at $0.5 \mathrm{~cm} / \mathrm{s}$

forces measured with the 0.125 inch cable. This would lend some support to the notion that a cableball interaction exists. It is clear that the effect, if any, is rather small. The conclusion from these data is that the cable has little influence on the drag force on the ball. For the case of the actual planned in-situ ball rheometer, where the cable diameter will be 0.125 inches and the ball diameter will be 3.6 inches, any effect should be entirely negligible.

\section{A3.5 Effects of Interfaces and Distances Required for Steady-State Flow}

The drag force data can be related to expectations based on fluid flow models if the flow is a steady state flow. It requires some distance from the start of ball motion before steady state flow conditions are reached. This distance could conceivably depend on the fluid rheological properties as well as ball diameter and velocity. It is important to know these distances so that the distance over which a ball must be pulled or dropped at a constant velocity before steady state is achieved can be estimated. The planning of experiments is aided with this information. In addition, the distance required for steady state flow to develop may be useful for the estimation of fluid properties, although this possibility has yet to be explored to any degree greater than simple speculation. In actual practice, the steady state pull distance will be determined empirically. It may provide some qualitative information about the nature of the fluid which is independent of the drag force measurements. However, fluid properties must still be determined from the steady state drag force data.

The presence of interfaces in the fluid, such as an air-fluid boundary or a sludge-liquid boundary or the boundary between the bottom of the tank and the fluid can result in differences between the drag forces measured near the interfaces and those measured far away from the interfaces. We have two 
Table A.3. Drag Force on Ball with Different Cables

\begin{tabular}{|c|c|c|c|}
\hline & \multicolumn{3}{|c|}{ Ball Velocity $(\mathrm{cm} / \mathrm{sec})$} \\
\hline \multirow[t]{3}{*}{$\begin{array}{c}\text { Cable Diameter, } \\
\text { (inches) }\end{array}$} & 0.1 & 0.5 & 1.0 \\
\hline & \multicolumn{3}{|c|}{ Drag Force on Ball (grams) } \\
\hline & \multicolumn{3}{|c|}{ Chemical Simulant/Ball Diameter $=1$ inch } \\
\hline 0.125 & 1.5 & 1.5 & 2.0 \\
\hline \multirow[t]{2}{*}{0.250} & 1.4 & 1.5 & 2.1 \\
\hline & \multicolumn{3}{|c|}{ Chemical Simulant/Ball Diameter $=2$ inches } \\
\hline 0.125 & 6.0 & 6.5 & 6.0 \\
\hline \multirow[t]{2}{*}{0.250} & 6.5 & 6.5 & 6.5 \\
\hline & \multicolumn{3}{|c|}{ Carbopol/Ball Diameter $=1$ inch } \\
\hline 0.125 & 17 & 21 & 22 \\
\hline \multirow[t]{2}{*}{0.250} & 18 & 19 & 19 \\
\hline & \multicolumn{3}{|c|}{ Carbopol/Ball Diameter $=2$ inches } \\
\hline 0.125 & 80 & 87 & 100 \\
\hline \multirow[t]{2}{*}{0.250} & 76 & 84 & 101 \\
\hline & \multicolumn{3}{|c|}{ Bentonite Clay/Ball Diameter $=1$ inch } \\
\hline 0.125 & 140 & 150 & 165 \\
\hline \multirow[t]{2}{*}{0.250} & 130 & 135 & 150 \\
\hline & \multicolumn{3}{|c|}{ Bentonite Clay/Ball Diameter $=2$ inches } \\
\hline 0.126 & 600 & 625 & 625 \\
\hline 0.250 & 575 & 625 & 625 \\
\hline
\end{tabular}

natural interfaces within our experiments, the fluid container bottom and the free surface of the fluid. In the natural course of experimentation both the steady state pull distances and the effects of interfaces have been investigated. We will first consider the pull distance necessary to reach a steady state flow condition. Results obtained from plots such as are shown in the figures presented here are given in Table A.4. The pull distance to steady state is greatest for carbopol (most of the time), which has almost no yield stress and a viscosity between those of the chemical simulant and bentonite 
Table A.4. Pull Distances to Steady-State Flow

\begin{tabular}{|c|c|c|c|}
\hline & \multicolumn{3}{|c|}{ Ball Velocity $(\mathrm{cm} / \mathrm{sec})$} \\
\hline \multirow[t]{3}{*}{$\begin{array}{l}\text { Ball Diameter, } \\
\text { (inches) }\end{array}$} & 0.1 & 0.5 & 1.0 \\
\hline & \multicolumn{3}{|c|}{ Pull Distance (cm) } \\
\hline & \multicolumn{3}{|c|}{ Chemical Simulant } \\
\hline 1.0 & 0.5 & 0.5 & 1.5 \\
\hline \multirow[t]{2}{*}{2.0} & 0.5 & 0.5 & 1.5 \\
\hline & \multicolumn{3}{|c|}{ Carbopol } \\
\hline 1.0 & 4.0 & 5.0 & 5.0 \\
\hline \multirow[t]{2}{*}{2.0} & 7.0 & 7.0 & 7.0 \\
\hline & \multicolumn{3}{|c|}{ Bentonite Clay } \\
\hline 1.0 & 2.0 & 7.0 & 10.0 \\
\hline 2.0 & 4.0 & 4.0 & 5.0 \\
\hline
\end{tabular}

clay. The pull distance is least for the chemical simulant, which has the lowest viscosity. Except for one case with the bentonite clay, the pull distance does not depend strongly on velocity. Most of the data suggest that it scales with ball size, but not linearly. Examination of the results in Table A.4 show no correlation with the fluid Bingham numbers or the Reynolds numbers.

The distance at which interfaces begin to affect the drag forces was also obtained from data plots. The results are shown in Table A.5. This distance does not seem to depend on ball velocity. Both the carbopol and the chemical simulant give similar results and the results are similar for both ball sizes. The distance is largest for the Bentonite clay, for which case ball size seems to be important. Bentonite clay has a much larger yield stress than either the chemical simulant or the carbopol, and it would seem that yield stress may be the important factor in determining how close the ball can approach an interface before the drag force is affected. Again however, we have found no correlation with either the fluid Bingham numbers or the Reynolds numbers.

\section{A3.6 Fluid Rheograms}

Samples were obtained for each fluid and rheograms were obtained with a laboratory Bohlin VOR rheometer. Results of such testing are shown in a separate report by Jon Phillips. Rheograms for the three fluids are shown in Figures A.20 through A.22. We will glean some of these results and 
Table A.5. Interface-Effects Distance

\begin{tabular}{|c|c|c|c|}
\hline & \multicolumn{3}{|c|}{ Ball Velocity $(\mathrm{cm} / \mathrm{sec})$} \\
\hline \multirow[t]{3}{*}{$\begin{array}{c}\text { Ball Diameter, } \\
\text { (inches) }\end{array}$} & 0.1 & 0.5 & 1.0 \\
\hline & \multicolumn{3}{|c|}{ Interface-Effect Distance (cm) } \\
\hline & \multicolumn{3}{|c|}{ Chemical Simulant } \\
\hline 1.0 & 2.0 & 2.0 & 2.0 \\
\hline \multirow[t]{2}{*}{2.0} & 2.0 & 2.0 & 2.0 \\
\hline & \multicolumn{3}{|c|}{ Carbopol } \\
\hline 1.0 & 2.0 & 2.0 & 2.0 \\
\hline \multirow[t]{2}{*}{2.0} & 2.0 & 2.0 & 3.0 \\
\hline & \multicolumn{3}{|c|}{ Bentonite Clay } \\
\hline 1.0 & 3.0 & 3.0 & 3.0 \\
\hline 2.0 & 7.0 & 8.0 & 8.0 \\
\hline
\end{tabular}

compare them to the results determined from the ball rheometer as given in Table A.2.

The data in Table A.2 show that the drag force on the ball scales roughly as the square of the ball diameter and is a weak function of the ball velocity. These observations suggest that a Bingham or generalized Bingham fluid model may be useful in describing the fluids. A simple form for the equation relating drag force on the ball to viscosity and yield stress for a Bingham fluid is given by Bhavaraju et al. (1978) as

$$
F_{d}=3 \pi \mu_{o} d V\left(1+1.6 \frac{\tau_{0} d}{\mu_{o} v}\right)
$$

where,

$$
\begin{aligned}
F_{d} & =\text { drag force on ball } \\
\mu_{\mathrm{o}} & =\text { zero shear rate viscosity } \\
\mathrm{d} & =\text { ball diameter } \\
\mathrm{V} & =\text { ball velocity } \\
\tau_{\mathrm{o}} & =\text { yield stress }
\end{aligned}
$$


Viscometry of $0.2 \%$ (wt) Carbopol 980

(040794.8\&9.visc.data)

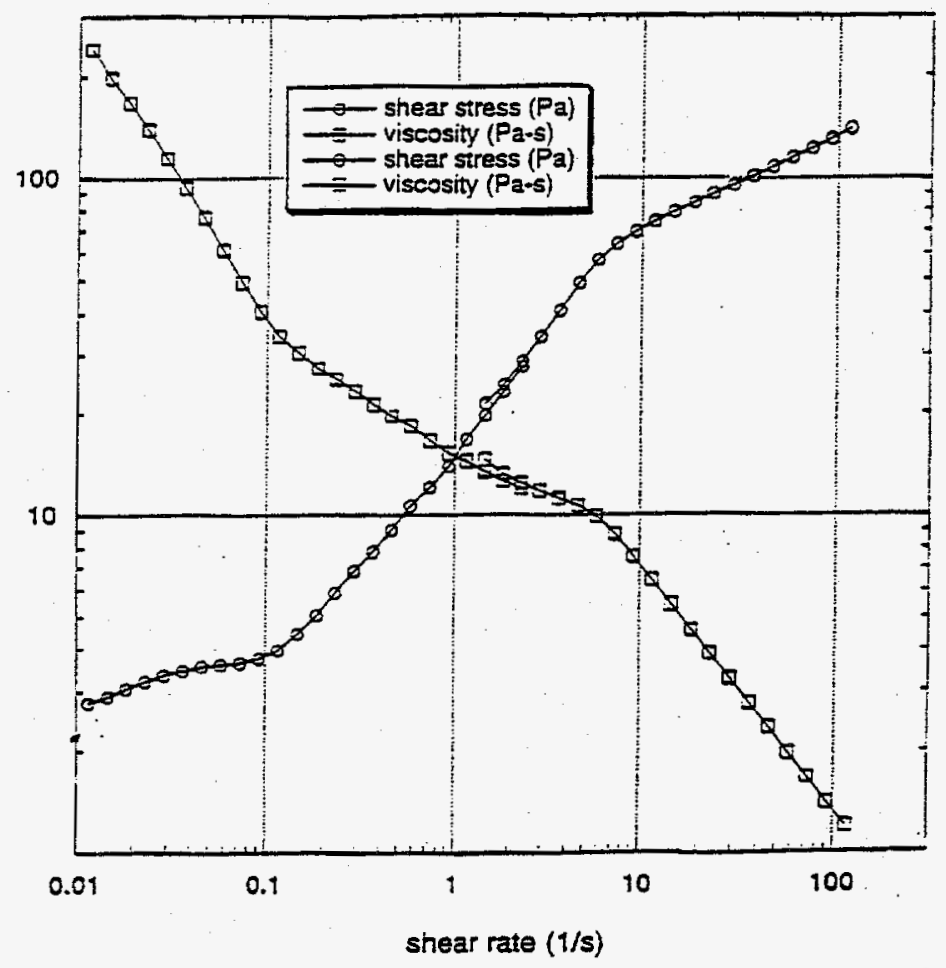

Figure A.20. Rheogram for carbopol as measured with the Bohlin rheometer

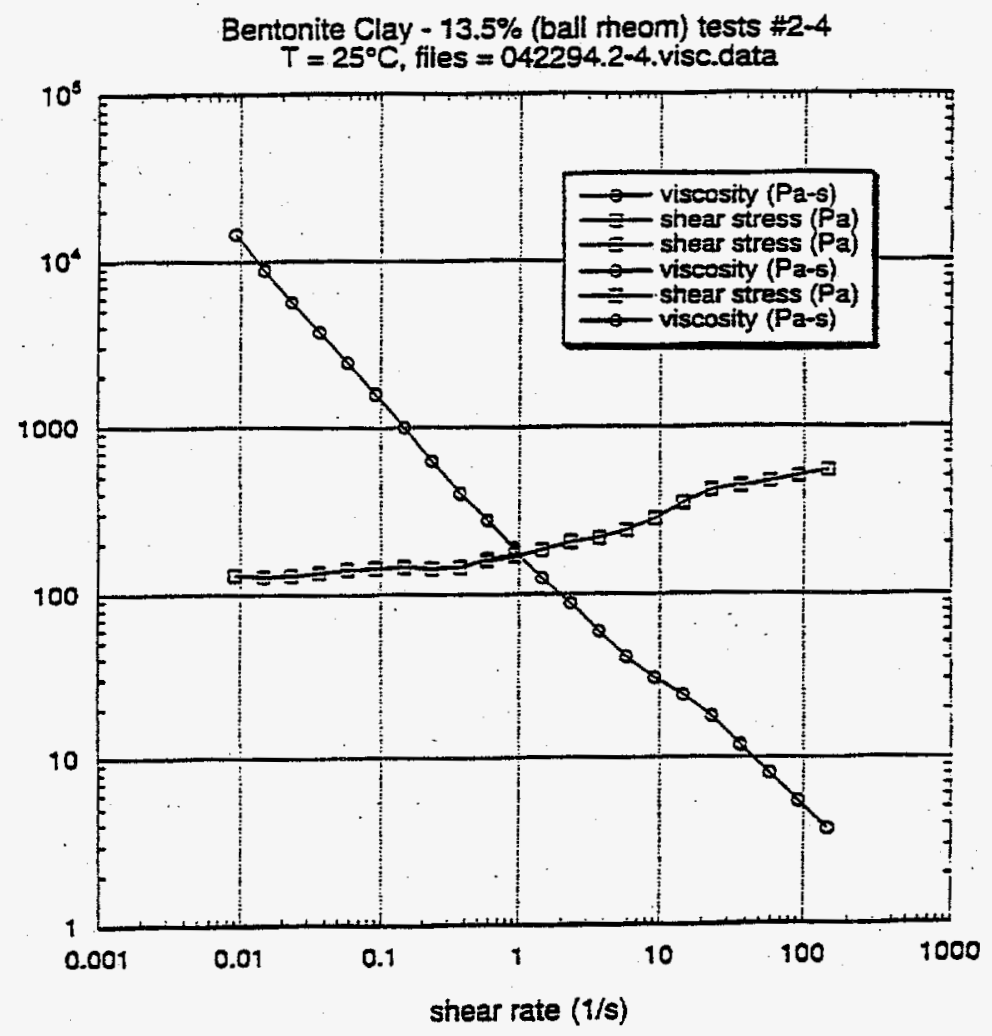

Figure A.21. Rheogram for bentonite clay as measured with the Bohlin rheometer 


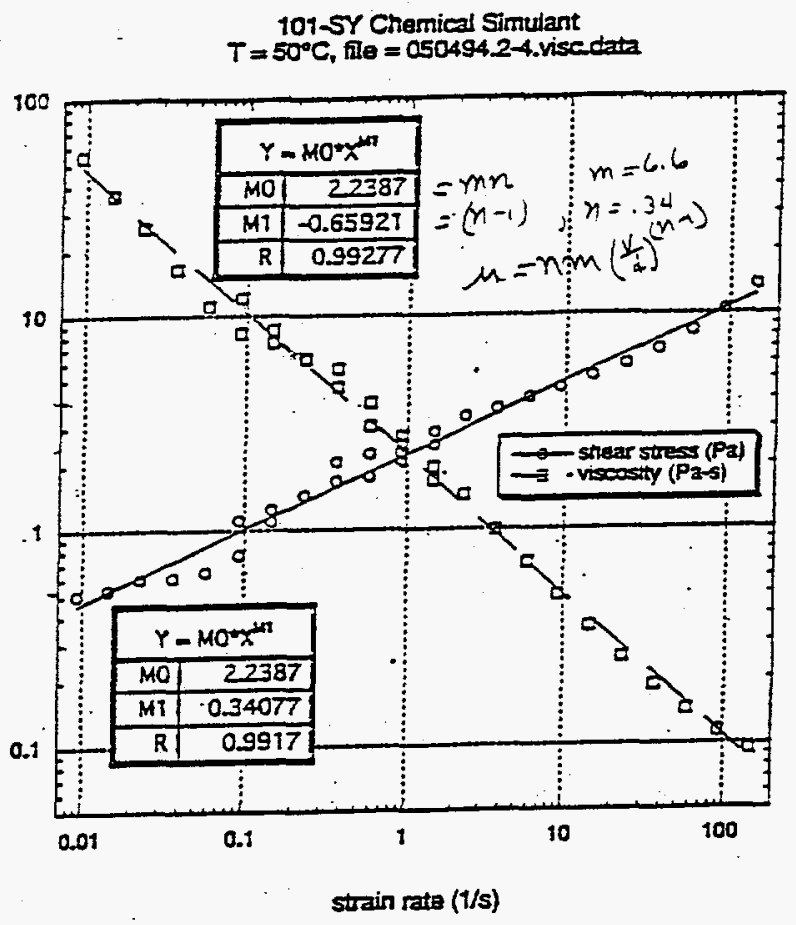

Figure A.22. Rheogram for chemical simulant as measured with the Bohlin rheometer

Simplifying Eq. (A.13) we find that it contains a term which depends on viscosity and velocity (the usual Stokes term) and another which depends on the yield stress and the square of the ball diameter.

$$
F_{d}=3 \pi \mu_{o} d V+4.8 \pi \tau_{o} d^{2}
$$

If we assume the applicability of this description of the fluid we can reduce the data contained in Table A.2 and determine values for the yield stress and the viscosity. These values can be compared to results obtained with the laboratory viscometer. The comparison is shown in Table A.6, where ranges of measured values are reported. Results with the Bohlin rheometer show that in all cases the viscosity is shear rate dependent. The shear rates obtained in the ball rheometer studies (ball speed/ball diameter) range from less than $0.1 / \mathrm{s}$ to less than $1 / \mathrm{s}$, and in order to facilitate comparison, we chose the region of the flow curves between shear rates of $0.1 / \mathrm{s}$ and $1.0 / \mathrm{s}$ in order to obtain results from the Bohlin rheometer. The table shows that for the chemical simulant and the bentonite clay, both instruments provide comparable numbers for the yield stress but the viscosities determined with the ball rheometer are generally somewhat lower than those found with the Bohlin rheometer. In the case of carbopol, the yield stress given by the ball rheometer is much greater than the actual yield stress as measured with the Bohlin rheometer. Carbopol is known to be undescribable in terms of a simple Bingham fluid, and the disagreement here is not surprising. The disagreement in measured viscosities may be due to failure to include a power law term in the reduction of the ball rheometer data. The data obtained with the Bohlin rheometer indicate that the fluids are describable in terms of a power law model. Continued research at our laboratory has shown that both the bentonite clay and the chemical simulant can be described with a generalized Bingham fluid model. The carbopol cannot be so described. This study has yet to be completed, however all indications are that reduction of the actual in-situ data obtained from the tank should begin using a generalized Bingham fluid model. 
Table A.6. Comparison of Experimental Results Obtained with Ball Rheometer and Laboratory Rheometer for Three Simulants

\begin{tabular}{|c|c|c|}
\hline & \multicolumn{2}{|c|}{ Ball Velocity $(\mathrm{cm} / \mathrm{sec})$} \\
\hline & $\begin{array}{c}\text { Yield Stress } \\
\text { (Pascals) }\end{array}$ & $\begin{array}{c}\text { Viscosity } \\
\text { (Pascal-sec) }\end{array}$ \\
\hline & \multicolumn{2}{|c|}{ Chemical Simulant } \\
\hline Ball rheometer & $1.5-1.6$ & $2.2-2.8$ \\
\hline \multirow[t]{2}{*}{ Bohlin rheometer } & $<1.0$ & $2-10$ \\
\hline & \multicolumn{2}{|c|}{ Bentonite Clay } \\
\hline Ball rheometer & $135-170$ & $60-200$ \\
\hline \multirow[t]{2}{*}{ Bohlin rheometer } & 130 & $200-1000$ \\
\hline & \multicolumn{2}{|c|}{ Carbopol } \\
\hline Ball rheometer & $15-19$ & $11-19$ \\
\hline Bohlin rheometer & $\sim 2.0$ & $20-30$ \\
\hline
\end{tabular}

\section{A4.0 References}

Bhavaraju, S. M., R. A. Mashelkar, and H. W. Blanch. 1978. "Bubble Motion and Mass Transfer in Non-Newtonian Fluids," AICHe Journal 24 (6), 1063.

Pasamehmetoglu, K. O., C. Unal, and J. Edwards. December 1993. The Evaluation of Methods for Rheology Measurements of the Waste Contained in Hanford Tank 241-SY-101. Los Alamos National Laboratory Report LA-UR-93-4300.

Shepard, C. L. 1994. Report on Data Requirements and Hardware Selection for In-Situ Ball Rheometer, PNL-10171. Pacific Northwest Laboratory, Richland, Washington.

Shepard, C. L., J. B. Colson, K. O. Pasamehmetoglu, C. Unal, J. H. Edwards, and J. Abbott. 1994. Theory of Operation for The Ball Rheometer, PNL-10240. Pacific Northwest Laboratory, Richland, Washington. 


\section{Appendix B}

Experiments Performed at Los Alamos National Laboratory 


\section{Figures}

B.1. Picture of Laboratory-Scale Falling-Ball Apparatus $\ldots \ldots \ldots \ldots \ldots \ldots \ldots$

B.2. Comparison of the Numerical Results with the Theoretical Predictions . . . . . . . . B.16

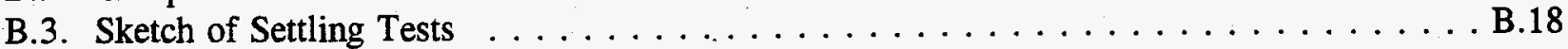

B.4. Settling Behavior of Aged and Fresh Simulants . . . . . . . . . . . . . . B.19

B.5. Balls of the Same Density and Size Give Good Reproducibility . . . . . . . . . . . . B.20

B.6. Reproducibility in Settled Experiments for AS3 . . . . . . . . . . . . . . B.22

B.7. Settling Data Reduced Assuming Power-Law Behavior and Resulting Wall-Effects Gives Power-Law Behavior . . . . . . . . . . . . . . . . . . B.25

B.8. Rheogram for AS1 at Various Temperatures . . . . . . . . . . . . . B.26

B.9. Low Shear Behavior of AS1 Shows that the Yield Stress is Less than 10 dynes $/ \mathrm{cm}^{2}$ or 1

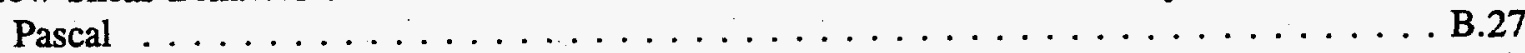

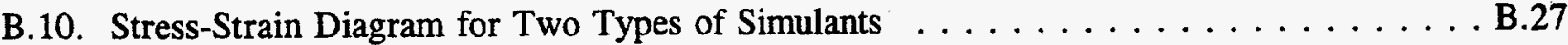

B.11. Effect of Short-Term History on the Settling Rate . . . . . . . . . . . . . . . . . . B.29

B.12. Velocity of First Ball Dropped to Second Ball Dropped After Suspension has Settled for Several Hours $\ldots \ldots \ldots \ldots \ldots \ldots \ldots \ldots \ldots \ldots \ldots$

B.13. Viscosity of Hanford Waste Sludge at the Temperatures Indicated . . . . . . . . . B.32

B.14. Comparing Falling-Ball Viscosities with Couette Viscosities . . . . . . . . . . . . B.32 


\section{Tables}

B.1. Components Used in Agnew's Simulant $\ldots \ldots \ldots \ldots \ldots \ldots \ldots$

B.2. Components Used in the Fresh Simulant $\ldots \ldots \ldots \ldots \ldots \ldots \ldots \ldots$

B.3. Properties of Agnew's Simulant $\ldots \ldots \ldots \ldots \ldots \ldots \ldots \ldots$

B.4. Dimensions for Theoretical and Numerical Calculations $\ldots \ldots \ldots \ldots \ldots \ldots \ldots$

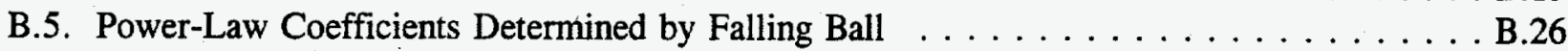

B.6. Measured Viscosity of Aged Simulant Using Couette Viscometer . . . . . . . . . . . B.31

B.7. Power-Law Parameters of Aged Simulant Obtained from Couette Viscometer . . . . . . . . B.31 


\title{
Rheological Characterization of Nuclear Waste Using Falling-Ball Rheometry
}

\author{
James Abbott, Cetin Unal, Kemal Pasamehmetoglu, and Alan L. Graham \\ Los Alamos National Laboratory
}

\section{B1.0 Introduction}

Success of many of the mitigation/remediation and retrieval schemes proposed for the Hanford Site high-level radioactive waste tanks requires the knowledge of the rheological properties of the material contained within these tanks. The mitigation of tank 101-SY received most of the attention since it is known to release flammable and toxic gases periodically. Over time, core samples have been taken from various regions of the tank to characterize the rheological and chemical properties of the waste. ${ }^{1}$

The waste consists of a saturated salt solution containing solid salt crystals. Because of the various crystal types, the waste can be thought of as a suspension with various sizes and shapes of suspended particles. The settling time for the particles is slow.

Prior to mixer pump operation, the waste in Tank 101-SY exhibited four distinct layers: 1) crust, 2) convective (C) layer, 3) nonconvective (NC) layer, and 4) sludge at the bottom. The waste shows strong time dependency. This is believed to be caused by the continuous evolution of salt crystal structures and generation of gas. The salt crystalline structures trap gas generated by the waste in the lower, settled (NC) layer. This occurs until the NC layer has accumulated enough gas so that its average density is less than the $C$ layer above it. The buoyancy of the less-dense NC layer eventually causes it to rise through the $C$ layer in an event called a "rollover." The rollover shears the NC layer, releasing the trapped gases. Also, as the NC layer with trapped gas rises, the change in pressure head ( 5 to $10 \mathrm{~m}$ ) can cause expansion of the volume of waste in the tank before the gas is released. Understanding the rheological behavior of both layers will aid in understanding rollovers and in implementing mitigation, remediation, and retrieval of the waste.

Core samples (windows $\mathrm{C}$ and $\mathrm{E}$ ) have been taken from various regions of the tank to characterize the chemical and rheological properties of the waste (see Footnote 1). However, the properties of these samples were not the same in either the $\mathrm{C}$ or NC layers. For example, there was a considerable difference in the $C$ layer viscosity for windows $C$ and $E$ samples. Viscosity measurements for the NC layer showed scatter over one to two orders or magnitude. NC layer data also indicated that over a certain range of temperatures and strain rates, viscosity increases with increasing temperature.

Attempts have been made to obtain rheological properties of $\mathrm{C}$ and NC layers using a cone and plate viscometer (Footnote 1 ). The results lacked reproducibility, probably because the clearance of the

\footnotetext{
'Tingey, J. M. 1992. "Rheological Properties of Waste from Tank 101-SY," Pacific Northwest Laboratory draft report (May).
} 
cone-and-plate viscometer were on the same order as the crystalline sizes existing in the waste (the crystalline particles in the waste slurry are believed to be 1 to $100 \mu \mathrm{m}$ in size).

The waste, consisting mostly of seven different salts in water, were used to create a simulant that is chemically similar to the waste. The resulting simulant is used to test different viscometry methods. By comparing the results of viscosity measurements made by different methods, a suitable method can be identified for in-situ measurements of the waste in the tank.

An additional study performed at Los Alamos National Laboratory ${ }^{2}$ demonstrated that the cone-andplate viscometer yields reasonably reproducible results for Newtonian fluids and for non-Newtonian fluids with very fine particles. However, the reproducibility of the cone and plate data using a waste simulant had an unacceptable amount of scatter.

Spindles also were used to measure the viscous behavior of the waste simulant. Although spindles gave repeatable results, the measured quality was in question because of the concern associated with particle migration and wall slip in the shear flow fields.

Suspension viscosity in concentrated systems has been measured by using falling-ball rheometry (Mondy et al. 1986). Pasamehmetoglu (Footnote 2) performed additional tests using falling ball rheometry. These preliminary tests showed shear thinning behavior. However, the measured values were similar to those obtained using the spindle method. To see if falling-ball rheometry was a better technique than spindle tests, more accurate falling-ball experiments were necessary.

In most techniques, the bulk of the fluid is continuous sheared (cone and plate, spindle) or is shear at high rates for short amounts of time (capillary). However, the settling ball in a falling-ball experiment continuously encounters undisturbed fluid as it falls, and the bulk amount of the fluid is sheared very little, if at all. This minimizes suspend particle interactions, which can cause particle migration (Abbott et al. 1991b).

Because the waste exhibits a very complex time-dependent fluid behavior, the applicability of fallingball rheometry was determined. The most important issue is whether the well-mixed waste can be treated as a homogenous media. If the waste behaves as a homogenous fluid, the apparent viscous behavior of the simulant can be determined using various sizes and densities of falling balls.

This study tests the reproducibility of falling-ball tests in the various waste simulants. The settling velocities are to be analyzed, assuming various shear-rate-dependent viscosities, until the assumed behavior matches the observed behavior. Two chemically similar simulants will be used to determine the characteristics of the mixed waste. The major difference between the two simulants is when they were created. Therefore, the differences will highlight any differences caused by aging.

The results of this study will be used to design an in-situ viscometer and determine a procedure for determining the viscosity from in-situ tests. A brief summary of state-of-the-art falling-ball rheometry will be given as it applies to concentrated suspensions. Also, some of the issues regarding our

\footnotetext{
${ }^{2}$ Pasamehmetoglu, K., Unal, C., and Edwards, J. N. 1993. "Evaluation Methods for Rheology of the Waste Contained in Hanford Tank 241-SY-101, "Los Alamos National Laboratory draft report (October).
} 
current experiments will be discussed. We will present the results and conclusions following the description of the simulant used in these experiments.

\section{B2.0 Falling-Ball Rheometry}

Determining the viscosity of liquid from the terminal settling velocity of a ball is a well-known technique and has been the subject of numerous experimental, numerical, and theoretical papers. The solution of the equation of motion for a ball falling in an unbounded Newtonian fluid at a low Reynolds number ( $\operatorname{Re}<0.1$, also known as creeping flow) is known as Stokes's law:

$$
u_{0}=\frac{d^{2}\left(\rho_{b}-\rho_{f}\right) g}{18 \mu}
$$

where $\mu_{0}$ is the terminal velocity, $\mathrm{d}$ is the sphere diameter, $\rho_{\mathrm{b}}$ is the sphere density, $\mathrm{g}$ is the gravitational acceleration, and $\rho_{\mathrm{f}}$ and $\mu$ are the density and viscosity, respectively, of the Newtonian fluid.

This equation is obtained by balancing the drag force on the sphere with its buoyancy force. Beyond a Reynolds number of 0.1 , corrections for inertia are needed. Also, in many problems, wall effect corrections are needed. For Newtonian and many non-Newtonian fluids, these corrections are known. However, for materials exhibiting a significant yield stress or in large containers, wall effects can be insignificant.

Falling-ball rheometry recently has been used for dilute and concentrated suspensions by several researchers (Mondy et al. 1986, Powell and Walla 1991, Abbott 1993, Abbott et al. 1991b, Milliken et al. 1989a, Milliken et al. 1989b, and Mondy et al. 1990). Although suspensions are not always represented as Newtonian continua, they may be partially characterized by an apparent viscosity if the suspended particles only interact hydrodynamically. However, this assumes that a reproducible settling velocity can be determined. This definition originates from Einstein's (1906 and 1911) works, which concentrated on neutrally buoyant suspensions subjected to elongation. Subsequently, Burgers (1939) obtained an identical result for simple shear flow between parallel plates.

Suspensions differ from homogeneous fluids with the turbulence dissipation and migration of suspended particles caused by hydrodynamic interactions. The differences between suspensions and homogeneous fluids under turbulence are believed to be caused by the interaction between the particle size and the size of turbulent eddies.

As shown by the above-mentioned studies, suspensions exhibit Newtonian flow behavior at low Reynolds numbers. When we deal with higher Reynolds numbers, the inertial and turbulence effects must be considered. Suspensions are known to behave differently under turbulence, and any continuum model must reflect these differences. It is not clear whether all of these differences have been accounted for; direct numerical simulations of turbulence with particles have been able to reproduce only the results of modest amounts of turbulence owing to limitations on memory and time requirements necessary to solve these problems. 
Particle migration occurs when initially well-mixed suspensions are subjected to inhomogeneous shear flows (Abbott et al. 1991b). The suspended particles migrate from the regions of high shear rate to regions of low shear rate. This migration can occur over relatively short shearing lengths and results in the development of large concentration gradients.

The above test assume that the suspension could be modeled as a homogenous Newtonian fluid. From previous tests, the actual waste has appears to have a yield stress and shear-thinning behavior. Therefore, models assuming Bingham and/or shear-thinning behavior will be tested while reducing the data. Again, homogenous fluid models may not be applicable to two-phase suspension media.

For the settled simulant, the $\mathrm{C}$ and NC layers will be analyzed separately. The $\mathrm{C}$ layer will be treated as a Newtonian fluid. Because of its low viscosity, capillary viscometers will be used to determine the viscosity. The settled layer will be treated like the well-mixed waste.

Preliminary experiments suggest that the NC layer, while exhibiting yield stress characteristics, may not be adequately modeled as a Bingham plastic. A Bingham plastic recovers its prestressed material properties instantaneously upon removal of external stress. This model works when the recovery time scale is short compared to the time scale of the motion. Preliminary experiments suggest that this time range may be from several minutes to as long as several days for the simulant. Thus, a history-dependent Bingham plastic model may be necessary.

If the waste behaves as a time-dependent Bingham plastic, we have two options for reducing the data. First, we can operate at the Stokes regime and use the drag coefficient correlation of Beris et al. (1985), which is obtained analytically for creeping flow around spheres for Bingham fluid. This requires small-ball velocities (on the order of $\mathrm{mm} / \mathrm{s}$ ). The experimental average shear rate will be low for low-ball velocities. However, once we get the yield stress and Bingham plastic viscosity from two experimental data points, the extrapolation to evaluate the viscosity at higher shear rates is possible because we have already expressed the shear/stress-shear rate relation as obeying the Bingham relation; and the analytical solution for the drag coefficient already was obtained using the same relation. However, we can question the reliability of our estimate for the flow curve when it is used at higher shear rates if we get drag-vs.-Reynolds-number data within a limited range of shear rates. In this case, we should extend the ball velocity range to higher desired shear rate values to confirm the flow curve.

Evaluation of yield stress and Bingham viscosity for high shear rates may not be obtained by the analytical solution of Beris et al. (1985) because of inertial effects. However, we also can reduce this data from empirical experimental correlations available by Ansley and Smith (1967), Ito and Kajiuchi (1969), and Brooks and Whitmore (1969); these researchers obtained the drag coefficient as a function of the Bingham number and plastic Reynolds number. Using clay and other types of Bingham plastics, they dragged the ball up to the plastic Reynolds number of 1000 . Ansley and Smith (1967) were able to collapse all drag coefficient data to a single curve by defining a dynamic parameter in terms of the Bingham number and plastic viscosity number. Thus, tests theoretically can be run with high velocities if these correlations hold. The danger of this approach is the limited range of the dynamic parameter (between 0.01 to 2000) in Ansley and Smith's (1967) study because their Bingham fluids had very low yield stress. If the waste yield stress is high, as suggested, the dynamic parameter becomes very low for reasonable plastic viscosities. In this case, we may need to extrapolate the correlation, which is always difficult to justify. This extrapolation approach was taken in the preliminary drag force evaluation analysis of Pasamehmetoglu (Footnote 2). 
Our research attempts to answer questions asked above in a step-by-step approach. We have discussed some of our alternatives for data reduction. The final approach will be determined on the basis of experimental results we obtain from the tests.

\section{B3.0 Simulant Characteristics}

The wastes that were added to Tank 101-SY consist of double-shell slurry (DSS) and complexant concentrate $(\mathrm{CC})$ waste, which were concentrated by evaporation before storage. The complexants added to the $\mathrm{CC}$ waste consist primarily of $\mathrm{Na}_{4}$ EDTA, $\mathrm{Na}_{3} \mathrm{HEDTA}$, sodium citrate, and sodium hydroxy acetate (glycolate). Both wastes consisted mostly of precipitated, inorganic salts.

To adequately predict the behavior of the waste in the tank, falling-ball experiments must be performed with a representative waste simulant. A chemically similar simulant (described below) has shown that, like the waste, long amounts of time (month to years) are necessary for the simulant to stabilize. Because this study needed to be performed in a 6- to 7-month time frame, an aged simulant was needed. Also, to perform large-scale experiments and determine the effects of aging, a fresh simulant was made. These two simulants are described below.

\section{B3.1 Composition}

On the basis of chemical analysis of the core samples from Tank 204-SY-101, Agnew ${ }^{3}$ suggested the mixture shown in Table B.1 as a chemically accurate reproduction of the waste in the tank.

Agnew (Footnote 3) prepared his simulant in a progressive manner. First, the least soluble components were added to an appropriate amount of tap water (complexants). Next, 2.3 M NaOH was added, which heated the solution. The aluminate $\left(\mathrm{NaAlO}_{2}\right)$ was added after the $\mathrm{NaOH}$. However, Agnew later found that the sodium carbonate was much less soluble than the aluminate. As discussed later, we added the sodium carbonate before aluminate when preparing our fresh simulant. After adding the aluminate, the sodium nitrite, carbonate, and nitrate were added. This mixture stood for a few days at $60^{\circ} \mathrm{C}$ in a $33.4-\mathrm{L}$ model tank; then we observed that the settled solids were $2.54-\mathrm{cm}$ deep. The total sodium was increased by increasing the amount of sodium hydroxide from 2.3 to 3.3 $\mathrm{M}$ to compensate for the lack of other cations that are present in the actual waste. Some of the components not added to the simulated waste are citrate, glycolate, nitrilo triacetate, phosphate, fluoride, chloride, and other anions, potassium, calcium and other common cations, chromium, iron, and other transition metals. The simulated waste made by Agnew includes the major chemical species believed to adequately represent the physical and chemical nature of the tank slurry.

Agnew's slurry showed characteristics of four layers: 1) foam layer, 2) clear C layer, 3) soft slurry layer, and 4) a stiff bottom layer. This simulant waste was prepared approximately 2 years ago and kept at typical tank temperatures in a model tank. As with the actual waste, the vast majority of the settled simulant was contained in the $\mathrm{C}$ and soft slurry layers.

\footnotetext{
${ }^{3}$ Agnew, S. F., and L. H. Sullivan. 1993. "Evaluation of Ultrasonic for the Mitigation of Episodic Gas Release in Hanford Waste Tank 241-SY-101." Draft report.
} 
Table B.1. Components Used in Agnew's Simulant

\begin{tabular}{|c|c|}
\hline Component & $\begin{array}{c}\text { Concentration } \\
\text { Moles } \mathrm{L}(\mathrm{M})\end{array}$ \\
\hline $\mathrm{NaNO}_{3}$ & 3.7 \\
\hline $\mathrm{NaNO}_{2}$ & 3.6 \\
\hline $\mathrm{NaOH}$ & 3.5 \\
\hline $\mathrm{NaAlO}_{2}$ & 2.3 \\
\hline $\mathrm{NaCO}_{3}$ & 0.5 \\
\hline $\mathrm{Na}_{4} \mathrm{EDTA}$ & 0.12 \\
\hline $\mathrm{Na}_{3} \mathrm{HEDTA}$ & 0.13 \\
\hline
\end{tabular}

We obtained $4 \mathrm{~L}$ of this aged waste simulant from Agnew's model tank after the waste simulant was mixed homogeneously. These individual $1-\mathrm{L}$ samples were kept in a vacuum oven to maintain $\approx 50$ to $60^{\circ} \mathrm{C}$. Later tests showed that the temperature in the oven varied between 52 and $58^{\circ} \mathrm{C}$ in each cycle (about $30 \mathrm{~min}$ ).

The 4-L samples are indicated as AS1, AS2, AS3, and AS4 (aged simulant). Each simulant taken from Agnew's tank was treated separately because each has a different temperature and shear history. For example, two of the samples were taken $\approx 1$ month after the first two. Also, all samples were at room temperature when they were moved.

To complete this study, 20 to 30 gallons of simulant was needed. Because there was less than 10 gal. of aged simulant, more simulant had to be created.

Using the recipe and procedure suggested above, a sample liter was made. The chemical components are listed in Table B.2. The compositions given below are identical to those shown in Table B.1, except in $\mathrm{g} / \mathrm{L}$ vs. moles/L.

The components are listed in the order they are added to the water. All salts dissolved at room temperature until the addition of the sodium nitrate. At $50^{\circ} \mathrm{C}$, the carbonate (and possibly the EDTA and HEDTA) came out of solution after the addition of the aluminate. The simulant was then transferred into a plastic container with a lid to reduce evaporative loses. The container was placed in the same oven with the Agnew's simulants to maintain its temperature.

Using the test procedure given above, a 113.6-L (30-gal.) batch of simulant was made in a 55-gal. barrel. Initially, the temperature of the simulant caused by the heat of solution (mainly from the aluminate and sodium hydroxide) was $30^{\circ} \mathrm{C}$. Over two days, the simulant temperature was raised to the setpoint of $50^{\circ} \mathrm{C}$. This mixture was constantly stirred using a barrel mixer. After several months, a sample of this simulant (fresh simulant, or FS2) was taken from the barrel.

\section{B.6}


Table B.2. Components Used in the Fresh Simulant

\begin{tabular}{|c|c|}
\hline $\begin{array}{c}\text { Component } \\
\text { Concentration } \\
\text { g/L }\end{array}$ \\
\hline $\mathrm{Na}_{4}$ EDTA & 50.00 \\
\hline $\mathrm{Na}_{3} \mathrm{HEDTA}$ & 50.00 \\
\hline $\mathrm{Na}_{2} \mathrm{CO}_{3}$ & 56.19 \\
\hline $\mathrm{NaAlO}_{2}$ & 196.07 \\
\hline $\mathrm{NaNO}_{3}$ & 317.05 \\
\hline $\mathrm{NaNO}_{2}$ & 244.95 \\
\hline $\mathrm{NaOH}$ & 139.60 \\
\hline $\mathrm{H}_{2} \mathrm{O}^{*}$ & 536.14 \\
\hline
\end{tabular}

*amount calculated such that there would be $1590 \mathrm{~g} / \mathrm{L}$ total.

To prepare the new simulant for experimental use, the simulant is taken to $70^{\circ} \mathrm{C}$ for a minimum overnight period. The simulant (still above $60^{\circ} \mathrm{C}$ ) then was mixed vigorously for 30 to $60 \mathrm{~min}$, then cooled to $50^{\circ} \mathrm{C}$. At $70^{\circ} \mathrm{C}$, the nitrate and nitrite salt crystals dissolved completely. When the temperature was reduced, the resulting crystals were more representative of crystals seen in the NC layer. This was equivalent to redistributing the sludge layer in the tank and diminished the variability of the simulant taken from the barrel at different times.

\section{B3.2 Density and Particle Shapes and Sizes}

The shape and size of solid particles and the solid fraction are very important parameters controlling the rheological properties of suspensions. They also determine the settling rate of the suspension. Other physical properties are important, such as densities of the mixed simulant, saturated liquid, and the precipitated crystals.

For the simulant received from Agnew (Footnote 3), the densities were measured, along with information on the size and shape of the solid particles. Densities of Agnew's simulant and their comparison with waste measurements are given in Table B.3.

Agnew's simulant showed a certain pattern of particle sizes that may be a trend for the actual waste. Larger crystals were made of sodium nitrate, sodium nitrite, and sodium carbonate. Sodium nitrate crystals are rhombohedral and tend to be very symmetrical prisms, while the sodium nitrite crystals are monoclinic and grow in variety of different ways. Generally, they are flat, triangular plates, although dendritic forms grow readily out of rapidly cooled solutions. The sodium carbonate crystals most often appear as needles clustered like haystacks (Footnote 3 ). These forms only appear in waste 
Table B.3. Properties of Agnew's Simulant

\begin{tabular}{|l|c|c|c|c|}
\hline $\begin{array}{c}\text { Density } \\
\left(\mathrm{g} / \mathrm{c}^{3}\right)\end{array}$ & $\begin{array}{c}\text { Convective } \\
\left(\mathrm{g} / \mathrm{c}^{3}\right)\end{array}$ & $\begin{array}{c}\text { C Layer } \\
\left(\mathrm{g} / \mathrm{c}^{3}\right)\end{array}$ & $\begin{array}{c}\mathrm{NC} \text { Layer } \\
\left(\mathrm{g} / \mathrm{c}^{3}\right)\end{array}$ & $\begin{array}{c}\mathrm{Mixed} \\
\left(\mathrm{g} / \mathrm{c}^{3}\right)\end{array}$ \\
\hline $\begin{array}{l}\text { Agnew's } \\
\text { Simulant }\end{array}$ & 1.51 & & 1.59 \\
\hline $\begin{array}{l}\text { E-Core } \\
\text { Sample }\end{array}$ & 1.50 & 1.57 & 1.70 & \\
\hline $\begin{array}{l}\text { C-Core } \\
\text { Sample }\end{array}$ & & 1.49 & 1.63 & \\
\hline
\end{tabular}

that is cooler than $\approx 30^{\circ} \mathrm{C}$, and the carbonate exists in another, much smaller crystal at the tank temperature.

The CC is present in Agnew's slurry primarily as small crystals because it is fairly insoluble in the 12-M sodium supernatant. HEDTA components could not be found in the actual waste or in Agnew simulant, even though they were present initially in both. We assume that the HEDTA degrades quickly into some as yet undetermined products (Footnote 3 ).

The rate of crystal growth/dissolution is unknown. Indirect evidence, such as change in appearance and viscous behavior of the simulant, suggests that the rate is weeks, not hours.

In this study, the density of aged simulants was measured. The density of supernate at $50^{\circ} \mathrm{C}$ was determined to be $1.544 \mathrm{~g} / \mathrm{c}^{3}( \pm 0.004)$. The well-mixed simulant was measured as $1.593 \mathrm{~g} / \mathrm{c}^{3}$ $( \pm 0.004)$ and $1.561 \mathrm{~g} / \mathrm{c}^{3}( \pm 0.004)$ for AS1 and AS2, respectively.

The solid fraction in a given simulant also can be changed by varying the temperature. Falling-ball tests were conducted at different temperatures with the well-mixed aged simulant to investigate the solid fraction effect. However, the amount of dissolved salts in the saturated liquid will decrease with decreasing temperature, causing a decrease in viscosity, whereas the viscosity of the supernate at a constant amount of dissolved salts will increase with decreasing temperature. 


\section{B4.0 Description of Experiments}

\section{B4.1 Falling-Ball Tests and Real-Time Radiography}

A good description of falling-ball rheometry in opaque suspensions can be found in Mondy et al. (1986). Here, only the parts unique to this study will be presented.

The falling-ball paths were recorded using a standard VHS, editing video system. This system records 30 frames per second; the VCR could be advanced one frame at a time, yielding the highest accuracy within the limitations of the technique. The accuracy in position and time are estimated to be $\pm 0.2 \mathrm{~cm}$ in the position and $\pm 0.03 \mathrm{~s}$ in time, respectively. Because objects placed closer to the $\mathrm{x}$-ray source will appear larger in the recorded image than objects further away, rulers with 0.32-cmdia. metal markers were placed in front on the right side and in back on the left side of the column. First-order corrections for errors due to perspective could be determined. Second-order corrects would be on the scale of other errors.

The test cylinder has a inside diameter of $5.08 \mathrm{~cm}$ and a length of 46 to $50 \mathrm{~cm}$. A cylindrical jacket, through which water was pumped to maintain a constant temperature, surrounded the test cylinder. The water temperature was maintain by using a constant temperature bath that controlled the temperature in the bath to within $\pm 0.01^{\circ} \mathrm{C}$ and in the column to within $\pm 0.03^{\circ} \mathrm{C}$. The top of the test cylinder was covered with a lid to reduce evaporative losses.

The falling ball used in this study varied from $0.32 \mathrm{~cm}$ to $1.27 \mathrm{~cm}$ in diameter. Tungsten carbide, brass, steel, aluminum oxide (ruby), ceramic and aluminum balls were used to obtain various densities. Aluminum balls settled under a low shear rate, but the simulant (like the real waste) corroded aluminum. The initial experiments completely dissolved $0.64-\mathrm{cm}$ aluminum balls in less than 3 days.

While inertial effects will be important in many of the experiments, the low Reynolds number data will be useful as a starting point to understand the more complex behavior at higher Reynolds numbers.

To obtain lower shear rates, 1.27 - and $0.64-\mathrm{cm}$ plastic balls were used. These plastic balls had a density of 1.18 , which is much less than the simulant density of 1.6 . To increase the $1.27-\mathrm{cm}$-dia. ball average density, $0.32-$ to 0.48 -cm-dia. holes were drilled in the ball and filled with various sizes of tungsten carbide, brass, and steel balls. These balls are referred to as PFBs. Similarly, 0.159-cmdia. holes were drilled in the 0.64-cm-dia. plastic balls and filled with $0.159-\mathrm{cm}$-dia. gold wire to increase the average density of the ball. These balls are referred to as PFGs. All holes were sealed with an acrylic epoxy.

\section{B4.2 Falling-Ball Tests}

The purpose of these falling-ball tests was to get experience and anticipate the possible difficulties during in-situ measurements. The tests are described below.

To see if it was practical to use a laboratory-scale apparatus to simulate the falling-ball system to be placed in Tank 101-SY, a small laboratory-scale model was made and tested. This apparatus would 
be used like the real system, except that the ball would rise or fall under a constant force. Initial tests were performed in a well-characterized Newtonian fluid under low Reynolds number flows to see if density and viscosity could be measured either through theoretical calculations or by calibration with another fluid.

In Figure B.1, a schematic of the falling-ball apparatus is shown. The major parts are a ball glued to a wire, which goes over two pulleys and then is connected to a counterweight. The counterweight can be adjusted so the ball either will rise or settle into the fluid. Initially, standard pulleys were used. However, the frictional loses were much greater than the weight of the ball. To reduce these losses to manageable levels, air pulleys (like air bearings) were used. These had very low frictional losses. However, the air flow in the pulleys would cause them to rotate without any load conditions. This force would depend on the rotation rate.

\section{B4.3 Couette Viscometer Tests}

In addition to falling-ball tests, Couette viscometer experiments measured the viscous behavior of the simulant. Couette viscometry based on dissapative resistance in a fluid between two concentric cylinders with at least one of them rotating. For a narrow-gap Couette viscometer, the shear rate is relatively constant, and the torque needed to rotate the cylinders specifies the shear stress. As mentioned previously, the particle migration and wall slip can be seen in the rotational viscometers. To compare the falling-ball results with results from a rotational viscometer, a Couette device was selected. The simulant used in Couette viscometer experiments was an aged simulant provided by Agnew (Footnote 3).

Approximately $200 \mathrm{ml}$ of aged simulant (AS4) was provided to the Naval Air Warfare Center Weapons Division at China Lake to perform Couette flow tests. The sludge was sent in two 125-ml

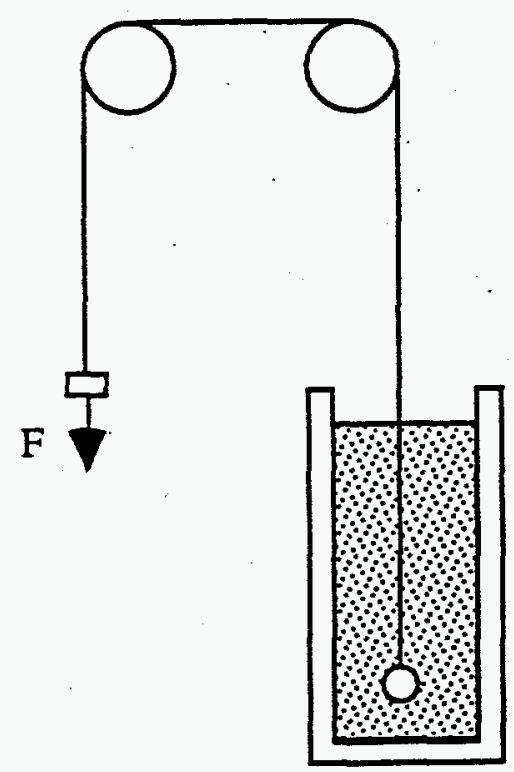

Figure B.1. Picture of Laboratory-Scale Falling-Ball Apparatus. The ball would either settle or rise under a relatively constant force. 
polyolefin screw-top bottles. When not in use, the sludge was stored at room temperature (20 to $25^{\circ} \mathrm{C}$ ). Before making measurements, the bottles of simulant were stored for several days in an environmental chamber at the test temperature. The sludge was stirred by inverting or shaking the bottles. Air bubbles introduced by shaking were allowed to rise to the surface before pouring samples of the sludge into a viscometer for viscosity measurements. Only a few seconds were required to allow bubbles to rise to the surface. It was noticed that the simulant gave off a slight ammonia odor at $40^{\circ} \mathrm{C}$.

A Couette (cup and bob) viscometer was used, although a parallel plate viscometer was tried. The parallel plate was $50 \mathrm{~mm}$ in diameter. In loading the parallel plate viscometer, sludge was poured onto the center of the lower plate; the upper plate was then lowered to squeeze the sample to the edge of the plates. During the measurement, a crust appeared to form over part of the exposed surface at the edge of the sample. The torque was measured at various rotation rates. The torque appeared to decrease with increasing rates, which may have resulted from a breakup of the crust at higher rates. The torque also may have been influenced by sedimentation of the suspended particles. For these reasons, the parallel plate viscometer was not used further.

Samples measured in the Couette viscometer were loaded by pouring between 28 and $29 \mathrm{~g}$ of simulant into the cup, mounting the cup into the viscometer, lowering the bob into the sample, and then spreading a layer of mineral oil on top of the sample. The mineral oil was added drop-wise from an eyedropper to form a 1- to 2-mm-thick layer floating on top of the simulant. This oil layer kept the simulant from evaporating and prevented the formation of any crust. For samples run without the oil layer, a crust was seen to form on the exposed surface; these runs showed higher and less reproducible torques than runs made with the oil layer in repeat experiments. The oil was low in viscosity $\left(0.3 \mathrm{P}\right.$ at $\left.23^{\circ} \mathrm{C}\right)$, and the layer was thin enough that its contribution to the measured torque was negligible.

The Couette was in a temperature-controlled environmental chamber heated by convection. A thermocouple in the base of the cup was used to measure the sample temperature. In all cases, the simulant was maintained at the test temperature in a separate environmental chamber before pouring it into the Couette viscometer. The Couette viscometer was allowed to equilibrate to the test temperature in its environmental chamber into which the sample was loaded.

\section{B4.4 Falling-Ball Experiments}

For mixed-simulant tests, the simulant was poured into the circular cylinder after taking it out of the constant temperature oven. The column was maintained at a constant temperature, as described in Section 4.1. The stirring apparatus consisted of a hub with eight equally spaced rods projecting radially. A long axial rod connected the hub to a stirring handle. By moving the handle up and down while rotating it, the simulant was mixed for approximately 5 minutes. After mixing, the appropriate section of the column was imaged.

The balls were stored to within $2^{\circ} \mathrm{C}$ of the bath temperature before being used in an experiment. However, the column was normally 1 to $2^{\circ} \mathrm{C}$ cooler than the water bath because of convective losses to the surrounding air, so the temperature difference between the ball and the simulant was less than $2{ }^{\circ} \mathrm{C}$. 
To remotely release a ball into the top of the simulant, a vacuum ball dropper was used. This conically shaped piece could accommodate balls as small as $0.32 \mathrm{~cm}$ in diameter. When the external vacuum pump was turned off, the dropped slowly to atmospheric because of leaks in the hose. The ball then fell into the simulant.

Upon release of the ball, the $\mathrm{x}$-rays produced an image of the ball's path through an 20-cm-dia. window. These image were recorded so that the settling path could be determined. The motion of the ball also was displayed in real time on a monitor. Thus, decisions could be made for the next test based on the results of previous tests.

The mixing was not performed for the settled-waste tests. As discussed later, the simulant originally was mixed as described above and allowed to settle to a specified compressive strength. The balls then were dropped.

\section{B4.5 Settling Experiments}

To study the rheological effects of aging, three procedures were used. The first method involved an aging time of one week or less. The second method involved longer periods of time, typically for more than one month. The third procedure used a centrifuge to accelerate the settling rate.

In the first method, the simulant would be mixed and allowed to settle for the aging time. Balls then would be dropped through the simulant. The most important data obtained would be from the first and second balls dropped. Here we were trying to determine how long the structure-yielding higher viscosity and yield behavior took to develop from the well-mixed case. Because short time were used, the experiments could be repeated by mixing the simulant and letting it settle again.

In the second method, the simulant would be allowed to settle for several weeks after mixing. Like the first method, balls then would be dropped in the simulant. However, at the end of the experiment, the simulant would not be mixed. Here, the waiting time would be how long the simulant took to recover. The objective was to see how much of the structure was caused by aging and how much by the higher concentration of crystals in the settled layer. If the rheological behavior of the simulant recovered in a few days to weeks, the structure then would be predominately caused by the increased concentration. The implication for the real waste would be that if the disturbance caused by the pump did not fully mix the tank, the waste could be much thicker than if the waste had been well mixed.

In the third method, a centrifuge was used to accelerate the settling. This method allowed several months of settling to occur in a matter of hours. Using this method, most of the simulants were tested for complete settling and the corresponding compressive strain.

\section{B4.6 Instrumentation Accuracy}

The uncertainty associated with the evaluation of the terminal velocity in these experiments is derived from errors in estimating the distance between specified marks and the time of the flight between these marks. The accuracy of the flight time is set by the frame rate of the recording system $(1 / 30 \mathrm{~s})$. As mentioned before, this error is $\pm 0.03 \mathrm{~s}$. The position could be estimated with an accuracy of $\pm 0.2 \mathrm{~cm}$. The resulting error in the terminal velocities encountered in this work ranged from $\pm 2 \%$ caused by uncertainty in distance to $\pm 10 \%$ (additional $8 \%$ error in measuring time). 
The other measured parameters used in the data reduction method are the diameter and weight (or density) of spherical balls. Some balls (metal and ceramic) were fabricated to be almost perfectly spherical (within $\pm 0.002 \mathrm{~mm}$ ), with variations between different balls being \pm 0.006 . A ruby sphere had a uniform diameter to within our ability to measure $(<0.002 \mathrm{~mm})$. Plastic balls were much less accurate and precise in shape, with diameters that deviated by 0.001 on a given sphere and varied by \pm 0.02 between balls. These nonmetallic balls were used to create densities close to that of the fluid. The center of moment of these balls are not perfect. Some of the data obtained using these balls showed considerable scatter. The weight was measured with a sensitive scale that had an accuracy of $\pm 0.0001 \mathrm{~g}$. The range of ball densities in study varied from 1.7 (PFG) to 15.2 (tungsten carbide).

The falling-ball accuracy will not be discussed because no reliable data were obtained.

\section{B5.0 Results}

The results of the pulling-ball, settling, falling-ball, and Couette viscometer experiments are presented here. The falling-ball experiments yielded only qualitative conclusions because several sources of drag in the experiment could not be determined. Several simulants settled over a period of several month to quantify the settling rate and behavior of the simulants. Falling-ball experiments were performed with the well-mixed and settled simulants, while the Couette viscometer experiments were performed only with the well-mixed simulant.

\section{B5.1 Pulling Ball}

\section{B5.1.1 Experiments}

The first test measured the static load with the ball in air and then in water. This would give the displacement volume of the ball and wire. By placing the counter force on a balance, the differential load could be determined when in the counterweight weighed more than the ball. The load on the balance kept decreasing with time, which was caused by the wire stretching. As the wire stretched, the ball in the fluid would settle lower, increasing the buoyancy force and lowering the load on the balance.

In trial runs under constant force in a Newtonian fluid, the ball would settle or rise more slowly at the bottom than at the top. Because this occurred both on settling and rising, it was related to the amount of wire in the fluid. However, the ball would not settle even at an approximately constant velocity, and it was not clear how to correct for the effects of the wire stretching and the force caused by the uneven flow in the air pulleys; thus, this set of experiments was abandoned.

\section{B5.1.2 Theoretical Analysis}

In Newtonian fluids there exist analytical solutions for both a wire and a ball settling along the axis of an infinitely long circular cylinder. As a first-order approximation, the drag force on the sphere can be added to the drag on a wire, ignoring the effect of the sphere on the drag on the wire. This method should give an upper limit on the drag of a sphere being pulled by a wire.

The drag on a sphere in the cylinder is given by Happel and Brenner (1983) as 


$$
F_{s}=-\frac{3 \pi \mu d u_{0}}{\chi}
$$

where $\chi$ is the wall effect correction given by Faxen (1923)

$$
\chi=1-2.149 \frac{d}{D}+2.05\left(\frac{d}{D}\right)^{3}-0.95\left(\frac{d}{D}\right)^{5}+O\left(\frac{d}{D}\right)^{6}
$$

and where $\mathrm{d}, \mathrm{u}_{0}, \mu$, and $\mathrm{D}$ are the diameter and velocity of the ball, the viscosity of the fluid, and the diameter of the cylinder, respectively.

The drag per unit length, 1 , on an infinitely long wire in a cylinder is given by (Phan-Thien et al. 1993) as

$$
F_{W}=\frac{2 \pi \mu \nu}{\ln (\epsilon)+\frac{\left(1-\epsilon^{2}\right)^{2}}{1-\epsilon^{4}}}
$$

with

$$
\epsilon=\frac{2 r_{w}}{D}
$$

where $r_{w}$ is the radius of the wire. When the diameter of the tank becomes very large with respect to the radius of the wire, the force on the wire appears to go to zero. The limitation of the above equation applies only when the flow is at a steady state. However, a wire in an infinite sea of fluid never reaches steady state; if it could, the resulting force would be zero because the fluid would be moving affinely with the wire. To model the real situations, the finite length of the wire and the transient nature of the calculation have to be accounted for.

Two sets of calculations were performed. The first used the dimensions of the laboratory-scale setup described above, while the second set used the approximate dimensions of the tank. Table B.4 lists both sets of dimensions.

Using Eqs. (B.2) to (B.4), the relative magnitude ( $\chi$ ) of the wire contribution to the total drag is

$$
\chi=\frac{F_{w} l}{F_{s}+F_{w} l}
$$

Using the values in Table B.4 with $l$ equal to half of $h$, we find that $\chi$ is 0.63 and 0.82 for the laboratory-scale and tank-scale models, respectively. This suggests that the drag on the wire may be more important than the drag on the sphere. In the laboratory-scale experiment, the large magnitude of the drag on the wire relative to the sphere is due to the relatively large size of the wire relative to 
Table B.4. Dimensions for Theoretical and Numerical Calculations

\begin{tabular}{|c|c|c|}
\hline $\begin{array}{c}\text { Variable } \\
\mathrm{d} / 2\end{array}$ & $\begin{array}{c}\text { Laboratory Scale } \\
\text { (in) }\end{array}$ & $\begin{array}{c}\text { Tank } 101 \text { SY } \\
(\mathrm{m})\end{array}$ \\
\hline $\mathrm{r}_{\mathrm{w}}$ & 0.25 & 0.04572 \\
\hline $\mathrm{D} / 2$ & 0.0075 & 0.0015875 \\
\hline $\mathrm{h}$ & 1.00 & 10.9728 \\
\hline & 20.00 & 9.906 \\
\hline
\end{tabular}

the column diameter. However, in the tank simulation, it primary is due to the length of the rod compared to the diameter of the sphere. Here, the drag caused by the wire probably is not an accurate estimate.

To verify that the drag on the wire will be on the order of the drag on the sphere, a numeric model that accounts for the finite length of the tank, the interaction between the wire and the sphere, and the non-Newtonian nature of the waste would be needed. As an incremental improvement, we have checked the above theoretical results with a low Reynolds number, Newtonian model.

\section{B5.1.3 Numerical Calculations}

To see what effects the finite size of both the laboratory-scale and the tank-scale experiments have on the relative drag between the wire and the sphere, a low-Reynolds number, Newtonian, boundaryelement method code was used.

The code uses an integral boundary element method, which is named for replacing the boundary with a set of singularities representing the velocity and traction (the tangential component of the stress) on the boundary. By integrating over all the singularities, the partial differential equations reduce to a set of equations relating the strength of the singularities to each other. This reduces the order of the calculation by one dimension because now only the conditions on the boundary are important. However, the resulting matrices are dense vs. the banded matrices resulting from finite-element methods. This technique also is limited to cases where the equations are linear. For linear problems, the gains made by reducing the order of the problem far outweigh the extra time needed to invert dense matrices. Therefore, this technique is good for solving Stokes equations (the linear form of the Navier-Stokes equations occurring from creeping flow conditions). This assumes that the stress-strain relationship is linear (Newtonian).

In the laboratory-scale experiment, the agreement is better than that seen for the tank-scale experiment because the theoretical equations neglect end effects. End effects typically arise only when the ball is within one-container radii from the bottom or top. Therefore, end effect are important throughout the entire tank because the length of the tank is comparable to its radius (see Figure B.2). 
(a)

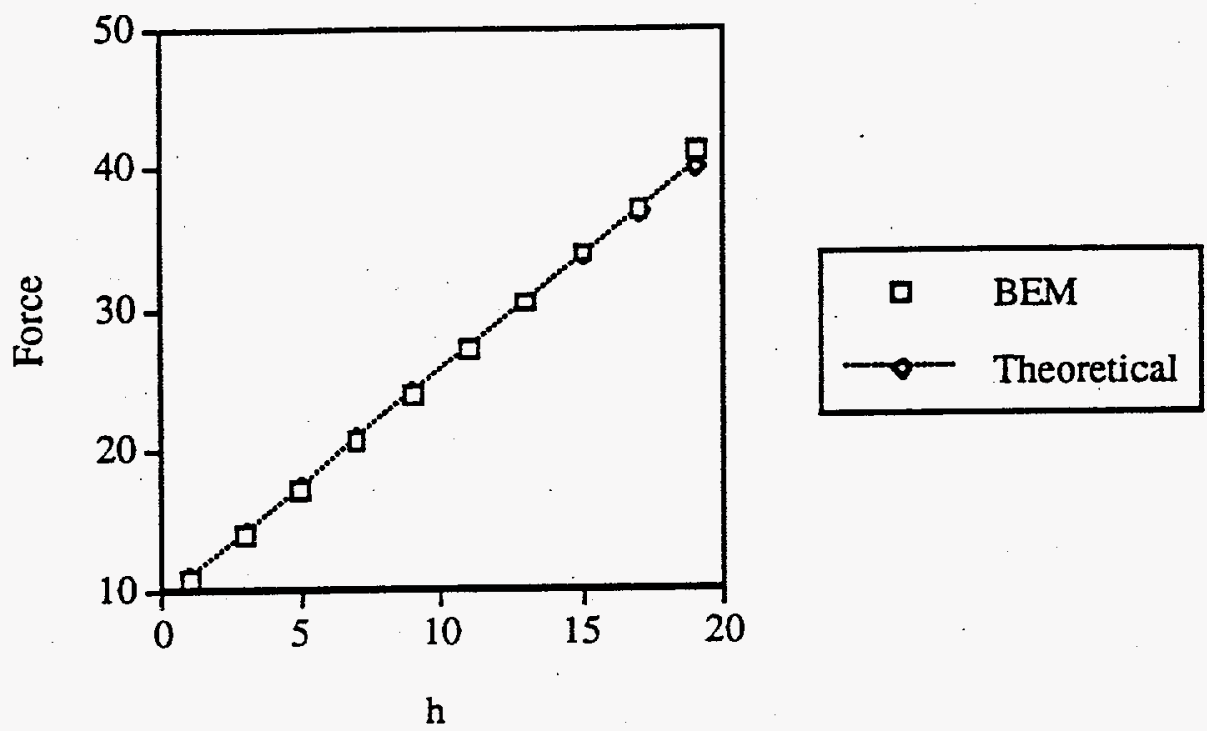

(b)

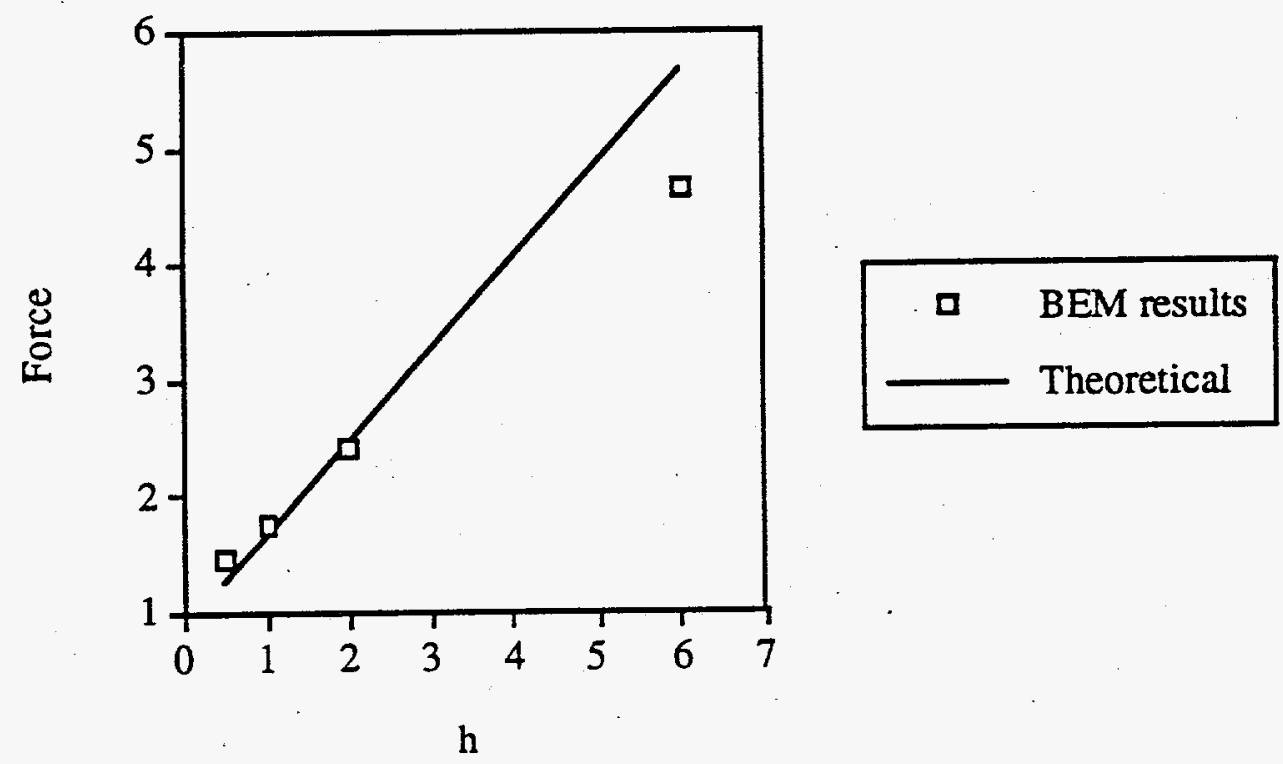

Figure B.2. Comparison of the Numerical Results with the Theoretical Predictions. The two figures show results using laboratory-scale experimental dimensions (a) and tank dimensions (b).

B.16 
Further improvements in the calculations can be made using non-Newtonian fluid models outside of the creeping flow regime. While it might be constructive to separate the effects of inertia from the effects of nonlinear constitutive equations, from a modeling standpoint these are both nonlinear effects. This means that the boundary-element method used in the above calculations must be replaced by a nonlinear, time-dependent numerical methods. Several packaged codes could be used if the constitutive relationships are shear-thinning and/or Bingham plastic. If esoteric constitutive equations such as a history-dependent Bingham plastic model are needed, then codes must be developed to account for these highly nonlinear effects. Currently, the amount of time necessary to complete such a project is unknown. To determine this, a fluid model either would need to be identified or created that correctly models the simulant behavior.

\section{B5.2 Settling Behaviors of Aged and Fresh Simulants}

The repeatability tests for well-mixed simulants are relatively easy and quick to perform. However, the procedure takes significantly more time and care for the settled simulant.

Before pump operations, the settled (NC) layer in Tank 101-SY was reformed after each gas release event (GRE). The average period between the GREs was $\approx 3$ months. At the end of this period, the NC-layer thickness was almost one half of the waste level. Following a GRE, a part of the NC layer mixed with the $C$ layer.

The NC layer is formed by salt crystals in the waste settling. The settling process of particles in Tank 101-SY is complex because the particles have differences in shape, density, and size. Also, the salts can form crystal networks as a result of flocculation and aggregation. The rate of change of the height of the NC layer is available only indirectly through axial temperature measurements.

Thermocouples do not provide enough resolution to track the interface between the $C$ and NC layer. In addition, the gas generated in the NC layer causes the settled waste to expand, which pushes up the interface location. Although settling plays an important role in the formation of NC layer, its rate is unknown.

Also, the settling behavior of the simulants is particularly important for the characterization of the state of a settled simulant. To demonstrate the repeatability of falling-ball tests in a settled layer, ideally, the simulant should settle completely, which requires the settling behavior to be known. We must perform settling tests to identify the time required for a complete settling. In typical settling tests, the sample is mixed very well initially and allowed to settle. The height of the interface between the particle-rich and the liquid-rich regions are then recorded. The ratio of the height of this interface to the height of the initially mixed suspension is called the compressive strength. The rate of change of the interface height is the settling rate. Initially, simulants with equivalent amounts of compressive strain will be compared.

The settling process of dilute systems are relatively well understood (Richardson and Saki 1954). However, settling of flocculated suspensions is not well understood (Michael and Bolger 1962, and Glasrud et al. 1993). In fact, there are few works that report on nonhomogeneous sedimentation. Glasrud et al. (1993) recently reported on the settling behaviors of iron oxide suspensions. They used a suspension with needle-like particles. The average length of the particles was $0.5 \mu$, and the average length-to-diameter ratio was 5 (extremely small particles). The continuous phase was mineral oil. Although the properties of the solid and liquid phases are very different from the properties of our 
simulant, this study reports interesting results. The settling rates decrease as the solid fraction increases, which was consistent with earlier works. Smaller tube diameters delayed settling. Air bubbles were found to accelerate the settling and had a larger effect at higher solid concentrations.

For the settling tests, the simulants were mixed very well and poured into circular cylinders with a diameter of $5.14 \mathrm{~cm}$ and a height of 46 to $51 \mathrm{~cm}$. Simulants were kept in a larger closed container in a constant-temperature oven. These cylinders were jacketed with circulating hot water to maintain a constant temperature, as shown in Figure B.3.

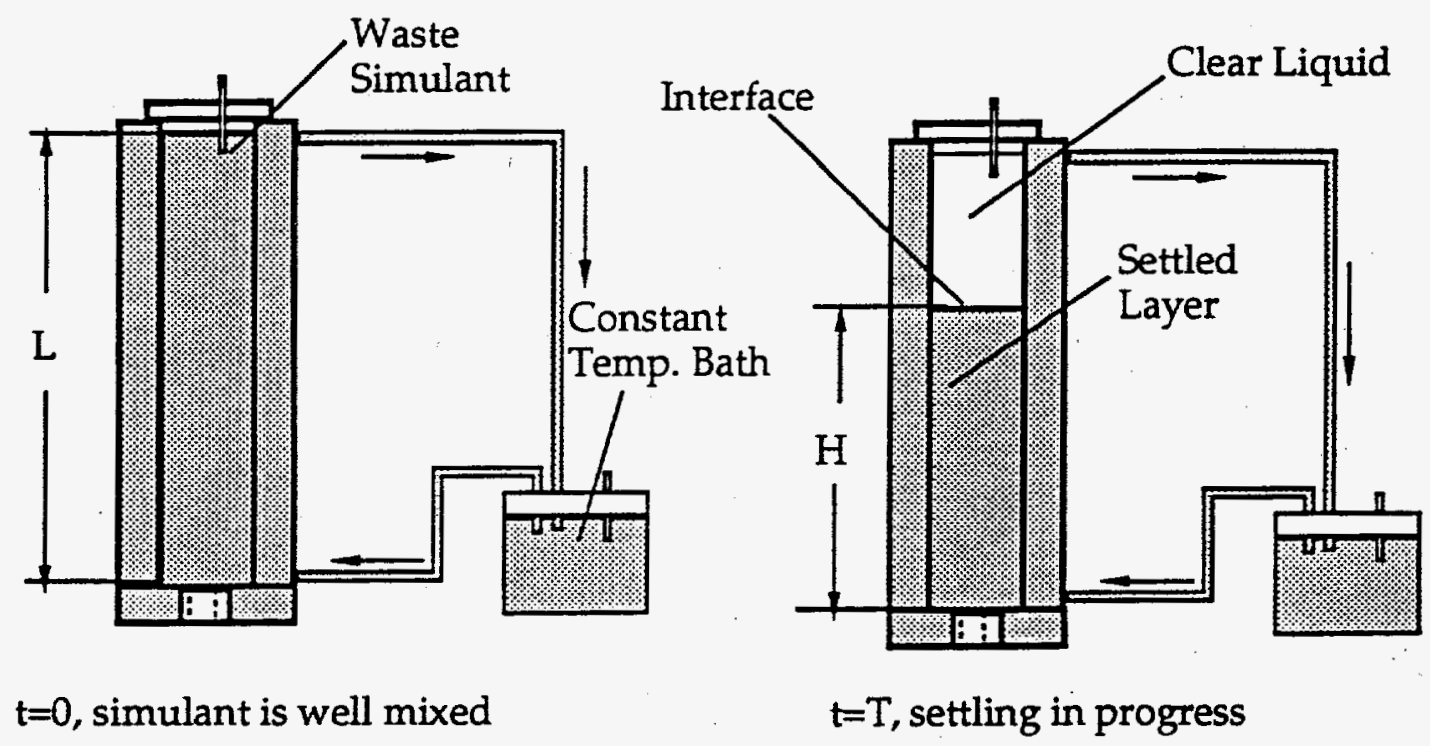

Figure B.3. Sketch of Settling Tests

Settling experiments were performed with aged and fresh simulants. Reproducibility was only checked with the aged simulants.

Initial data was taken in a tapered cylinder, shown below. Data reduction to find equivalent time and/or equivalent settled distance in a pure cylindrical geometry was not obvious. The experiments were redone using cylinders for comparison with the settling experiments.

In Figure B.4, the relative settling behavior is seen to vary between the aged and fresh simulants, with the aged simulants settling more slowly than the fresh simulants. The same simulant (AS3) took different amounts of time to start settling. When FS1 was allowed to settle at room temperature, it had many very large crystals $(>1 \mathrm{~mm}$ ), which probably significantly contributed to the fast settling rate. Until more results are available from the centrifuge experiments, the relationship between the fresh and aged simulants cannot be further defined.

Because complete settling of the simulant takes months, we performed simultaneous experiments. Three cylinders were filled with simulants, two of them filled with an aged simulant and one filled with the fresh simulant. All cylinders settled for a few weeks. The interface between the supernate and the slurry was checked hourly for the first day, then for longer periods during working hours. 


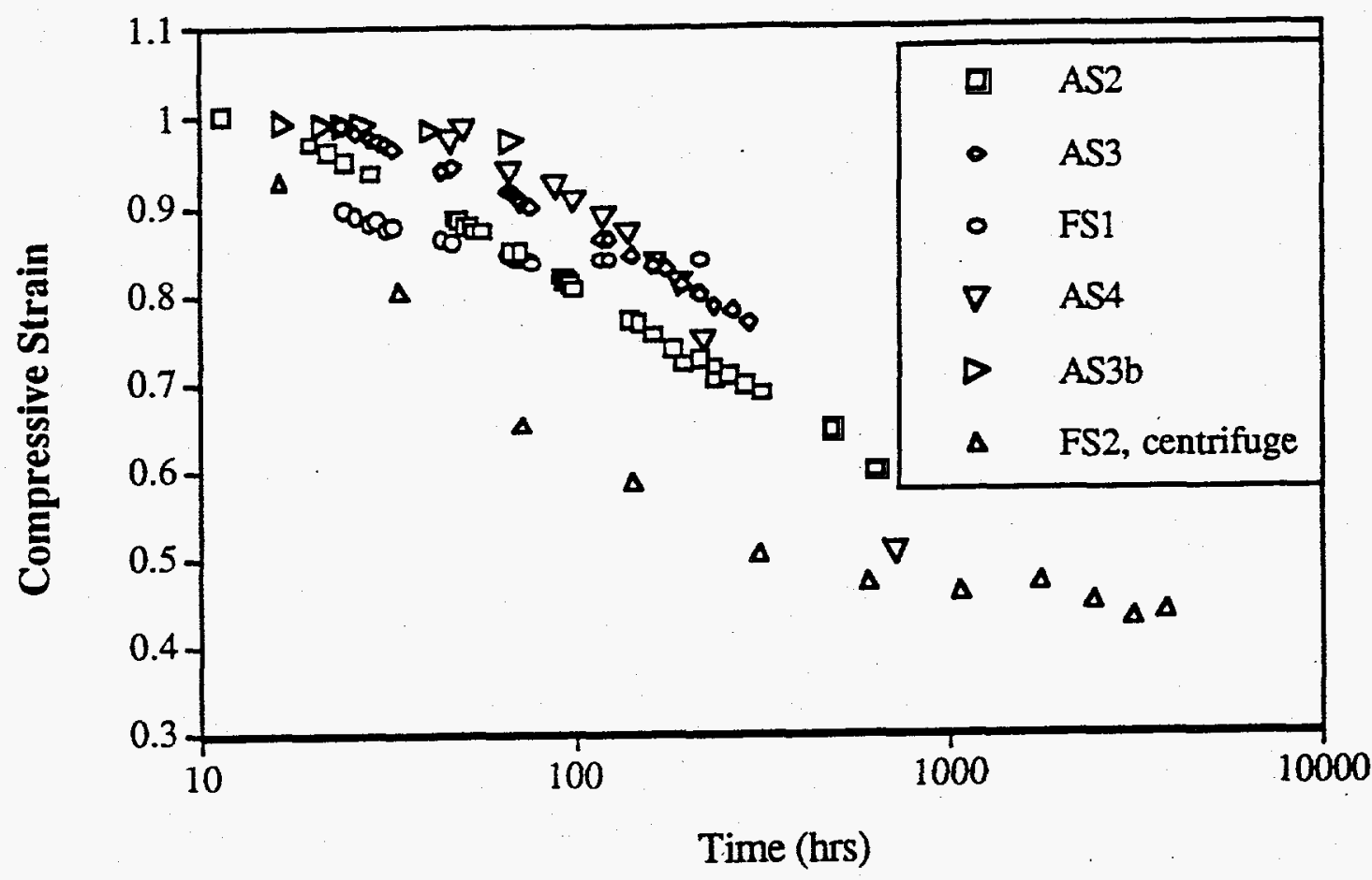

Figure B.4. Settling Behavior of Aged and Fresh Simulants

\section{B5.3 Falling-Ball Reproducibility}

Experiments were repeated in well-mixed and settled simulants to determine reproducibility. Thus, below we discuss four cases: (1) well-mixed, aged simulant (AS1), (2) well-mixed, fresh simulant (FS2), (3) settled, aged simulant (AS2 and AS3), and (4) settled, fresh simulant (FS2). Falling-ball experiments were performed on both the aged and fresh simulants. The fresh simulant was more viscous than the aged simulant. This span of viscous behavior will hopefully contain the actual waste behavior.

\section{B5.3.1 Reproducibility}

To simulate how the real waste would affect the settling force at a given settling velocity, falling-ball tests were performed using two simulants. These simulants and samples of a similar simulant made by Agnew (Footnote 3) are described in Section B.3. These samples will be referred to as FS2 for the simulant made in this study, and AS1, AS2, AS3, and AS4 for the simulant samples obtained from Agnew. Agnew's simulant was created over 2 yr ago and remained mostly at $\sim 50^{\circ} \mathrm{C}$. The fresh simulant was mixed up only 4 to 5 months ago, so it could still be aging. The reasons for differentiating the simulants from Agnew's tank are that they behave differently and have different temperature histories.

Before the constitutive behavior can be determined, the reproducibility of the settling experiments must be checked. In Figure B.5, the results are shown for AS1, although equivalent experiments were performed on all simulants shown in this study. The first set of falling balls consisted of sets of 0.64-cm-aluminum, $0.32-\mathrm{cm}$-steel, and $0.48-\mathrm{cm}$-steel balls. To determine if the simulant behaved as 


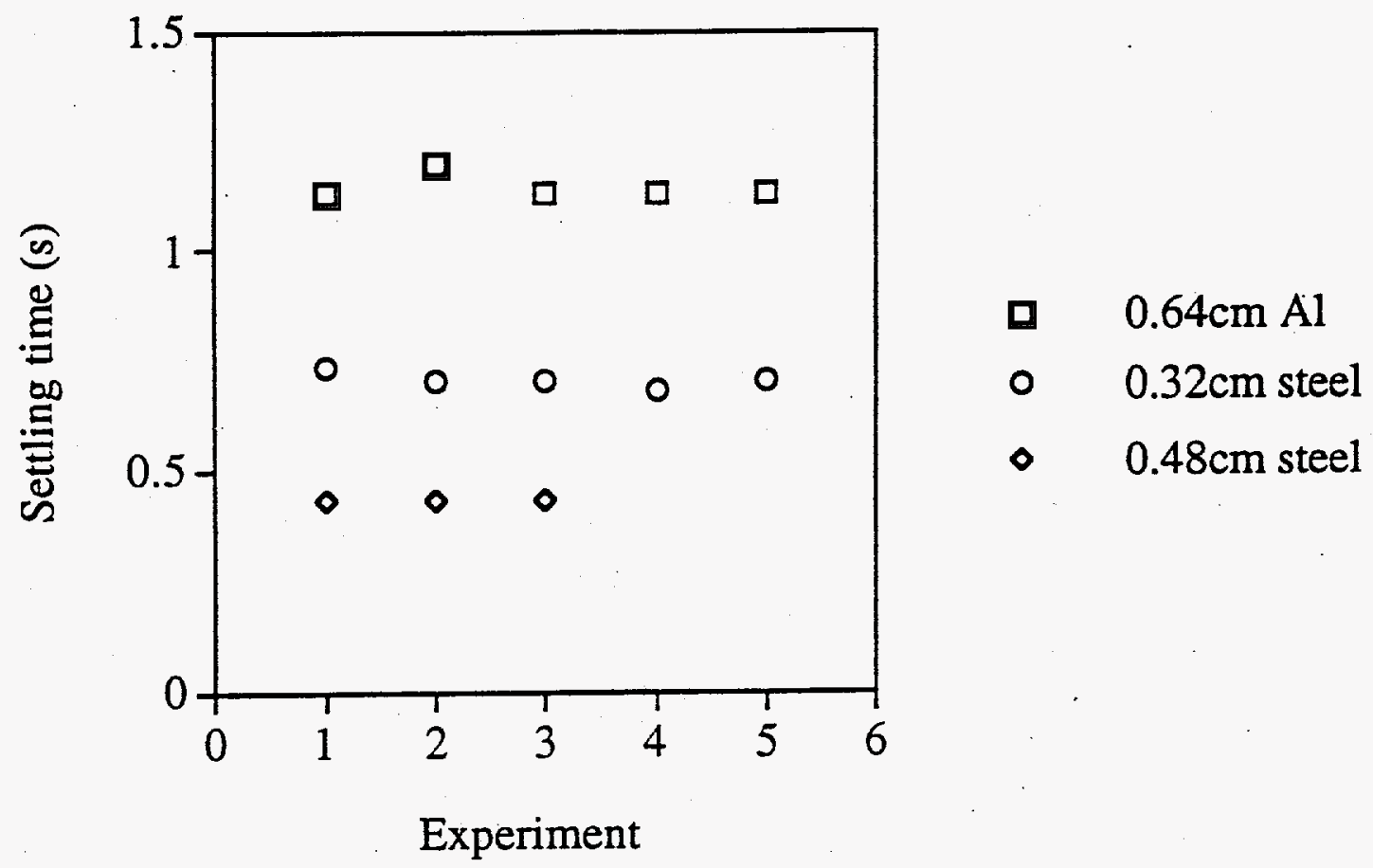

The shear rate for $0.64 \mathrm{~cm}$ of aluminum, $0.32 \mathrm{~cm}$ of steel, and 0.48 $\mathrm{cm}$ of steel are 22,70 , and $78 \mathrm{~L} / \mathrm{s}$, respectively. (The frame rate was 30 frames per second; therefore, the above difference for a given ball type are caused by differences of \pm 1 frame.)

Figure B.5. Balls of the Same Density and Size Give Good Reproducibility

a single-phase, homogenous fluid, each set consisted of 3 to 5 dropped balls. As seen in Figure B.5, the reproducibility of the settling times is within a few percent. Most of this error is due to the low resolution in time because of the rapid settling velocities in relationship to the thirty frames per second used to tape these experiments.

To determine the reactivity/corrosion of different balls in the simulant, the balls were recovered. The steel spheres did not appear to have been notably corroded (i.e., having the same mass, diameter, and surface quality). However, the aluminum balls were completely dissolved. Only some dark gray residue was found at the bottom of the simulant. Therefore, aluminum balls were never used again in this or any similar simulant after these initial experiments. Also, a large amount of foam developed in AS1 after a few days and before the balls were retrieved. This foam probably was caused by the initial off-gassing caused by dissolving/decomposition of the aluminum.

With the fresh simulant (FS2), the PFB and PFG balls did not settle through the well-mixed simulants where they had settled in AS1. Higher shear rate balls settled reproducibly through the simulant. This bounded the yield stress. However, using $0.32-\mathrm{cm}$ ruby balls, the settling velocities were reproducible. 
In earlier drops, a similar phenomenon was observed with the PFB and PFG balls in AS1. Also, occasionally a ball with a higher apparent density settled more slowly than a less-dense ball. At that time, it was assumed that the differences were caused by the nonuniform nature of the plastic ball (i.e., roughness, asymmetry, etc.). Also, some balls were not observed to settle when less-dense balls had settled. Because only $20 \mathrm{~cm}$ of the column can be observed at one time, the section observed was normally far below the upper interface where balls did get stuck in later drops. If a ball were trapped in this upper layer, stirring for the next ball would send it to the bottom.

The $0.32-\mathrm{cm}$ spheres were the best spheres used in this study, and they have given very reproducible results at high sphere rates. In FS2, their velocities were not constant over all the drops. In fact, the first ball settled twice as fast as the second ball. What this suggests is that the yield stress may not be uniform throughout the simulant or may not be uniform upon mixing. This would only manifest itself for balls that are near the yield point as they settle. A small change in the yield would cause large changes in the settling velocity. When using the in-situ viscometer, this effect will cause a small change in the force required to pull the ball.

\section{B5.3.2 Settled Simulants}

After settling for many weeks; the simulants were not settling noticeably over $24 \mathrm{~h}$. At this point, balls were dropped in one of the aged simulants. This simulant then was mixed and shorter settling times were used to test how the structure developed from a well-mixed simulant. These shorter times gave reproducible results. From analyzing the data, it appears that the settled height was more important then the time settled. However, these experiments were performed only for $\sim 100-\mathrm{h}$ time periods.

The second column filled with the aged simulant was allowed to settle continuously. After the first set of falling-ball experiments were performed, the simulant was not mixed. Instead, a certain amount of time passed to see if the simulant would recover its undisturbed properties. This would be tested by repeating the same balls as dropped initially. To determine if there was a critical waiting period, balls were dropped with increasing periods: $2 \mathrm{~d}, 4 \mathrm{~d}, 6 \mathrm{~d}$, etc.

The first set of these experiments was not successful because three times the temperature control was lost. The first was when the column was transferred from the laboratory to the $\mathrm{x}$-ray facility. This incident caused the formation of small crystals in the saturated liquid and caused a column of the settled layer to rise into the saturated liquid. After $\sim 1$ week, the column had settled back down on top of the settled layer. Tests run at this time showed very little difference between the resettled and undisturbed settled simulant.

The second time, temperature control was lost over the weekend, and an array of needle-like crystals had formed in the supernate layer. Upon restoring temperature control, the needles did not completely redissolve but settled mostly on top of the previously settled simulant. This layer of settled crystal needles had a significantly higher viscosity than the simulant below it.

At the same time, a sample of the saturated liquid was taken from the column. Using this sample, the viscosity and density of the saturated liquid was determined. 
Because the top of the column was not sealed well, a solid layer formed on top of the simulant while the liquid was being analyzed. The liquid was poured on top of this layer and did not dissolve it. Upon breaking this relatively thin layer through which balls would not settle, the pieces settled down on top of the settled simulant.

The final temperature loss was only over a few hours, so it produced only small crystals. However, the whole set of layers had been continuously stiffening so that now the viscosity of the wiry layer was more than an order-of-magnitude higher yield stress than the undisturbed settled simulant. To get around this region, a tube was placed inside the cylinder so that balls could be dropped directly into the lower, undisturbed layer.

Similar experiments gave the same results at high shear rates in settled experiments and/or with FS2, as can be for AS3 in Figure B.6.

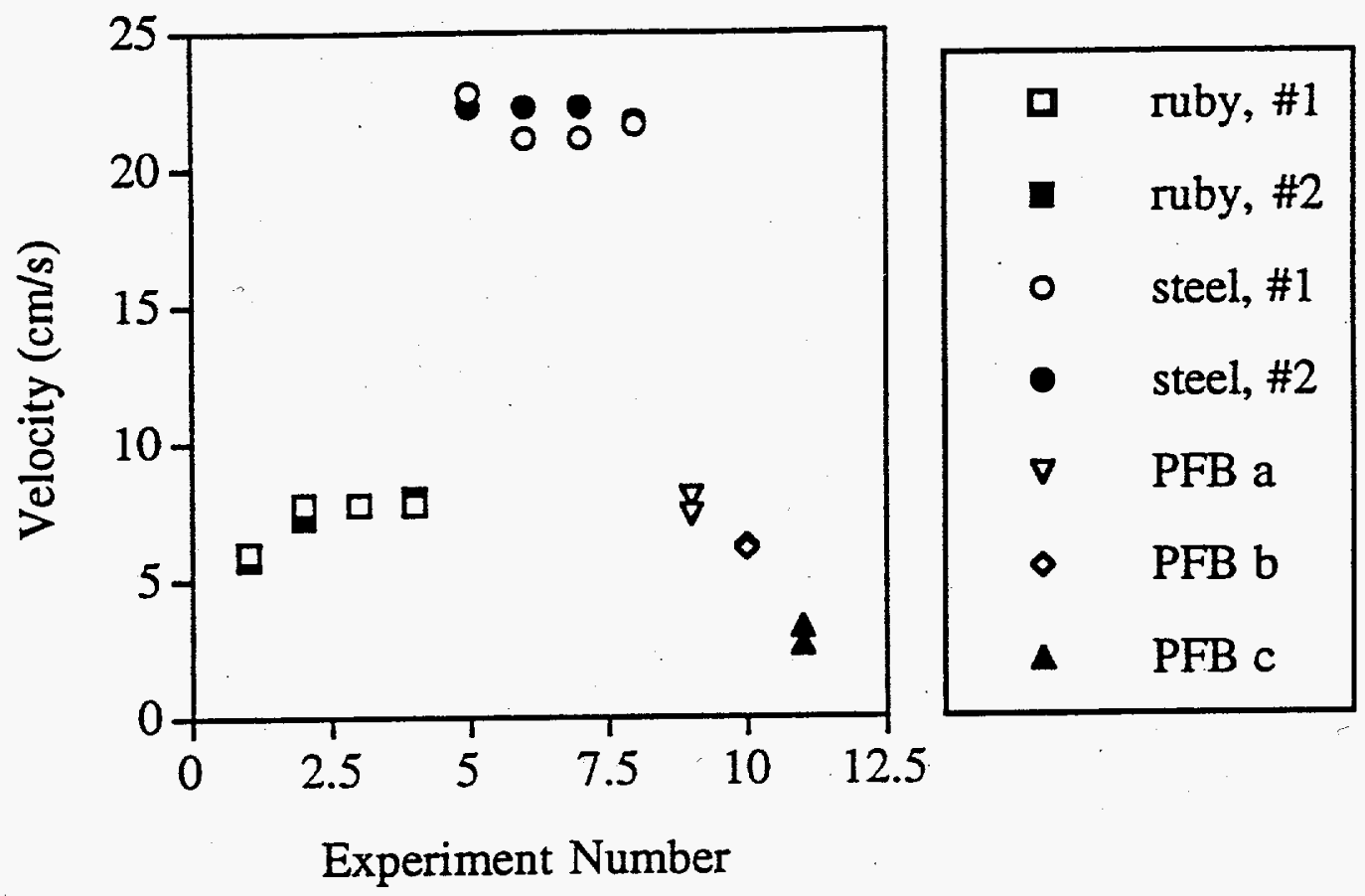

The shear rates for the $0.32-\mathrm{cm}$-dia. ruby and $0.32-\mathrm{cm}-\mathrm{dia}$. steel are 24 and $70 \mathrm{~s}^{-1}$, respectively. The $1.27-\mathrm{cm}$-dia. balls ranged from 1.6 to $6.3 \mathrm{~s}^{-1}$.

Figure B.6. Reproducibility in Settled Experiments for AS3

Similar experiments gave the same results at high shear rates in settled experiments and/or with FS2, as can be seen above for AS3.

Near the yield point, the results become much less reproducible. Variations by a factor of two have been observed. This is not from the structure breaking down, because the second ball went more slowly than the first ball. This occurred while testing the well-mixed characteristics of FS2, so it is not due to the second ball sampling part of the undisturbed simulant. While evidence pointed to the 
behavior earlier in the study, it was not until these tests with balls of uniform density and size were performed that definitive conclusions could be made. This implies that to get good reproducibility, the in-situ viscometer should operate at shear rate above $3 \mathrm{~s}^{-1}$. This all depends on the characteristic shear rate at which results are needed. If they are needed in the lower shear rate regimes, more tests must be performed to determine both the average and deviations about the average.

\section{B5.4 Constitutive Equations for Well-Mixed Simulants}

Above we demonstrated that the well-mixed simulant behaves as a homogenous fluid (continua). To estimate the flow curves (e.g., the relation between the shear stress and shear rate), various constitutive relationships will be tried. First, the simulant will be assumed to be a Newtonian fluid. Then the measured terminal velocity will be used to calculate the shear stress and shear rate. If the simulant is a Newtonian mixture, the calculated effective (apparent) viscosity will not be a function of the shear rate. If the viscosity depends on the shear rate, then a non-Newtonian fluid model will be used. However, the apparent Newtonian viscosity behavior as a function of shear rate should be used as a guide for selecting the non-Newtonian models to test. For the simulant, the apparent Newtonian viscosity was shear thinning with a very low yield stress. Below, these cases will be discussed in a progressive order.

As a first iterate, the settling rate of the falling balls was analyzed assuming the fluid behaved as a Newtonian fluid at low Reynolds numbers. Making this assumption, the apparent Newtonian fluid viscosity can be calculated directly from the settling velocities using the drag on a sphere in the cylinder, which is given previously [Eqs. (B.2) and (B.3)]. However, all balls did not predict the same viscosity. From examining the apparent viscosity as a function of the shear rate, the fluid appeared to be a shear-thinning, and possibly a power-law fluid. While the drop at different temperatures and in the different simulant could also be subjected to a Newtonian analysis, they were not because the power-law analysis appeared to work satisfactorily.

From this first set of experiments, the Reynolds number was estimated to be significantly greater than 0.3 (the creeping flow limit for balls settling in a Newtonian fluid). To get closer to creeping flow conditions, $1.27-\mathrm{cm}$ plastic balls (PFB) with a density of $1.18 \mathrm{~g} / \mathrm{c}^{3}$ were filled with $0.32-$ to $0.48-\mathrm{cm}$ brass, steel, and tungsten carbide balls such that the average density of the plastic balls ranged from 1.74 up to 2.0. Additionally, some $0.64-\mathrm{cm}$ plastic balls (PFG) were filled with $0.159-\mathrm{cm}$ gold wire. While these ball settled more slowly, only a few of the PFGs settled with Reynolds numbers below 0.3 .

The next constitutive equation tried was for a power-law fluid, based on the behavior seen in the Newtonian analysis. The analysis assumes that the drag coefficient as a function of Reynolds number is the same for power-law fluids as for Newtonian fluids. Making this assumption introduces a $30 \%$ uncertainty into the results. While this is normally considered satisfactory, better results could be obtained if the drag coefficient depended on the Reynolds number and the power-law index. However, other proposed analysis methods that use drag coefficients that depend on the power-law index have not improved the accuracy of this seemly first-order assumption.

The constitutive relationship for a power-law fluid is 


$$
v=m|\dot{\gamma}|^{-1} \dot{\gamma}
$$

where $\nu$ is the non-Newtonian viscosity, $\dot{\gamma}$ is the shear rate, and $\mathrm{m}$ and $\mathrm{n}$ are the fluid consistency index and power-law index, respectively. For $\mathrm{n}=1$, the Newtonian behavior is recovered with $\mathrm{m}=$ $\mu$. If $\mathrm{n}<1$, then the fluid is considered shear-thinning.

At moderate Reynolds numbers, the wall effects depend on the Reynolds number and the diameter of the settling ball relative to the diameter of the column. For a power-law fluid, the following relationships (Chhabra 1993) were used to determine the wall-effect $\mathrm{f}$ :

$$
\frac{1 / f-1 / f_{\infty}}{1 / f_{0}-1 / f_{\infty}}=\left\{1+1.3 \operatorname{Re}_{P L, m}^{2}\right\}^{-0.33}
$$

where

$$
\begin{aligned}
& f_{0}=1-1.6(d / D), \\
& f_{\infty}=1-3(d / D)^{3.5}, \\
& f=\frac{u_{0}}{u}
\end{aligned}
$$

and

$$
R e_{P L, m}=\frac{\rho_{f} d u}{m\left(\frac{u}{d}\right)^{n-1}}=\frac{\rho_{f} d^{n} u^{2-n}}{m}
$$

where $u_{0}$ is the measured velocity, $u$ is the theoretical settling velocity in an infinite sea of fluid, and $\rho_{\mathrm{f}}$ is the density of the fluid. Also, the drag coefficient $C_{D}$ is defined as

$$
C_{D}=\frac{4\left(\rho_{b}-\rho_{f}\right) g d}{3 u^{2} \rho_{f}}
$$

where $\rho_{\mathrm{b}}$ is the density of the ball and $\mathrm{g}$ is the gravitational constant. The densities of the simulant were measured and reported in an earlier section. Everything but the settling velocity is known a priori. The velocity used is the velocity corrected for wall effects, which depends on the Reynolds number.

The procedure consists of guessing a plastic Reynolds number, calculating the wall effect [Eqs. (B.7) to (B.8b], modifying the velocity [(Eq. (B.8c)], determining the drag coefficient [Eq. (B.10)], and finally calculating the Reynolds number from the drag coefficient assuming Newtonian behavior. From data found in Perry's handbook (1984), the following inverse relationship was determined for $0.5 \leq \operatorname{Re} \leq 50$ :

$$
\log (R e)=2.0292-1.999 \log \left(C_{D}\right)+0.60542 \log \left(C_{D}\right)^{2}-0.14072 \log \left(C_{D}\right)^{3}
$$


Higher Reynolds numbers were not encountered, and for lower Reynolds numbers the creeping flow result could be used where

$$
C_{D}=\frac{24}{\operatorname{Re}}
$$

Using the calculated Reynolds number as a guide, new Reynolds numbers were guessed until the calculated Reynolds number matched the guessed Reynolds number to three places. This procedure was repeated until all the different ball drops had self-consistent Reynolds numbers. From the plastic Reynolds number and the power-law index $n$, the apparent $m$ was determined. By calculating the variance of $m$ as a function of $n$, the best power-law index was determined. Because the wall effect is independent of the power-law coefficients $m$ and $n$, the determination of the Reynolds numbers could be separated from the determination of the power-law coefficients.

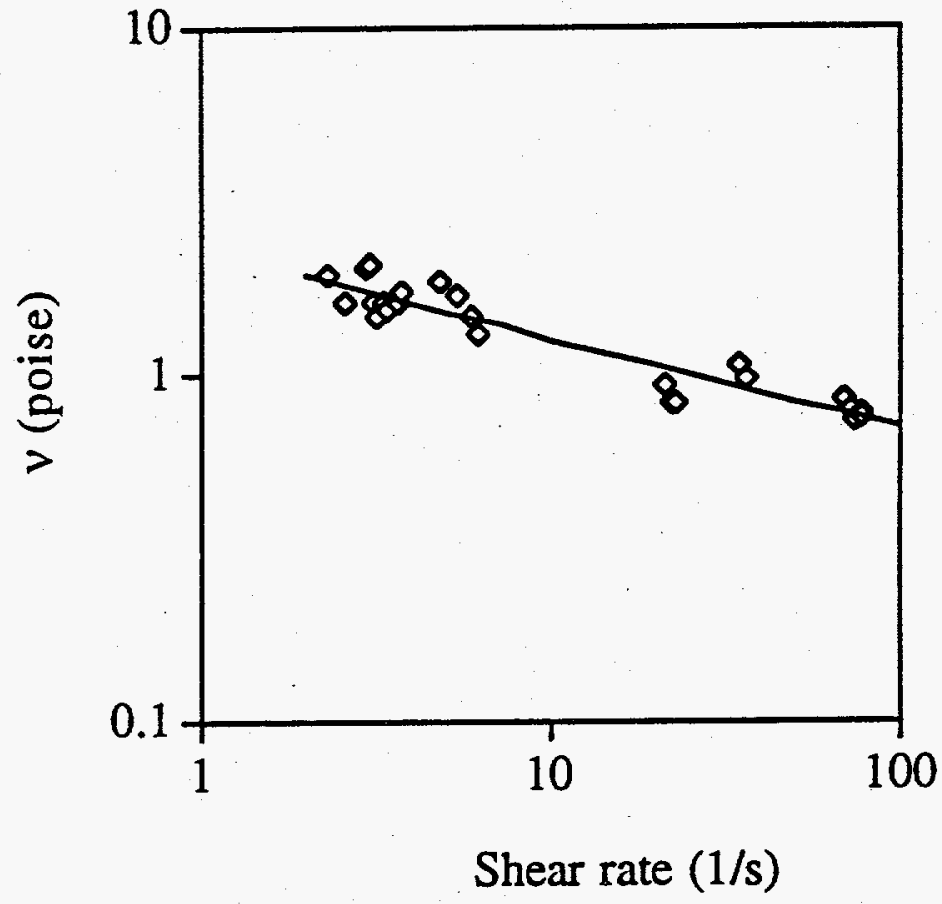

Figure B.7. Settling Data Reduced Assuming Power-Law Behavior and Resulting Wall-Effects Gives Power-Law Behavior

In Figure B.7, the results of this analysis are shown. The power-law coefficients are 0.74 and 2.29 for the power-law and fluid consistency index, respectively. Next, the temperature was changed to $40.8^{\circ} \mathrm{C}$, followed by a change to $25.2^{\circ} \mathrm{C}$. After that, all balls except the aluminum balls were recovered. Because the off-gassing occurred during drops at $51.2^{\circ} \mathrm{C}$ (set $\mathrm{A}$ and $\mathrm{B}$ ), the simulant was reheated to $50.0^{\circ} \mathrm{C}$, and the initial tests were repeated (set $\mathrm{C}$ ). The results can be seen in Figure B.8 and Table B.5. 
Table B.5. Power-Law Coefficients Determined by Falling Ball

\begin{tabular}{|c|c|c|}
\hline $\begin{array}{c}\text { Temperature } \\
(\mathrm{C})\end{array}$ & $\begin{array}{c}\mathrm{m} \\
\left(\mathrm{dyn} \mathrm{s} / \mathrm{cm}^{2}\right)\end{array}$ & \begin{tabular}{c}
$\mathrm{n}$ \\
\hline 51.2
\end{tabular} \\
\hline 25.2 & 1.59 & 0.72 \\
\hline 40.8 & 11.7 & 0.72 \\
\hline 50.0 & 4.34 & 0.72 \\
\hline
\end{tabular}

In Figure B.9, the stress vs. strain was plotted to determine if the well-mixed simulant had a yield stress (either real or apparent). As can be seen in the figure, if a yield exists, it is less than 10 dynes $/ \mathrm{cm}^{2}$ or 1 Pascal. Shown in Figure B.10, FS2 is compared with AS1, and FS2 appears to have a yield stress greater than 10 dynes $/ \mathrm{cm}^{2}$. If the yield stress is subtracted from the overall stress, the two simulants have very similar behavior.

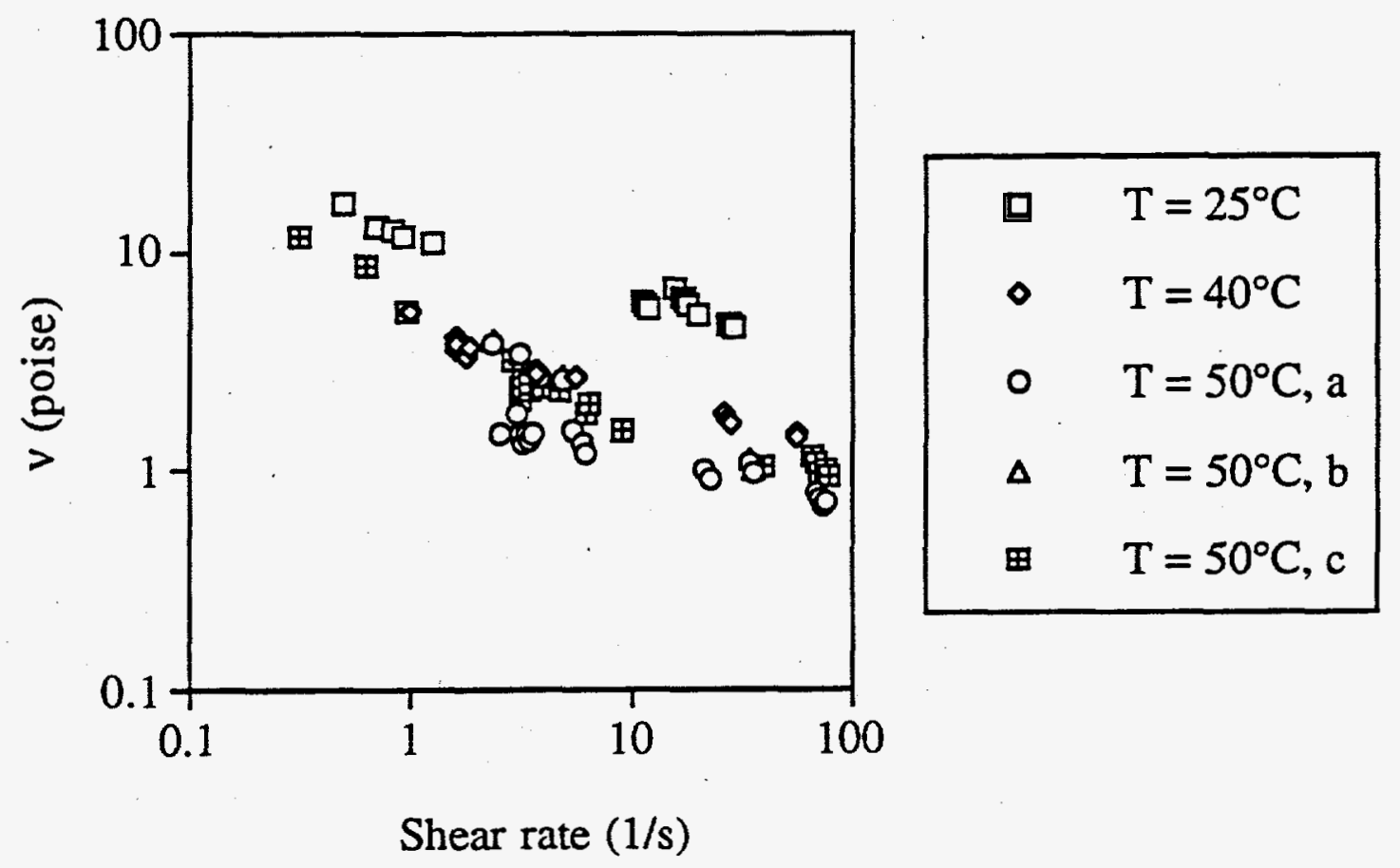

The first two tests at $50^{\circ} \mathrm{C}$ were performed while or soon after the aluminum balls were introduced into the simulant.

Figure B.8. Rheogram for AS1 at Various Temperatures 


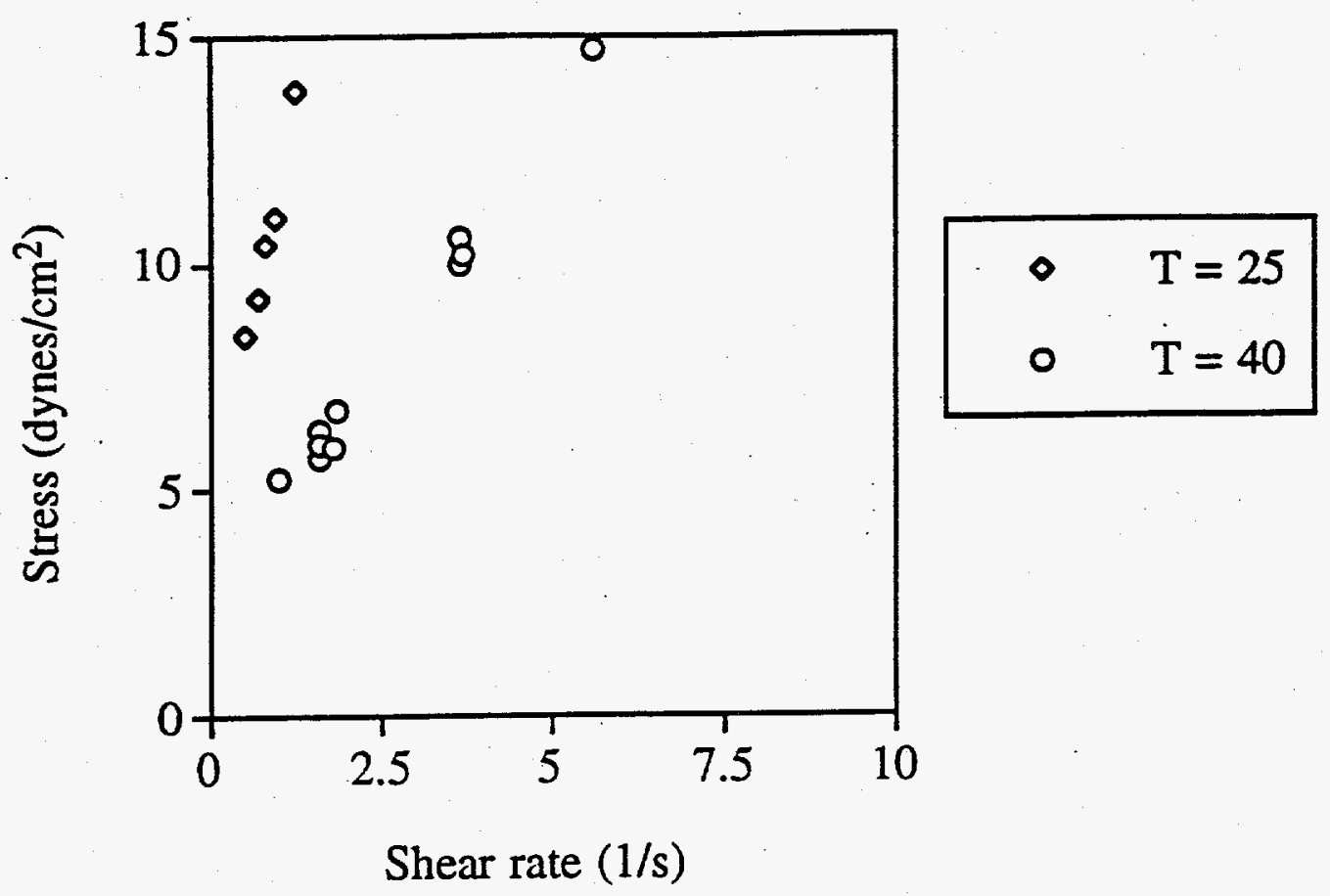

Figure B.9. Low Shear Behavior of AS1 Shows that the Yield Stress is Less than 10 dynes $/ \mathrm{cm}^{2}$ or 1 Pascal

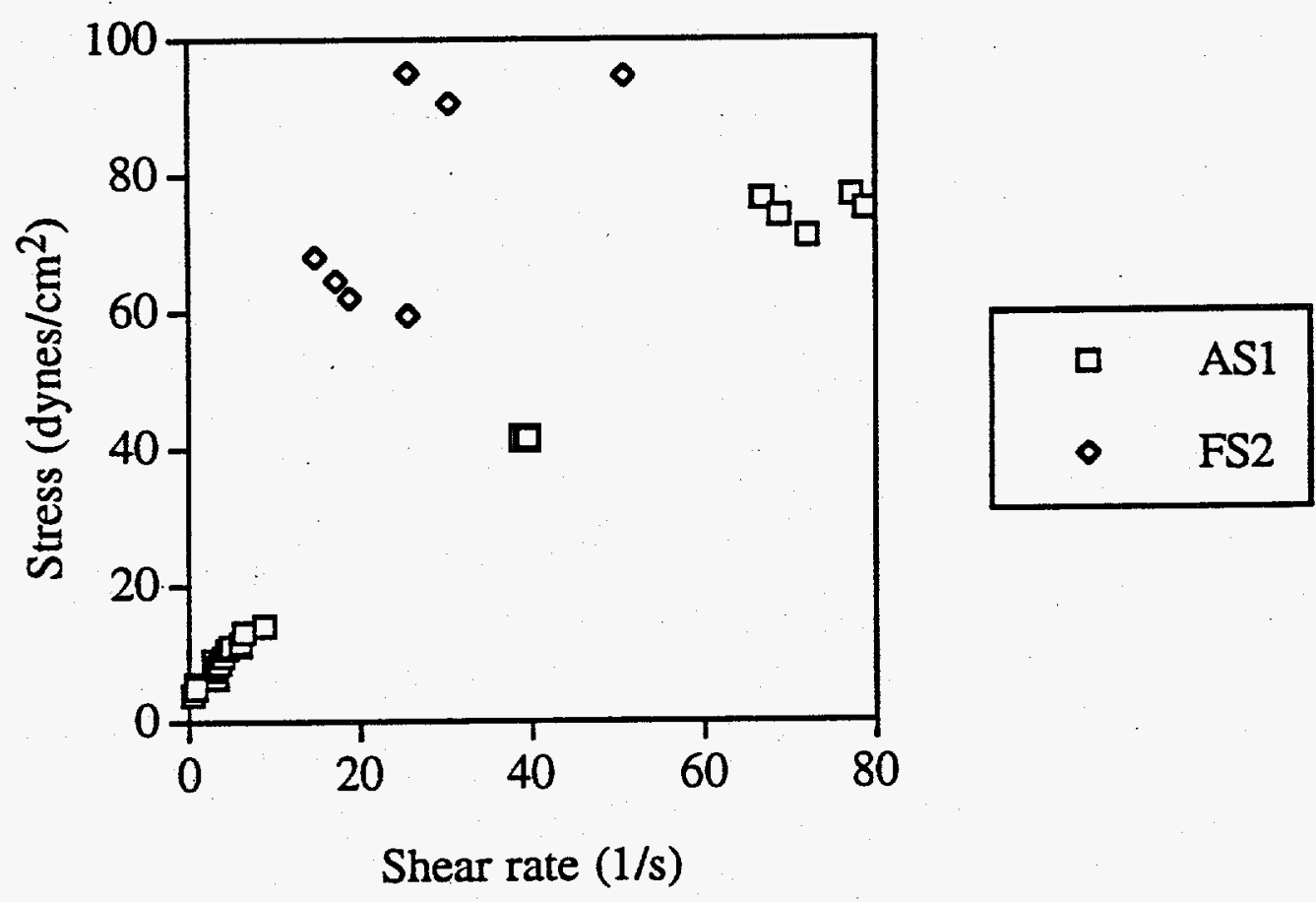

AS1 has a lower effective viscosity than FS2 due to a corresponding lower yield stress.

Figure B.10. Stress-Strain Diagram for Two Types of Simulants 


\section{B5.5 Constitutive Equations for Settled Simulant}

For the settled waste, the viscosity of the simulant was not calculated because in most cases, a steadystate settling velocity was either not reached or reproduced by the next settling ball. This implies that a history-dependent constitutive equation is necessary to accurately reduce the data. Also, both the settled and mixed simulants displayed yield stress; however, the settled waste had both a historydependent and a history-independent value.

The settled simulants (AS2, AS3, and FS2) displayed certain common features. First, the first ball would settle more slowly than the second ball. Second, if the same type of ball was dropped until a steady-state settling velocity was achieved, this velocity would be lower than that observed in the well-mixed simulant. An exception was when a set of high-shear-rate settling balls was followed by a low-shear-rate ball with a diameter less than or equal to the high-shear-rate balls. Then, the balls would reproduce the well-mixed settling velocities.

To analyze the falling ball's behavior, several methods were used to reduce the falling ball's trajectory. The first was to locate the ball's position in each frame. This was used when the ball moved at least $0.32 \mathrm{~cm}$ per frame (or about $9 \mathrm{~cm} / \mathrm{s}$ ). A second method was to record the time, elapsed or actual, for every $0.64 \mathrm{~cm}$ the ball settled. Finally, if the same type of ball had been drop previously, the elapsed time for the ball to settle between predetermined points would be recorded. This would result in average settling speeds over a given number of sections, typical two or four sections.

The settling rates of similar balls did not always increase. This was caused by balls falling down different channels in the settled simulant. Every time a ball settled more slowly through a section than the previous ball, a new hole could be seen in the interface between the supernate and the settled layers. However, most balls followed the pattern shown in Figure B.11 (the first ball dropped significantly slower than the second ball). Subsequent balls would settle at nearly the same rate as the second ball. However, if the simulant were mixed, balls dropped after mixing would settle faster than the balls before mixing. These effects are believed to be caused by some kind of structure that forms in the settled layer over a period of days. Therefore, the first ball breaks down the fluid structure around its settling path. If the second ball follows the first ball path through the fluid, it dissipates most of it energy in the fluid sheared by the first ball. If a high-shear-rate ball is followed by a low-shear-rate ball, the high-shear-rate ball will have disrupted a large enough region so that the low-shear-rate ball will only affect sheared fluid. This is why such a ball would reproduce the wellmixed settling velocities. This only holds if the compressive strain is -1 (no significant settling.)

In Figure B.12, it can be seen that there is a critical amount of time below which the settled suspension behaves like the well-mixed suspension. This critical time is somewhere between 10 and $16 \mathrm{~h}$. For times less than the critical time, balls settle at the same rate as in the well-mixed suspensions. Furthermore, from Figure B.4, this also appears to be the time at which the interface starts forming. Thus, there does not appear to be any significant settling in the bulk of the simulant before the interface between the supernate and the settled layer forms. 


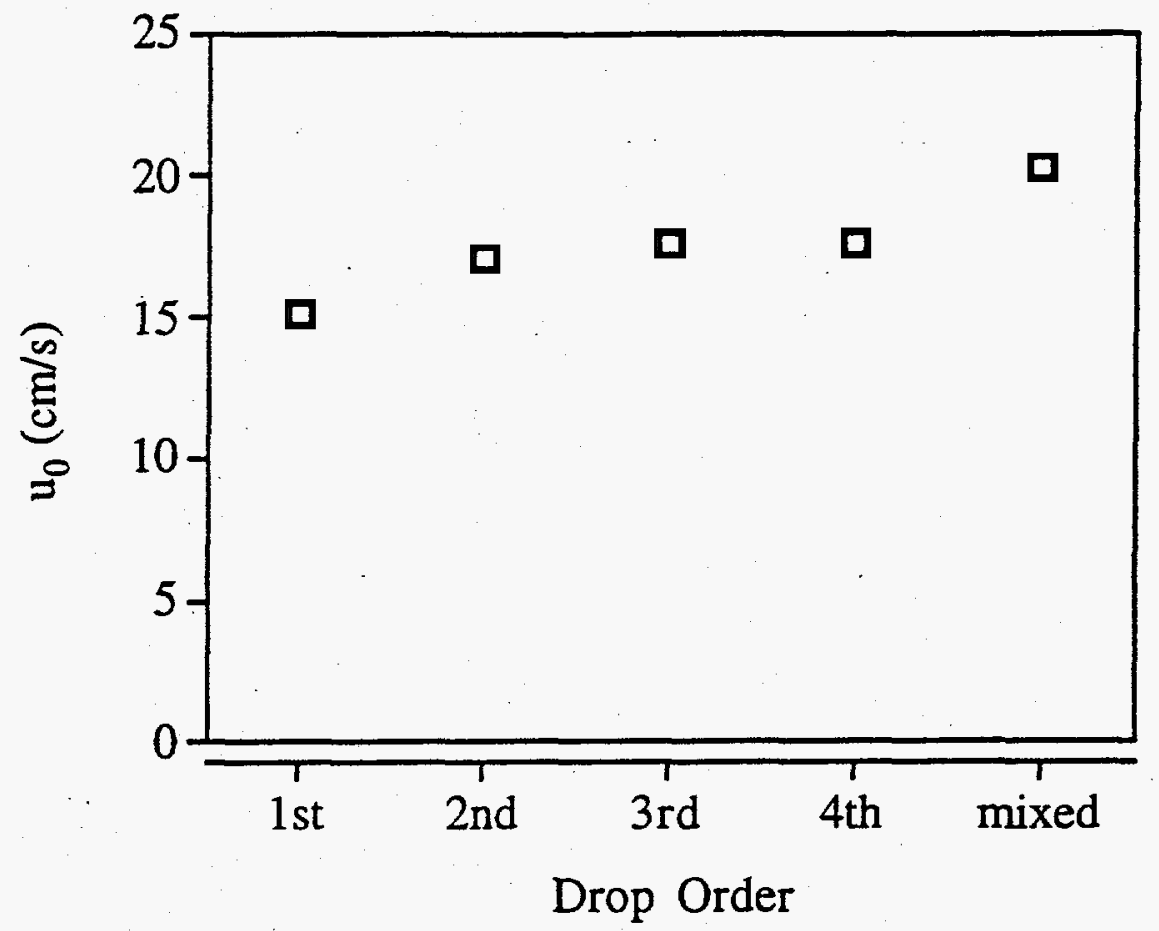

The drop order shows that: (1) the first ball settles through a different suspension than subsequent balls, and (2) successive balls reach a plateau-settling velocity that is lower than the well-mixed velocity.

Figure B.11. Effect of Short-Term History on the Settling Rate

\section{B5.6 Couette Viscometer Tests}

The viscosity was measured using a Couette viscometer with a bob radius of $1.9 \mathrm{~cm}$ and a cup radius of $2.3 \mathrm{~cm}$. The bottom of the bob was concave and captured a bubble of air beneath the bob to provide a shear-free surface. It was therefore assumed that the measured torque was due only to the sample being sheared in the annular gap between the cup and the bob. The shear stress in the gap was not uniform. From the conservation of momentum, it can be shown that the shear stress varies as the reciprocal of the radius squared. Thus, the shear stress varied from its maximum at the surface of the bob to $\left(R_{i} / R_{0}\right)^{2}$ of the maximum value at the inner surface of the cup. For the Couette used, the ratio of the minimum stress to the maximum stress was $\mathbf{0 . 6 8 2}$.

The mean shear stress was calculated as the arithmetic average of the stress at the bob and the stress at the cup. The shear rate corresponding to this shear stress was calculated by using a series solution given by Mooney (1930). This series requires estimating the second derivative of the raw data. Derivatives were calculated by finite differences. Second derivatives were found to be small, so that only the leading term was important in calculating shear rates. The series solution is valid assuming:

1) the material has a yield stress lower than the minimum stress in the gap so that all the material in the gap is shearing, 


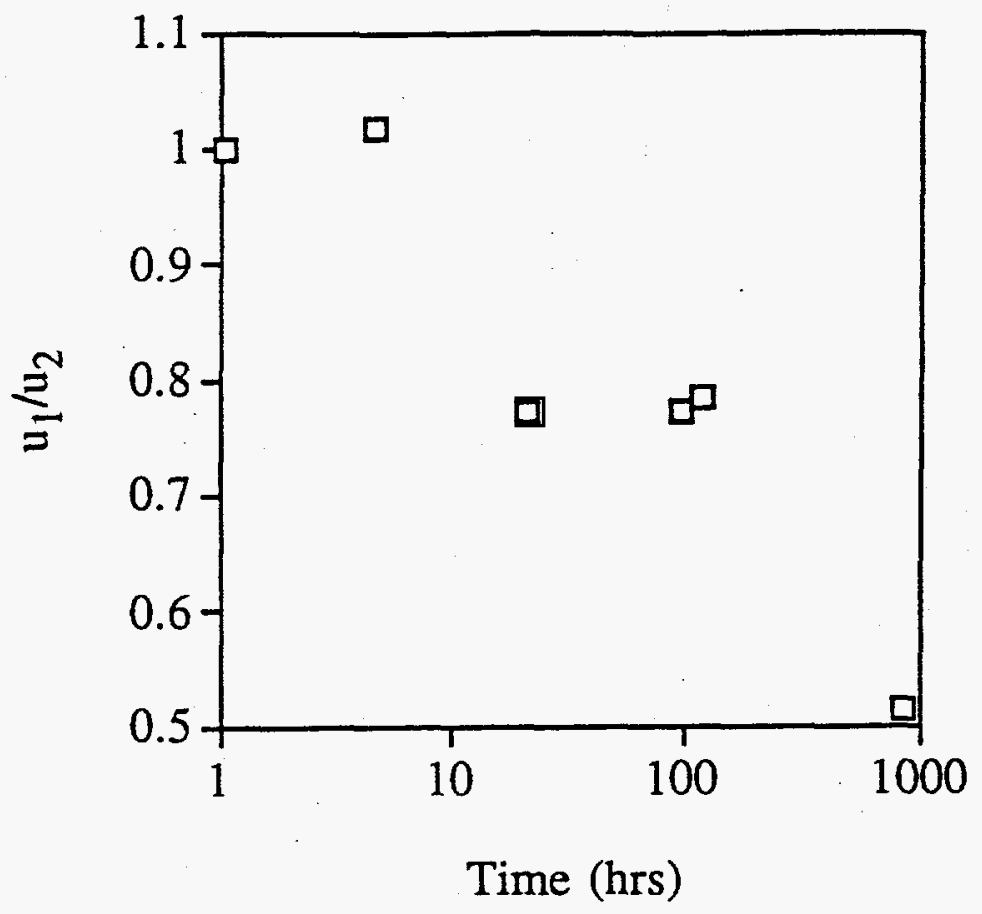

For times less than $16 \mathrm{~h}$, the simulant has not changed from it wellmixed state, so the first ball settles at the same speed as the second ball. For longer times, the second ball settles significantly faster.

Figure B.12. Velocity of First Ball Dropped to Second Ball Dropped After Suspension has Settled for Several Hours

2) the material does not slip at the wall, and

3) the material remains homogeneous (sedimentation and particle migration are negligible).

Data were consistent with a zero or very small yield stress (lower than is measurable on the viscometer used), and the entire sample appeared by visual inspection to be sheared during measurements. No wall slip was detected by visual inspection either through the transparent cup wall or at the top surface in contact with the bob. Repeated runs on the same sample were reproducible to within $\pm 15 \%$ except at the lowest torques, where the noise in the torque signal was a significant fraction of the measured torque.

The measured viscosities at the three temperatures are listed in Table B.6 and shown in Figure B.13.

The viscosity was found to obey a power law relation [see Eq. (B.4)]. The power law parameters are listed in Table B.7.

A comparison of results obtained from Couette and falling-ball rheometers is given in Figure B.14. As seen from this figure, the viscosity measured by the Couette viscometer at a given shear rate is less than measured by a falling-ball viscometer. Also, the power-law index obtained from the Couette 
Table B.6. Measured Viscosity of Aged Simulant Using Couette Viscometer

\begin{tabular}{|c|c|c|c|}
\hline $\begin{array}{c}\text { Mean Shear } \\
\text { Rate }(1 / s)\end{array}$ & $\begin{array}{l}\text { Mean Shear } \\
\text { Stress (dynucm) }\end{array}$ & $\begin{array}{c}\text { Viscosity } \\
(P)\end{array}$ & $\begin{array}{l}\text { Temperature } \\
\left({ }^{\circ} \mathrm{C}\right)\end{array}$ \\
\hline 0.473 & 2.55 & 5.40 & 24.2 \\
\hline 0.841 & 4.41 & 5.25 & 24.2 \\
\hline 1.50 & 5.47 & 3.66 & 24.2 \\
\hline 2.66 & 8.59 & 3.23 & 24.3 \\
\hline 4.73 & 12.89 & 2.73 & 24.3 \\
\hline 0.841 & 3.38 & 4.02 & 30.6 \\
\hline 1.50 & 5.22 & 3.49 & 30.5 \\
\hline 2.66 & 7.02 & 2.64 & 30.6 \\
\hline 4.73 & 9.68 & 2.05 & 30.6 \\
\hline 0.473 & 1.85 & 3.90 & 40.4 \\
\hline 0.840 & 2.71 & 3.23 & 40.4 \\
\hline 1.50 & 3.34 & 2.23 & 40.4 \\
\hline 2.66 & 4.57 & 1.72 & 40.5 \\
\hline 4.73 & 6.05 & 1.28 & 40.5 \\
\hline
\end{tabular}

is less (more shear thinning) than for the falling ball. There are five possible explanations for this effect: (1) particle migration, (2) slip at the walls, (3) yield stress with a short recovery time, (4) the

Table B.7. Power-Law Parameters of Aged Simulant Obtained from Couette Viscometer

\begin{tabular}{|c|c|c|}
\hline $\begin{array}{l}\text { Temperature } \\
(0 \mathrm{C})\end{array}$ & $\left(\mathrm{dyn} \mathrm{s}^{\mathrm{n}} / \mathrm{cm}^{2}\right)$ & $\mathrm{n}$ \\
\hline 24.2 & 4.45 & 0.678 \\
\hline 30.6 & 3.89 & 0.600 \\
\hline 40.4 & 2.79 & 0.503 \\
\hline
\end{tabular}




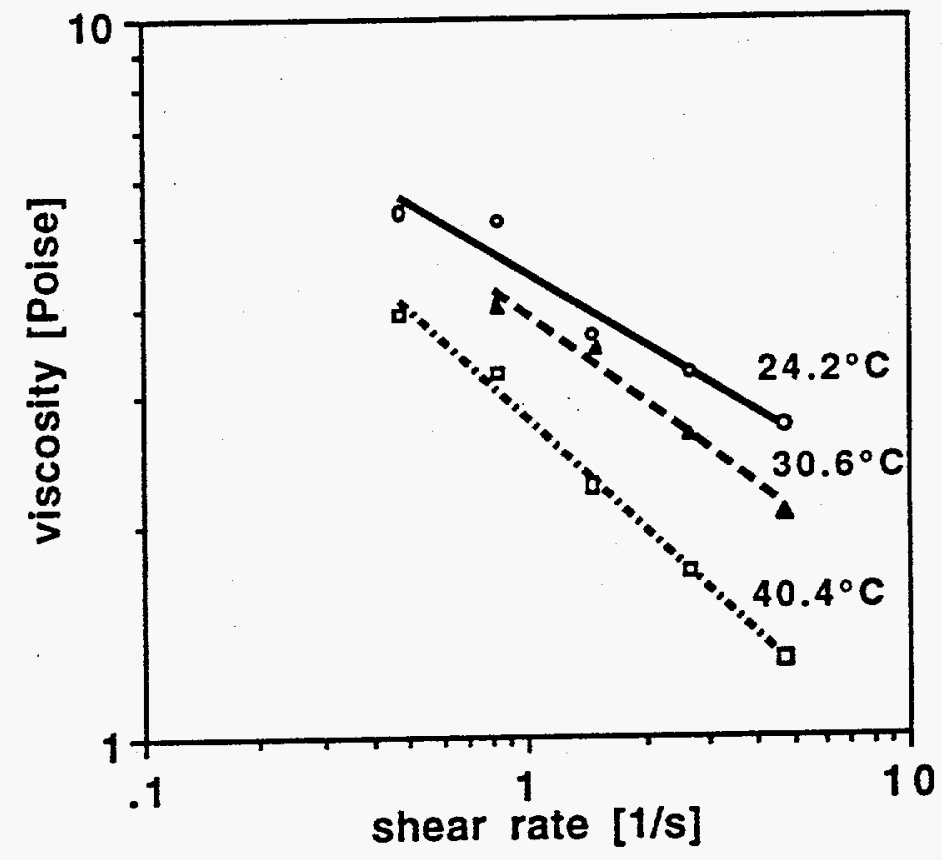

Figure B.13. Viscosity of Hanford Waste Sludge at the Temperatures Indicated

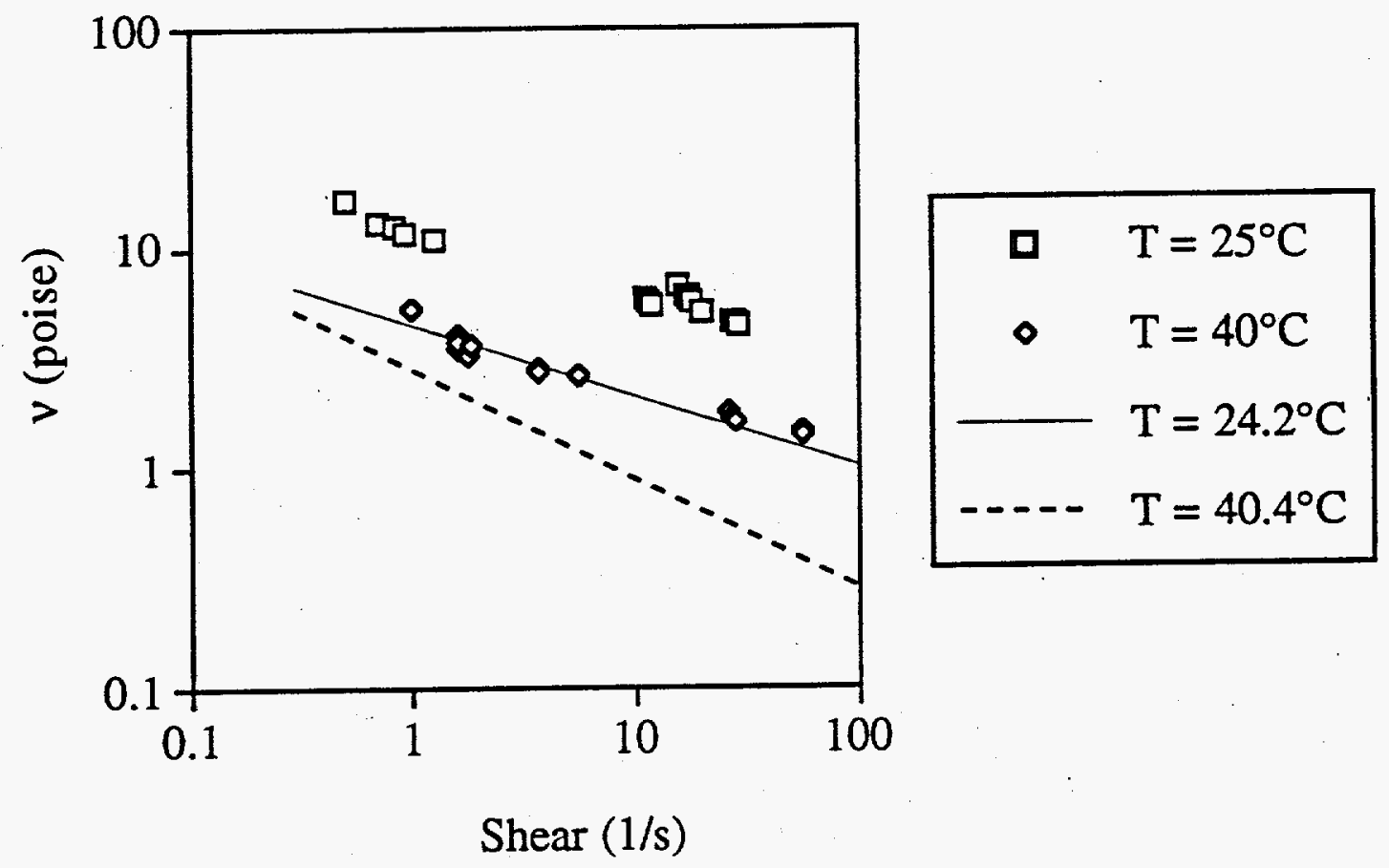

At a given temperature, the Couette viscosities determined in a Couette viscometer are less than half those determined by a falling ball.

Figure B.14. Comparing Falling-Ball Viscosities with Couette Viscosities 
different histories make comparisons between simulants futile, or (5) that the equations used to reduce the data are inaccurate.

The first explanation would be a function of the amount of migration, stabilizing only upon reaching the steady-state concentration profile. As seen in earlier studies (Abbott et al. 1993), particle migration depends on the amount of shear, not the shear rate used to get there. These tests were performed by ramping the velocity up in a stepwise fashion from lowest to highest and then ramping down. Because the viscosities measured on the way up matched those on the way down, the particle migration would have to be completed during the first test at low shear rates. This seems unlikely.

The second explanation was tested for and not found. The third explanation was tested by using the Couette viscometer, stopping the viscometer, and waiting a short period of time (a few seconds up to a few minutes). The viscometer then was restarted and checked for an initially high torque. These tests did not show any recovery of the fluid with times up to $2 \mathrm{~h}$. For the fourth reason, it seems more probably for our experience that the long times at room temperature would result in a more viscous, not less viscous, simulant.

Therefore, the final explanation needs to be tested with a well-characterized model fluid. Although as mentioned earlier, the data reduction already contains a $30 \%$ uncertainty caused by using the Newtonian drag vs the Reynolds number correlation to determine the stress. The largest possible source of error is that the well-mixed simulant (and the actual waste) is not adequately characterized by a power-law constitutive equation.

\section{B6.0 Summary and Conclusions}

To model the viscous behavior of the simulant at moderate Reynolds number, it was clear from the beginning that inertial effects would have to be accounted for. Additionally, because of the size of falling balls relative to the size of the column, wall-effect corrections would be important. The C layer is expected to behave as a Newtonian fluid. These falling-ball experiments performed with well-mixed waste simulants clearly show that the mixed waste and the NC layer are not Newtonian suspensions.

At high shear rates, a power-law analysis appears to adequately model the data. For the fresh simulant, which has a higher yield stress, a correction for the yield stress appears to be necessary. As a function of temperature, the yield stress did not scale with the increased viscosity.

At low shear rates, a yield stress appears to exist. However, a Bingham plastic analysis did not improve the fit of the measurements. Part of the problem is that more-dense balls do not always settle faster than less-dense balls. This suggests that mixing the suspension does not make it homogeneous. Most of the mixing studies to date have concentrated on the uniform, single material balls, which settled at high shear rates. The possible explanations are that the simulant is inhomogeneous or that the simulant recovers some yield stress after mixing. For the latter explanation, the recovery time would have to be on the order of $1 \mathrm{~min}$. This suggests that a history-dependent Bingham plastic model with multiple time scales may be necessary to reduce the actual tank data. These time scales do not appear to be longer than seconds and shorter than $2 \mathrm{~h}$ from the Couette experiments. 
The physics behind the time-dependent Bingham plastic appear to be related to structure formation of the precipitated salts. This would depend on the rate of crystal dissolution/recrystallization, which would increase with increasing temperature. This would explain why the yield stress did not increase with decreasing temperature.

\section{B7.0 References}

Abbott, J. R. 1993. "Dispersive Process in Concentrated Suspensions," Ph.D. Thesis, Department of Chemical Engineering, Massachusetts Institute of Technology, Cambridge, MA.

Abbott, J. R., N. Tetlow, A. L. Graham, S. A. Altobelli, E. Fukushima, L. A. Mondy, and T. S. Stephans. 1991. "Experimental Observations of Particle Migration in Concentrated Suspensions: Couette Flow," J. Rheology 35(5) (July).

Ansley, R. W. and T. N. Smith. 1967. "Motion of Spherical Particles in a Bingham Plastic," AIChE $J$ 13, 1193-1196.

Beris, A. N., J. A. Tsamopoulos, R. C. Armstrong, and R. A. Brown. 1985. "Creeping Motion of a Sphere through a Bingham Plastic," J. Fluid Mech 158, 219-244.

Brookes, G. F. and R. L. Whitmore. 1969. "Drag Forces in Bingham Plastics," Rheologica Acta 8 (4), pp. 472-482.

Brookes, G. F. and R. L. Whitmore. 1968. "The Static Drag on Bodies in Bingham Plastics," Rheologica Acta 7(2), pp. 188-193.

Burgers, J. M. 1939. On the Motion of Small Particles of Elongated Form Suspended in a Viscous Liquid, Chapter 3. Second Report on Viscosity and Plasticity. Nordemann, Amsterdam.

Chhabra, R. P. 1993. Bubbles, Drops, and Particles in Non-Newtonian Fluids, CRC Press.

Einstein, A. 1906. "A New Determination of Molecular Dimensions," Annln Phys., 19:2S9-306.

Einstein, A. 1911. "Correction to My Work: A New Determination of Molecular Dimensions," Annln Phys., 34:591-592.

Faxen, H. 1923. "Die Bewegung Einer starren Kugel lang der Achse eines mit zaher Flussigkeit gefullten Ruhres," Ark. Mat. Astr. Fys, 17(1).

Glasrud, G. G., R. C. Navarrete, L. E. Scriven, and C. W. Macosko. 1993. "Settling Behaviors of Iron Oxide Suspensions," AIChE Journal, Vol. 39, No. 4.

Happel, J. and H. Brenner. 1983. Low Reynolds Number Hydrodynamics, Martinus Nijhoff Publishers. 
Ito, S. and T. Kajiuchi. 1969. "Drag Force on a Sphere Moving in Plastic Fluid," Journal of Chemical Engineering of Japan 2(1), 19-23.

Michaels, A. S. and J. C. Bolger. 1962. "Settling Rates and Sediment Volumes of Flocculated Kaolin Suspensions," I\&EC Fund. 1(1), 24.

Milliken, W., M. Gottlieb, A. L. Graham, L. A. Mondy, and R. L. Powell. 1989a. "The Viscosity-Volume Fraction Relationship of a Randomly Oriented Suspension of Rods, " J. Fluid Mech., 202:217-232.

Milliken, W., L. A. Mondy, M. Gottlieb, A. L. Graham, and R. L. Powell. 1989b. "The Effect of the Diameter of Falling Ball on the Apparent Viscosity of Suspension of Spheres and Rods," Phys. 11 (3):341-355.

Mondy, L. A., A. L. Graham, and J. L. Jensen. 1986. "Continuum Approximations and Particle Interactions in Concentrated Suspensions," J. Rheology 30(5), 1031-1051.

Mondy, L. A., T. G. Morrison, A. L. Graham, and R. L. Powell. 1990. "Measurements of the Viscosity of Suspensions of Oriented Rods Using Falling Ball Rheometry," Int. J. Multiphase Flow 16 (4), 651-662.

Mooney, M. 1930. "Explicit Formulas for Slip and Fluidity," J. Rheol. 2(2), 210-222.

Perry's Chemical Engineering Handbook, 1984 6th edition, Don Green, Ed. MacGraw Hill.

Phan-Thien, N., H. Jin, and Rong Zheng. 1993. "On the Flow Past a Needle in a Cylindrical Tube," Journal of Non-Newtonian Fluid Mechanics, 47:137-155.

Powell R. L., and L. A. Walla. 1991. "Viscosity Measurement of Suspensions of Rod Mixtures," Liquid-Solid Flows-1991 (American Society of Mechanical Engineers, New York, New York), FEDVol. 118, pp. 117-122.

Richardson, J. F. and W. N. Zaki. 1954. "Sedimentation and Fluidization: Part I," Trans. Instn. Chem. Engrs. 32,35-53.

Richardson, J. F. and W. N. Zaki. 1954. "Sedimentation and Fluidization: Part III The Sedimentation of Uniform Fine Particles and Two-Component Mixtures of Solids," Trans. Instn. Chem. Engrs. 32, 348-356. 


\section{Distribution}

No. of

Copies

QFFSITE

12 DOE Office of Scientific and Technical Information

Billy C. Hudson

202 Northridge Ct.

Lindsborg, KS 67456

J. L. Kovach

Nuclear Consulting Services, Inc.

P.O. Box 29151

Columbus, OH 43229-0151

Thomas E. Larson

Los Alamos National Laboratory

MS-P915, DX-DO

P.O. Box 1663

Los Alamos, NM 87545

5 Los Alamos National Laboratory

P.O. Box 1663

Los Alamos, NM 87545

Attn: J. Abbott, K555

A. Graham, K555

K. Pasamehmetoglu, K555

C. Unal, K555

J. R. White, K555

D. Pepson

U.S. Department of Energy

Trevion II Building, EM-35

Washington, D.C. 20585-0002

Dana Powers

Sandia National Laboratory

Dept. 6404/MS-0744

P.O. Box 5800

Albuquerque, NM 87815-0744
No. of

Copies

ONSITE

4 DOE Richland Operations Office

R. F. Christensen $\quad$ S7-54

R. E. Gerton $\quad$ S7-54

J. M. Gray \$7-54

G. W. Rosenwald $\quad$ S7-54

24 Westinghouse Hanford Company

W. T. Alumkal

S7-85

H. Babad

S7-30

R. E. Bauer

L6-37

G. T. Bear

R1-51

T. R. Benegas

N1-27

L. E. Efferding

R. L. Fritz

H0-33

C. E. Hanson

B4-08

H5-09

G. D. Johnson

S7-15

N. W. Kirch

R2-11

L. S. Krogsrud

R3-08

D. C. Larsen

R1-51

J. W. Lentsch (5)

S7-15

R. M. Marusich

H4-65

N. G. McDuffie

S7-15

M. A. Payne

S7-14

D. A. Reynolds

R2-11

C. P. Shaw

L5-07

T. I. Stokes

H5-09

J. E. Van Beek 
No of

Copies

36 Pacific Northwest Laboratory

J. M. Alzheimer

K5-22

W. J. Apley

S7-71

Z. I. Antoniak

K7-15

R. M. Bean

P8-08

S. Q. Bennett

K7-90

M. A. Chieda

K5-25

J. B. Colson

K5-10

E. J Eschbach

K7-15

J. D. Hudson

K7-15

B. M. Johnson

K1-78

L. J. Kirihara

K5-25

F. E. Panisko (5)

P8-34

J. R. Phillips

K7-15

K. P. Recknagle

K7-15

H. C. Reid

K7-15

P. A. Scott

P7-43

A. Shekarriz

K7-15

C. L. Shepard

K5-25

C. W. Stewart (5)

K7-15

T. I. Stokes

H5-09

G. Terrones

K7-15

D. S. Trent

K7-15

Publishing Coordination

Technical Report Files (5)

Distr.2 